Navigation Systems Research Program

\title{
Fitness-for-Purpose Evaluation of Hydraulic Steel Structures
}

Robert J. Dexter, Hussam N. Mahmoud, Joseph A. Padula, November 2007 and Guillermo A. Riveros 


\title{
Fitness-for-Purpose Evaluation of Hydraulic Steel Structures
}

\author{
Robert J. Dexter \\ University of Minnesota \\ Department of Civil Engineering \\ 500 Pillsbury Drive S.E. \\ Minneapolis, MN 55455-0116 \\ Hussam N. Mahmoud \\ University of Illinois at Urbana-Champaign \\ The Multi-Axial Full-Scale Sub-Structured Testing and Simulation Facility \\ 2142 Newmark Civil Engineering Laboratory \\ MC-250 \\ Urbana, IL 61822-2352 \\ Joseph A. Padula \\ Geotechnical and Structures Laboratory \\ U.S. Army Engineer Research and Development Center \\ 3909 Halls Ferry Road \\ Vicksburg, MS 39180-6199 \\ Guillermo A. Riveros \\ Information Technology Laboratory \\ U.S. Army Engineer Research and Development Center \\ 3909 Halls Ferry Road \\ Vicksburg, MS 39180-6199
}

Final report

Approved for public release; distribution is unlimited.

\footnotetext{
Prepared for U.S. Army Corps of Engineers Washington, DC 20314-1000

Under Inspection and Condition Assessment of Steel Hydraulic Structures
} 


\begin{abstract}
Hydraulic structures such as locks, spillway gates, and maintenance closure structures may have fabrication defects and flaws that can be large enough to threaten the integrity of the structure. In addition, some defects that are not allowed based on stringent specifications are not at all harmful to the structure. "Fitness-for-purpose" evaluation is a method for determining a factor of safety against fracture and the risk of collapse in existing structures. This report discusses the different types of hydraulic steel structures, typical fatigue cracks that could exist in such structures and details that could lead to brittle fracture. Using steps developed by the British Standards Institute, the report describes a fitness-for-purpose evaluation procedure for hydraulic control structures under Mode I loading, including how large a crack-like discontinuity would have to be before it could lead to fracture in a typical steel member.
\end{abstract}

DISCLAIMER: The contents of this report are not to be used for advertising, publication, or promotional purposes. Citation of trade names does not constitute an official endorsement or approval of the use of such commercial products. All product names and trademarks cited are the property of their respective owners. The findings of this report are not to be construed as an official Department of the Army position unless so designated by other authorized documents. 


\section{Contents}

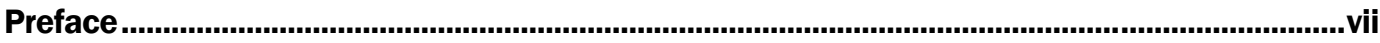

Unit Conversion Factors....................................................................................................................iii

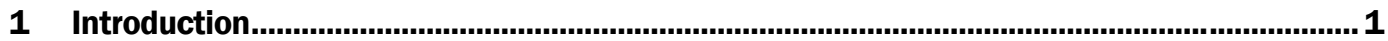

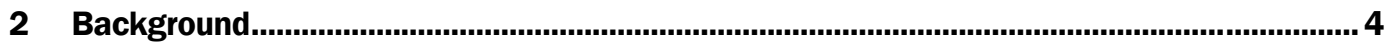

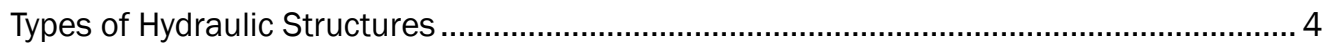

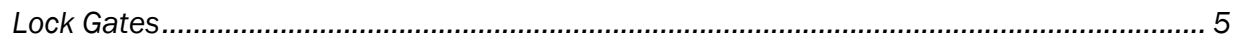

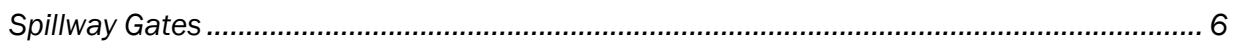

Maintenance and Closure Structures .......................................................................... 8

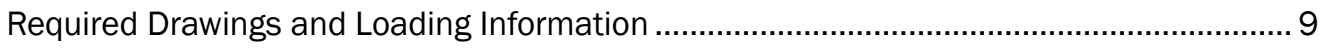

Identifying Fracture Critical Members ........................................................................ 10

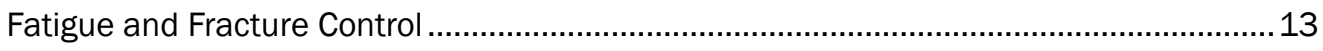

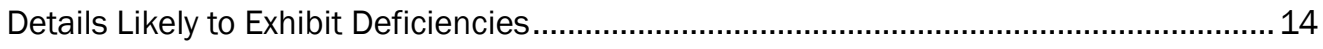

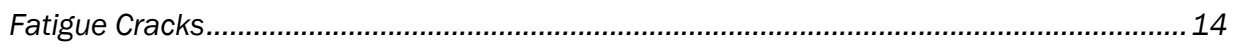

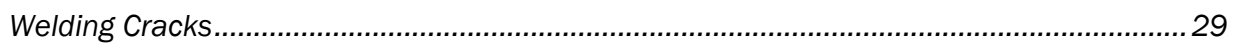

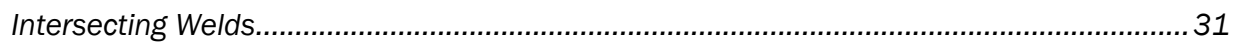

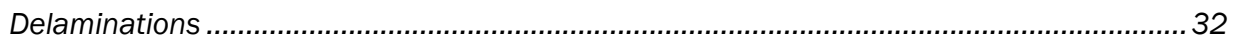

Workmanship Not Meeting Welding Code ....................................................................... 33

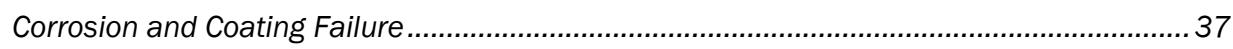

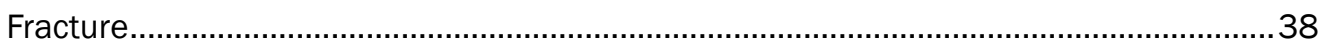

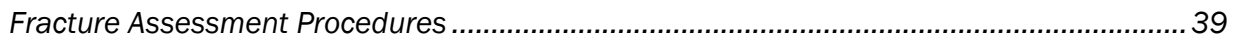

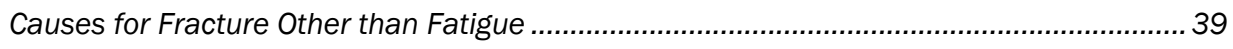

Specification of CVN for Fracture Resistance................................................................. 41

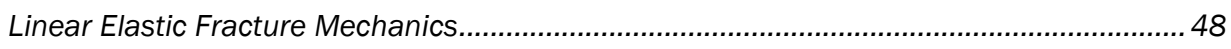

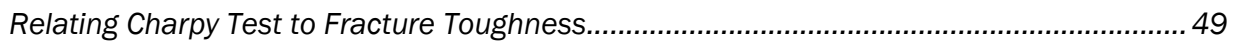

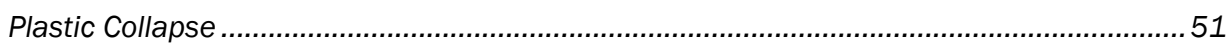

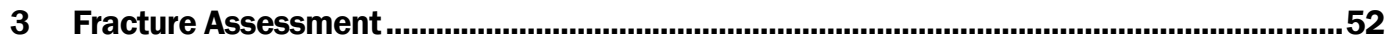

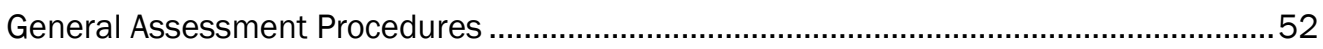

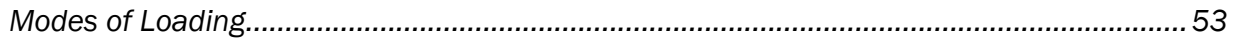

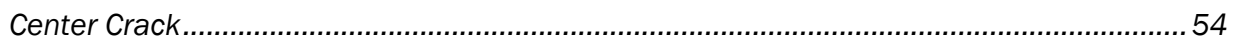

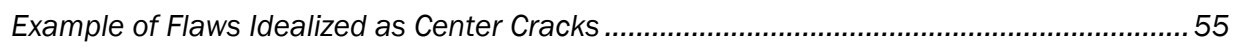

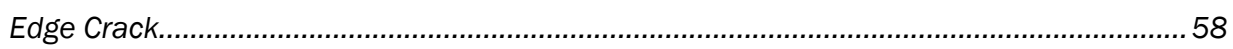

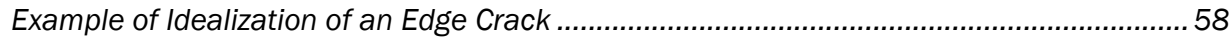

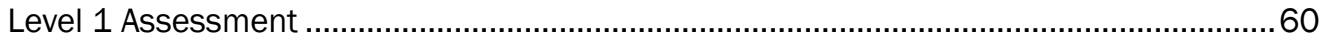

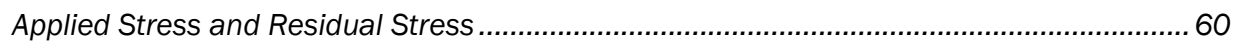

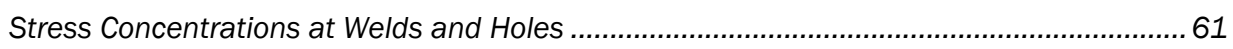

Assumed Lower-Bound Fracture Toughness or Material Testing........................................ 61

Using the Level I Failure Assessment Diagram to Calculate the Maximum Tolerable

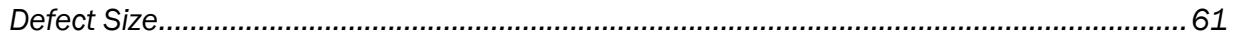

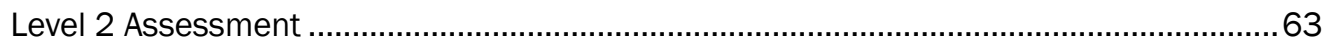




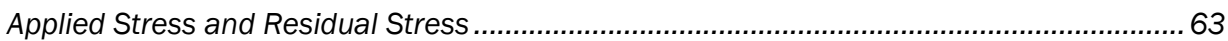

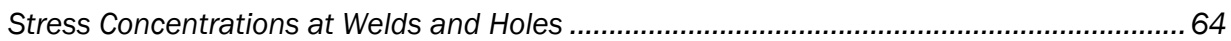

Material Sampling, Confidence, and Testing to Estimate Fracture Toughness...................... 64

Use of Nondestructive Testing to Refine Estimates of Defect Size........................................ 65

Using the Level II Failure Analysis Diagram to Calculate the Maximum Tolerable

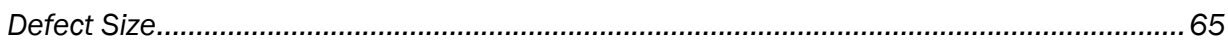

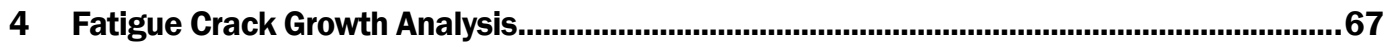

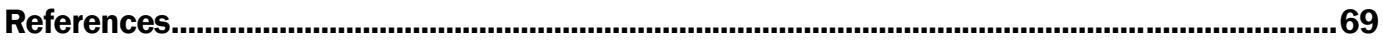

Report Documentation Page..................................................................................................................72 


\section{Figures and Tables}

\section{Figures}

Figure 1. Horizontally framed miter gate ..................................................................................... 5

Figure 2. Sector gate lifted to be positioned in place ………............................................................. 6

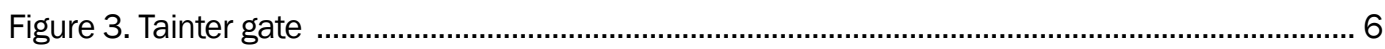

Figure 4. Vertical-lift spillway gate, Elidon Dam, Australia .................................................................... 7

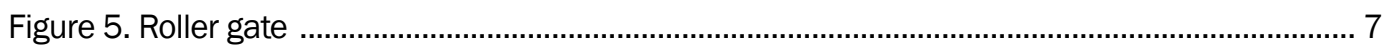

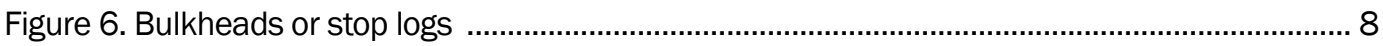

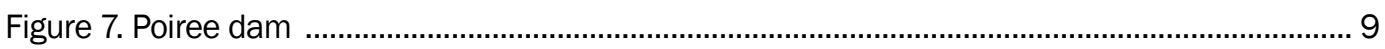

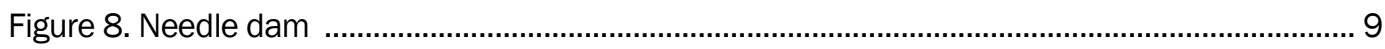

Figure 9. Examples of internally redundant members ................................................................ 11

Figure 10. Retrofit redundancy plate bolted to web of existing two-girder superstructure ..............12

Figure 11. Category $\mathrm{C}$ detail at the termination of a vertical weld used for attaching the transverse stiffener to the girder web ....................................................................................... 16

Figure 12. Category $C$ detail at the toe of a transverse fillet weld ................................................. 16

Figure 13. Category $\mathrm{C}$ detail for attachments perpendicular to a flange ....................................... 17

Figure 14. Category $C$ detail for a cruciform joint .................................................................... 17

Figure 15. Example of a butt splice in a tension chord of a bulkhead .......................................... 18

Figure 16. Category $C$ detail of a typical groove welded butt joint. ................................................. 19

Figure 17. Category E detail at the termination of a longitudinal weld at cover plate detail ............20

Figure 18. Category $\mathrm{E}$ detail at the termination of a welded longitudinal stiffener detail

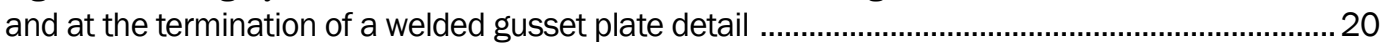

Figure 19. Crack location at the termination of a longitudinal stiffener detail in a tension stress field

Figure 20. Through-thickness crack at the termination of a longitudinal stiffener detail. ............... 21

Figure 21. Category E detail at the termination of longitudinal intermittent welds .........................22

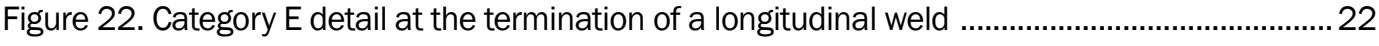

Figure 23. Crack initiating from a poorly cut cope hole ............................................................... 23

Figure 24. Crack initiating from a cope hole with a roughness not in confirmation with ANSI ........23

Figure 25. Category $E$ detail for attachments normal to the flange and the web of a girder ........... 24

Figure 26. Category E detail for a diagonal member welded to a truss chord ................................25

Figure 27. Category E detail and typical crack location for a gusset plate attachment normal to the flange of a girder ..................................................................................................2 25

Figure 28. Category E detail of a longitudinal butt weld on a bearing pad attachment normal to the flange of a truss chord ……................................................................................... 26

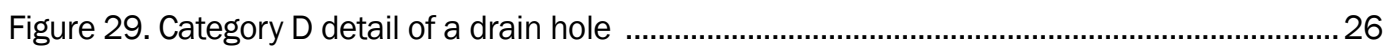

Figure 30. Category D riveted detail loaded in shear ................................................................. 27

Figure 31. Crack initiating at a riveted detail .................................................................................... 27 
Figure 32. Crack forming from a lack-of-fusion defect ............................................................. 29

Figure 33. Several fatigue cracks forming from distributed porosities ...........................................30

Figure 34. Fatigue crack forming from a piping porosity defect .................................................. 30

Figure 35. Hydrogen fisheye crack ........................................................................................ 31

Figure 36. Another hydrogen fisheye crack. ........................................................................... 31

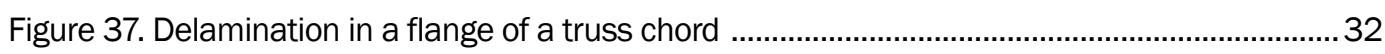

Figure 38. Pop out delamination .......................................................................................... 33

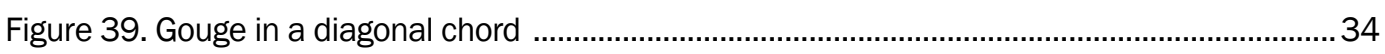

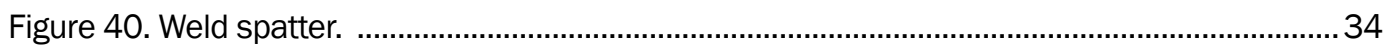

Figure 41. Poor vertical weld at a bearing pad attachment ..........................................................35

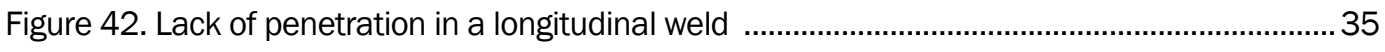

Figure 43. Lack of penetration in a transverse weld .................................................................... 36

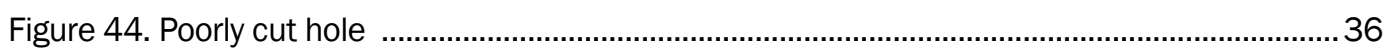

Figure 45. Crevice corrosion in the longitudinal direction in a bearing plate .................................. 37

Figure 46. Crevice corrosion in the transverse direction in a bearing plate ..................................... 37

Figure 47. Brittle fracture of flange of tub girder of Bryte Bend Bridge while under

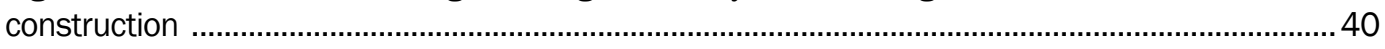

Figure 48. Fractured girder of the Hoan Bridge in Milwaukee and a critical shelf plate

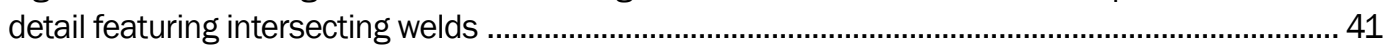

Figure 49. Charpy energy transition curve for A709 Grade 50 structural steel .............................. 42

Figure 50. Fracture toughness data for a number of brittle materials that have caused

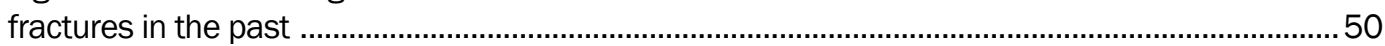

Figure 51. The three modes of loading …………………….................................................... 53

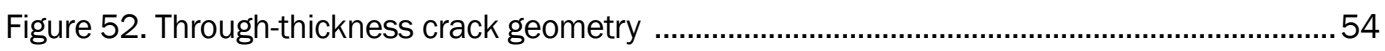

Figure 53. Incomplete penetration in a double-bevel groove weld idealized as a center crack ......55

Figure 54. Partial joint penetration weld with a crack-like condition resulting from

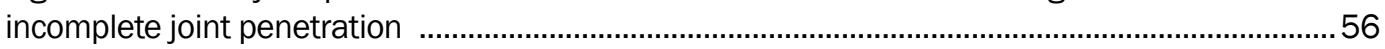

Figure 55. Incomplete penetration in a double-bevel groove weld idealized as a center crack ...... 57 Figure 56. Butt weld with an inclined flaw resolved into a component perpendicular to the direction of the primary stresses ............................................................................................ 57

Figure 57. Edge crack geometry ......................................................................................... 58

Figure 58. Shallow edge cracks or undercut at the termination of a longitudinal butt weld on a bearing pad attachment. ................................................................................................ 59

Figure 59. Buried penny-shaped crack geometry ....................................................................59

Figure 60. FAD used in Level 1A ....................................................................................... 63

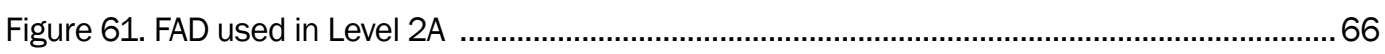

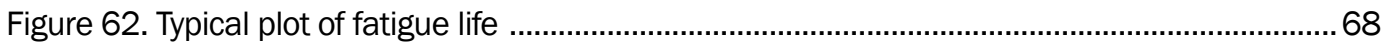

\section{Tables}

Table 1. Minimum Charpy impact test requirements for fracture-critical members ......................... 44

Table 2. Fracture toughness values equivalent to the minimum of three results ............................65 


\section{Preface}

This research was conducted under Contract No. W912HZ-04-P-0235 under the Navigation Systems Research Program, Work Unit 9K76D4, "Inspection and Condition Assessment of Steel Hydraulic Structures." Program Managers were Dr. J ohn E. Hite, Acting Chief, Navigation Branch, Navigation Division, Coastal and Hydraulics Laboratory (CHL), U.S. Army Engineer Research and Development Center (ERDC); and James M. Clausner, Acting Technical Director, CHL.

This report was prepared by Robert J. Dexter (deceased), formerly of the Department of Civil Engineering, University of Minnesota, Minneapolis, MN; Hussam N. Mahmoud, The Multi-Axial Full-Scale Sub-Structured Testing and Simulation Facility, Newmark Civil Engineering Laboratory, University of Illinois at Urbana-Champaign; J oseph A. Padula, Geotechnical and Structures Laboratory (GSL), ERDC, Vicksburg, MS; and Dr. Guillermo A. Riveros, Information Technology Laboratory (ITL), ERDC, Vicksburg, MS.

The report was prepared under the general supervision of J ames S. Shore, Chief, Structural Engineering Branch, GSL; Chris A. Merrill, Chief, Computational Analysis Branch; David R. Richards, Acting Chief, Computational Science and Engineering Division; and Dr. Deborah F. Dent, Acting Director, ITL.

At the time of publication of this report COL Richard B. J enkins was the Commander and Executive Director of ERDC, and Dr. J ames R. Houston was the Director. 


\section{Unit Conversion Factors}

\begin{tabular}{|l|l|l|}
\hline Multiply & By & To Obtain \\
\hline Feet & 0.3048 & Meters \\
\hline Inches & 0.0254 & Meters \\
\hline Lbs & 4.448 & Newtons \\
\hline Ft-lb & 1.354 & Joules \\
\hline Ksi & 6.894 & MPa \\
\hline
\end{tabular}




\section{Introduction}

The Corps of Engineers Engineering Regulation ER 1110-208157, Responsibility for Hydraulic Steel Structures, requires that hydraulic steel structure fracture-critical members meet AASHTO/ AWS* D1.5, Bridge Welding Code (AASHTO 2002). The AWS D1.5 criteria are stricter than AWS D1.1 since they are applied to bridges that see a large number of fatigue cycles in their lifetime. Acceptance to AWS D1.5 standards requires ultrasonically testing (and possibly repairing) all buttjoints and also testing of any secondary welds over $102 \mathrm{~mm}$ (4.02 in.) in length attached to fracture-critical members. However, the engineering regulation allows the use of structures with known defects if an analytical determination of load capacity is made.

The AWS codes provide guidance and procedures for welding but also provide inspection criteria for newly fabricated structures. The philosophy behind these welding codes is that the welding should be as good as welltrained welders typically produce. This philosophy is called a workmanship standard, since it is expected that the workmanship will be as good as is typically provided. The workmanship standards are reasonable expectations for weld quality, and the fabricator should be penalized if they consistently fail to meet these standards.

However, the acceptance criteria in the workmanship standards are not based on the effect that these rejectable discontinuities might have on the performance of the structure, particularly the resistance to fatigue and fracture. Some defects that are not allowed by AWS workmanship criteria are not at all harmful to the structure. For example, porosity typically must be less than $3 \mathrm{~mm}$ ( $0.12 \mathrm{in}$.) in diameter to meet the AWS standards, yet it is widely accepted that a small porosity like this does not affect fatigue or fracture of a structure under even the moist demanding of conditions. Small discontinuities such as slag inclusions and porosity are inevitable and are present in all welds. Therefore, it is not economical to reject or repair a structural component because it does not meet the workmanship standards if it does not degrade the resistance to fatigue or fracture.

* AASHTO is the American Association of State Highway and Transportation Officials. AWS is the American Welding Society. 
Furthermore, weld repairs of minor discontinuities can often introduce more severe defects that cannot be detected, making the situation worse.

Finally, it is a misapplication to apply these workmanship standards to evaluations of existing structures. The AWS standards are for new fabrication and were not intended for existing structures. Obviously, if there is no impact on fatigue and fracture, an owner will be more reluctant to take out of service, or repair at his expense, a structure that is found to have poor workmanship than he would be if the component is still in the fabrication shop and the repairs will be at the fabricator's expense.

Evaluation of new or existing structures is known as "fitness-for-purpose" analysis. The analysis considers a particular structural element to be adequate as long as the conditions causing failure is not reached. The analysis was first formally used on the Alyeska pipeline project in the 1970s. Fitness-for-purpose calculations are widely accepted and are used extensively in many industries. For example, fitness-for-purpose calculations are used to set acceptable discontinuity limits for pipelines, offshore structures, and ships. They may be used for new construction or structures that are in service.

The British Standards Institute published a document outlining in detail how to perform all the steps involved in a fitness-for-purpose calculation. This document is called BS 7910: 1999, Guide on Methods for Assessing the Acceptability of Flaws in Metallic Structures (BSI 1999). BS 7910 is applicable to a broad range of structures including bulkheads and has been used for decades.

This guideline is intended to develop a general procedure for fitness-forpurpose evaluation of hydraulic control structures under Mode I loading. (Mode I, most common in civil structures, constitutes crack opening when the load is normal to the crack face. Failure due to Mode II, Mode III, or a combination of different modes could exist but is, however, not discussed in this report.)

Chapter 2 discusses the different types of hydraulic steel structures, typical fatigue cracks that could exist in such structures and details that could lead to brittle fracture. Chapter 3 presents the fracture assessment procedure listed in BS 7910, in a simple format, with emphasis on Level I 
and Level II procedures with Mode I loading. The established procedures of BS 7910 are used to calculate how large a crack-like discontinuity would have to be before it could lead to fracture in a typical steel member. 


\section{Background}

\section{Types of Hydraulic Structures}

Hydraulic structures such as locks, spillway gates, and maintenance closure structures are common in the United States. Fabrication defects and flaws such as gouges and corrosion products have been known to exist in the structural elements or components that make up these structures. The existence of flaws or defects is of concern if the size of the flaws or the defects is large enough to threaten the integrity of the structure.

Codes and guidelines have been developed for assessing flaw sizes in steel structures including bridges and offshore structures. The most commonly used by many engineers is BS 7910 (BSI 1999). Level I analysis is typically used in the initial evaluation. Depending on the outcome of the evaluation, recommendations for further nondestructive testing (NDT) and material testing will be made. If available, these data should be incorporated into a more complicated Level II analysis.

Guidelines for conducting a fitness-for-purpose evaluation of typical Corps of Engineers' hydraulic steel structures are listed in this report. The intention of the guidelines is to provide a consistent, accepted, and safe procedure for evaluating the factor of safety against fracture and the risk of collapse in the hydraulic steel structures described below.

Examples of common hydraulic steel structures are spillway gates and lock gates, which are used to provide damming surfaces. Spillway gates are typically installed on the top of a dam spillway to provide a movable damming surface (U.S. Army Corps of Engineers 2001). Tainter gates and lift gates are the most common forms of spillway gates. Spillway gates could also be in the form of bulkheads, needle beams, lock culvert valves, and stop locks. Lock gates are used to provide a movable damming surface across a lock chamber (U.S. Army Corps of Engineers 2001). Common lock gates are miter gates and vertical-lift gates (also used as spillway gates). Sector gates and submergible tainter gates are other forms of lock gates. The most commonly used hydraulic steel structures are briefly described below. 


\section{Lock Gates}

\section{Miter Gates}

Miter gates are generally economical to construct and operate. They are either vertically or horizontally framed. They consist of horizontal or vertical girders connected by skin plates, two end diaphragms, and intermediate diaphragms. In case of vertical gates, water pressure on the skin plate is transmitted by the vertical girders, which are supported at the ends by horizontal girders used to transfer the load on the miter and quoin at the top of the leaf into the sill at the bottom of the leaf (U.S. Army Corps of Engineers 2001). Water pressure on horizontal gates is transmitted through horizontal girders, which transfer the load into the quoin block and into the walls of the lock. Figure 1 shows a typical horizontally framed miter gate.

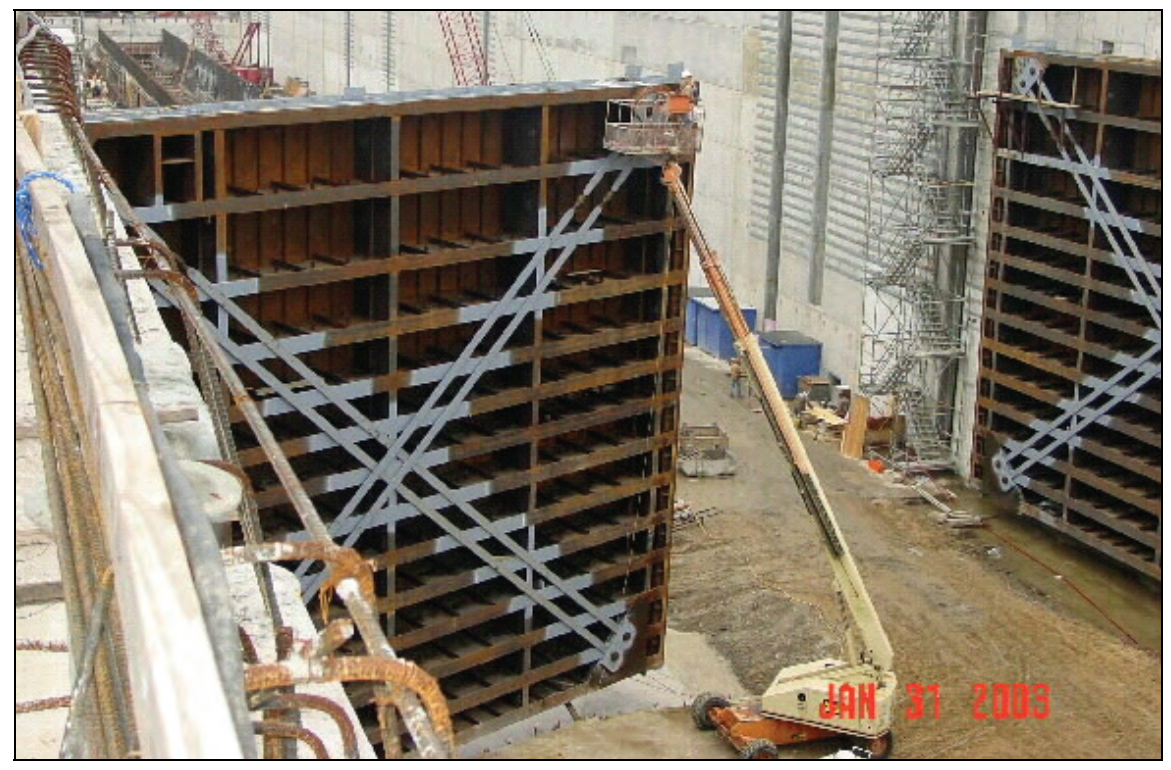

Figure 1. Horizontally framed miter gate. (Courtesy of www.swl.usace.army.mil.)

\section{Sector Gates}

Sector gates are generally used to control or restrict flow in a lock chamber. They are used in rivers or canals where dams are subjected to head reversal. The framing system of sector gates is similar to that of tainter gates. However, the gates pivot about a vertical axis, unlike tainter gates. Figure 2 shows a sector gate with two longitudinal girders and multiple transverse stiffeners. 


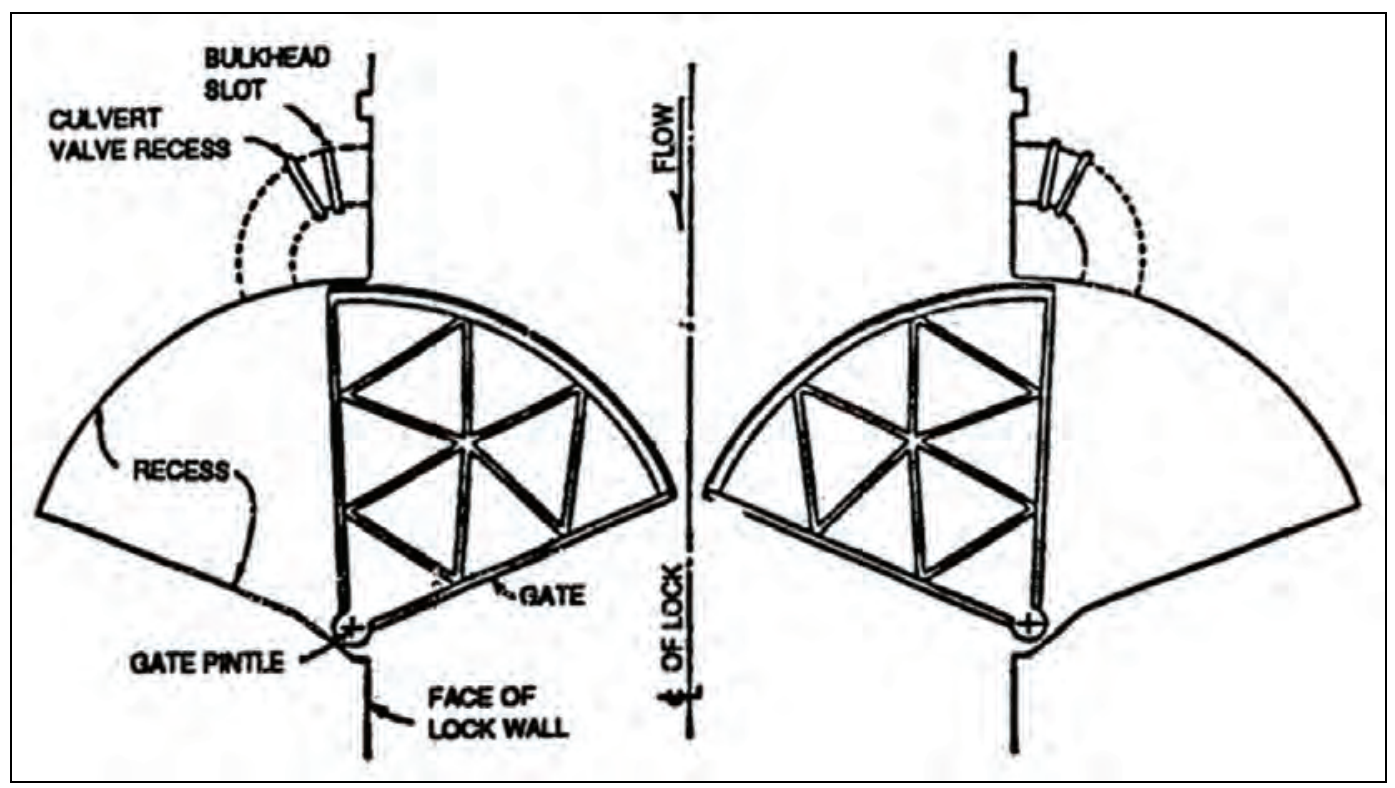

Figure 2. Schematic drawing of a sector gate.

\section{Spillway Gates}

\section{Tainter Gates}

Tainter gates (Fig. 3) typically have a vertically stiffened skin plate with circular profile that forms the damming surface. The skin plate is supported by horizontal beams and radial struts that transfer the hydrostatic load to trunnions anchored to the dam piers. Tainter gates are operated (raised/ lowered) by cables, chains or direct acting hydraulic cylinders that rotate the gate about the trunnions.

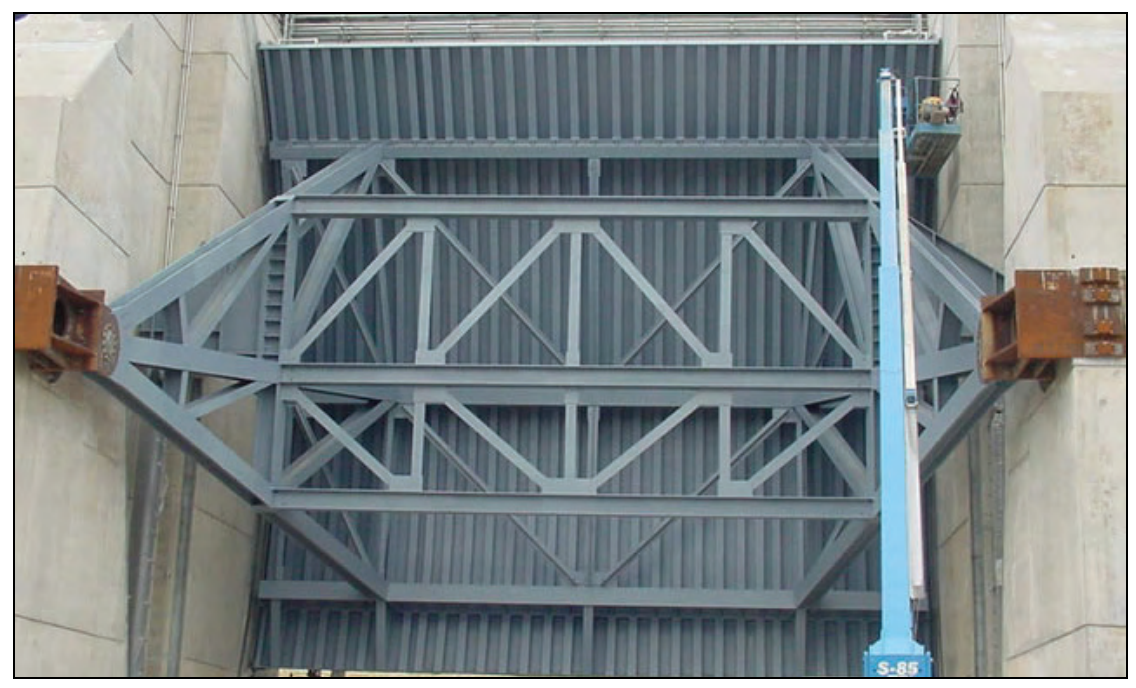

Figure 3. Tainter gate. (Courtesy of www.mvr.usace.army.mil.) 


\section{Lift Gates}

Vertical lift gates (Fig. 4) are raised and lowered vertically to open or close a spillway bay. They consist of stiffened plates, such that water pressure on the stiffened plate is transmitted through horizontal girders and into the wall of the lock monolith.

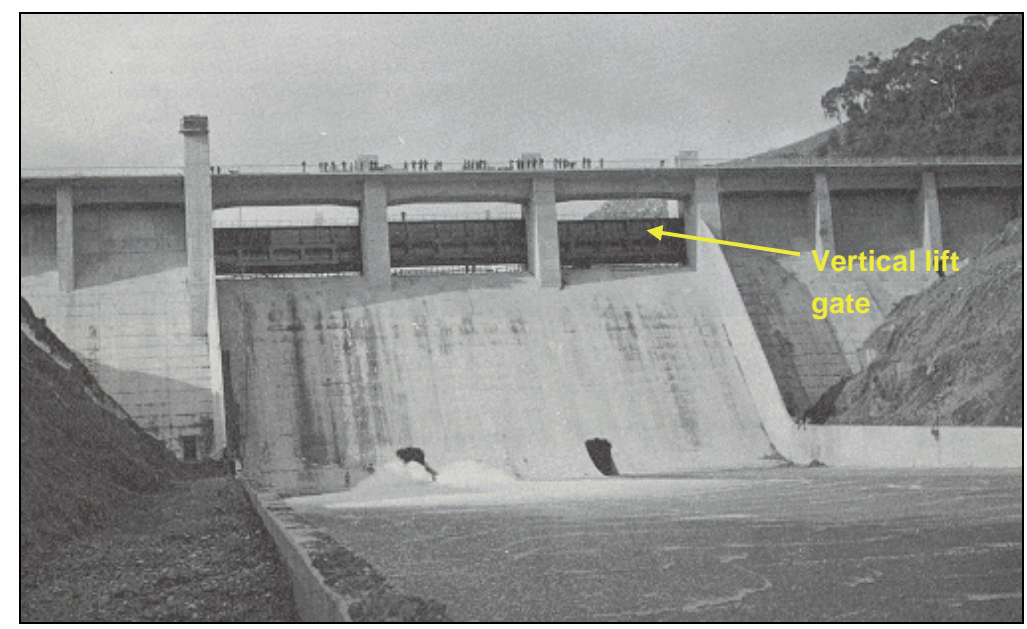

Figure 4. Vertical-lift spillway gate, Elidon Dam, Australia.

\section{Roller Gates}

Roller gates (Fig. 5) consist of steel rollers and rubber seals. The roller gates slide vertically against rails using a geared lift. The gate leaf is typically a rectangular welded structure. They are designed for face pressure only. Generally roller gates are not designed to withstand back pressure.

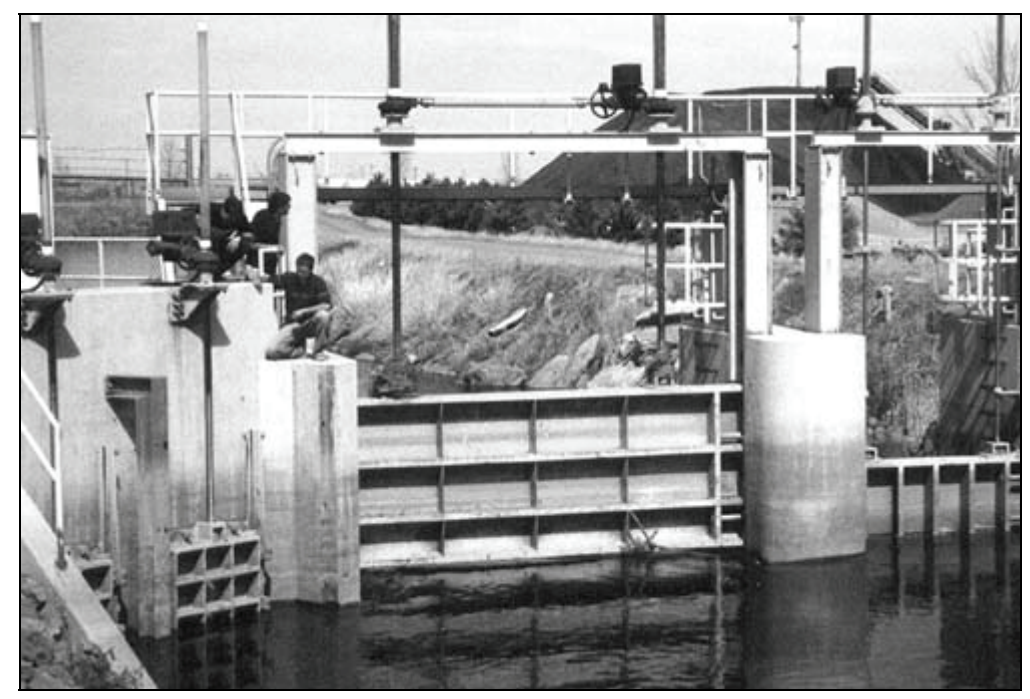

Figure 5. Roller gate. 


\section{Maintenance and Closure Structures}

Maintenance and closure structures are used when dewatering of a spillway bay is required for maintenance. The most common closure structures are bulkheads or stop logs, vertical lift gates, poiree dams, and needle dams.

\section{Bulkheads (stop logs)}

Bulkheads (often called stop logs) are stacked as shown in Figure 6 to form a temporary dam for dewatering of river lock structures. The bulkheads on the bottom of a stack are exposed to high loads from the water pressure.

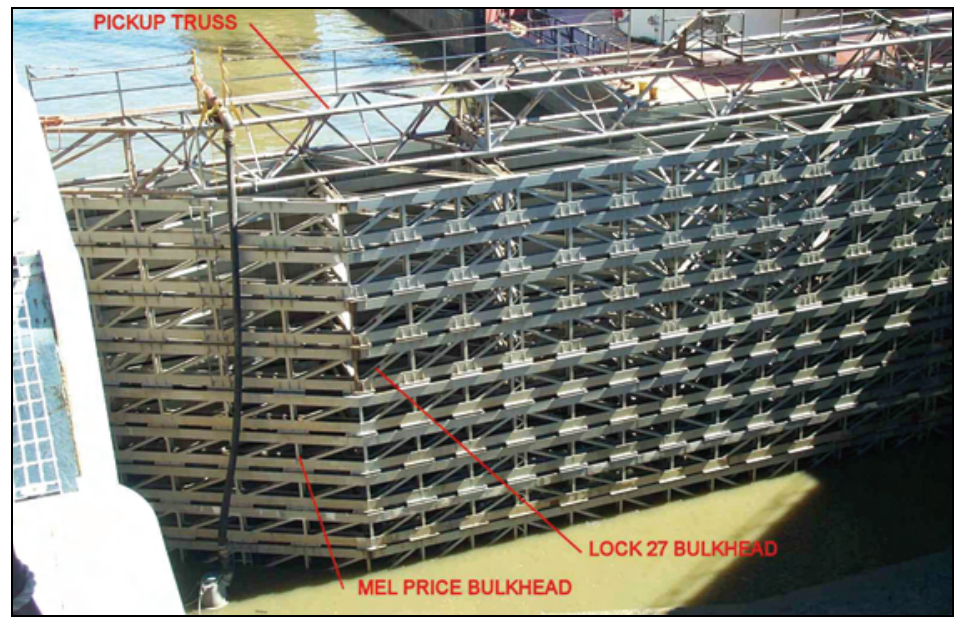

a. Bulkheads in use for dewatering.

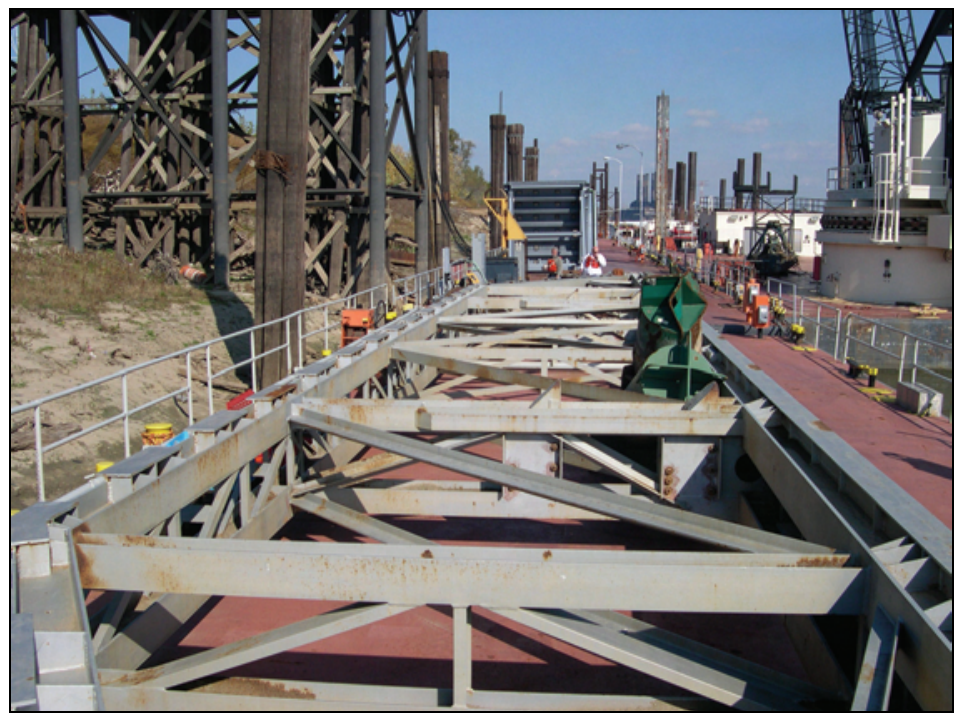

b. Bulkhead in storage

Figure 6. Bulkheads or stop logs. 
Poiree and needle dams

Design and construction of new poiree and needle dams are not recommended because of the difficulty associated with their installation. As shown in Figure 7, poiree dams consist of a shutter panel that transfers the water pressure to the A-frame truss members supporting the pane and further to the concrete sill.

Needle dams consist of vertical needle panels that are supported by the horizontal girder at the top and positioned on the concrete sill at the bottom. Figure 8 shows a typical framing system of a needle dam.

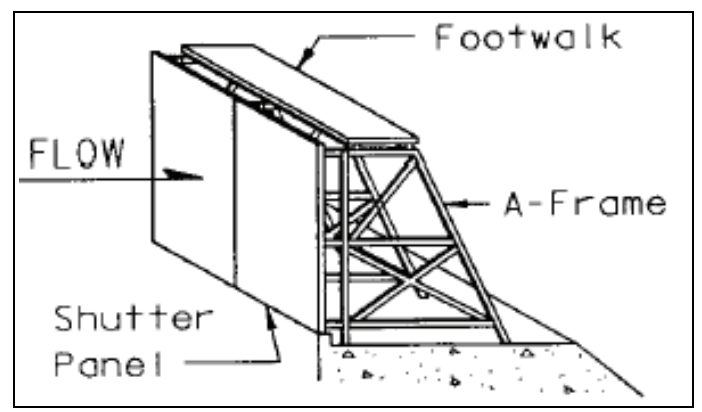

Figure 7. Poiree dam (U.S. Army Corps of Engineers 1995).

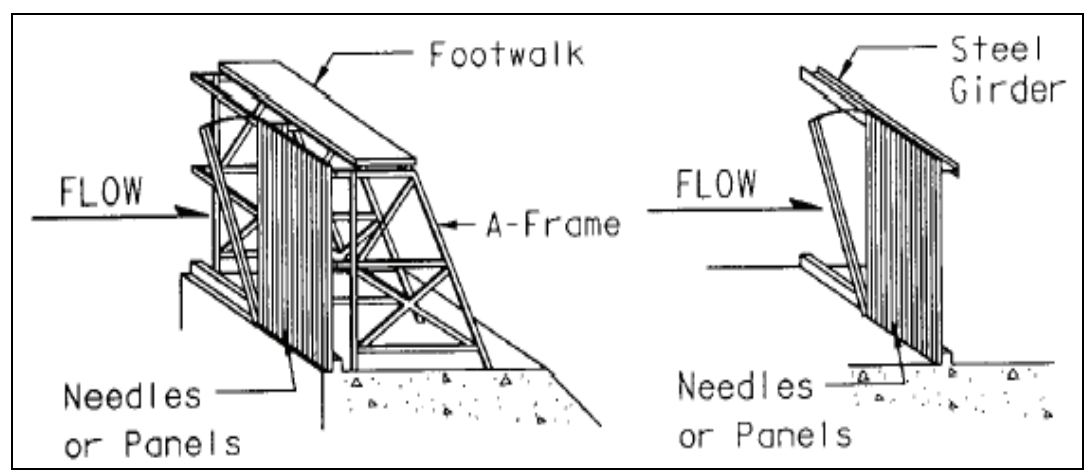

Figure 8. Needle dam (U.S. Army Corps of Engineers 1995).

\section{Required Drawings and Loading Information}

Drawings and plans of a hydraulic steel structure under evaluation must be obtained to determine:

- the framing system used in constructing the gates or the closure structures,

- the member types (plates or shapes such as angles, tees, wide-flange beams) and sizes including the thickness of all elements of a member, 
- the types of connections (fillet or groove welded versus bolted),

- the ASTM specification of the steel and the minimum specified yield strength (MSYS) and the minimum specified tensile strength.

For structural shapes, there are designations such as W10x68. This signifies a wide flange section, nominally $254 \mathrm{~mm}$ (10 in.) deep and weighing $100 \mathrm{~kg} / \mathrm{m}$ (68 lb/ft). The dimensions of these shapes can be obtained from the American Institute of Steel Construction (AISC) design manuals (AISC 1999). Tee sections are designated similarly; a WT5x34 is made by cutting a W10x68 in half longitudinally. Channel or C-sections are also designated by their depth and weight. Angles are designated as L4x3x3/ 8, where the first two numbers are the leg length in inches and the last is the thickness in inches.

The loading condition such as the hydrostatic water load and the dead load of the structure including mud and ice load need to be quantified. The dead load of the structure can be estimated from the weights of the members. In some cases vibration loading may result from water flow or from the operational motors used in opening or closing gates. Significant vibration loading could cause defects to grow by fatigue and must be quantified. Furthermore, high cycle vibration could cause bolted connections to become loose, resulting in higher than anticipated stresses in the structural component. Knowledge of the loading condition under which the structure is operating (i.e. tension loading versus bending loading or a combination) and the load path through which the applied load finds its way to the supports are also important in the evaluation, as will be explained in Chapter 3.

\section{Identifying Fracture Critical Members}

The engineering manual for designing lock gates and operating equipment (U.S. Army Corps of Engineers 1994b) defines fracture critical members as "members and associated connections subjected to tensile stresses and whose failure would cause the structure to be inoperable." Redundant members are usually not fracture critical. Redundancy is related to system behavior rather than to individual component behavior. Redundancy is often discussed in terms of three types (Hartle et al. 1991, Ghosn and Moses 1998):

- Internal Redundancy, also called member redundancy, can occur when a member is composed of multiple elements and a fracture that 
forms in one element cannot propagate directly into the adjacent elements. Examples include riveted or bolted built-up members (Fig. 9). Note that continuous plates or shapes may be bolted to a member to give it internal redundancy. Figure 10 shows an example of a redundancy retrofit of a two-girder bridge.Structural Redundancy is external static indeterminacy and can occur when a beam or truss is continuous for two or more spans. There are few examples of this type of redundancy in hydraulic structures because most of the structures are either cantilevered or have only two supports.

- Load-Path Redundancy is internal static indeterminacy arising from having three or more girders or redundant truss members.

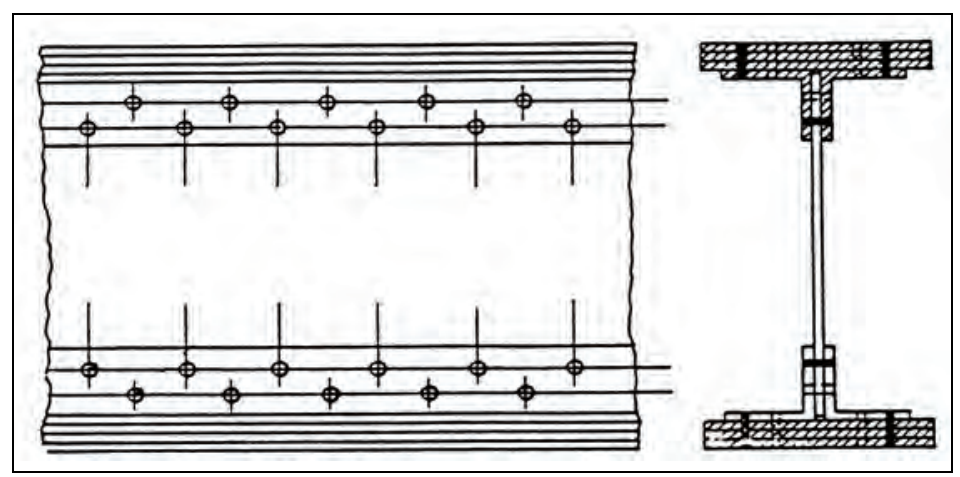

a. Riveted built-up girder.

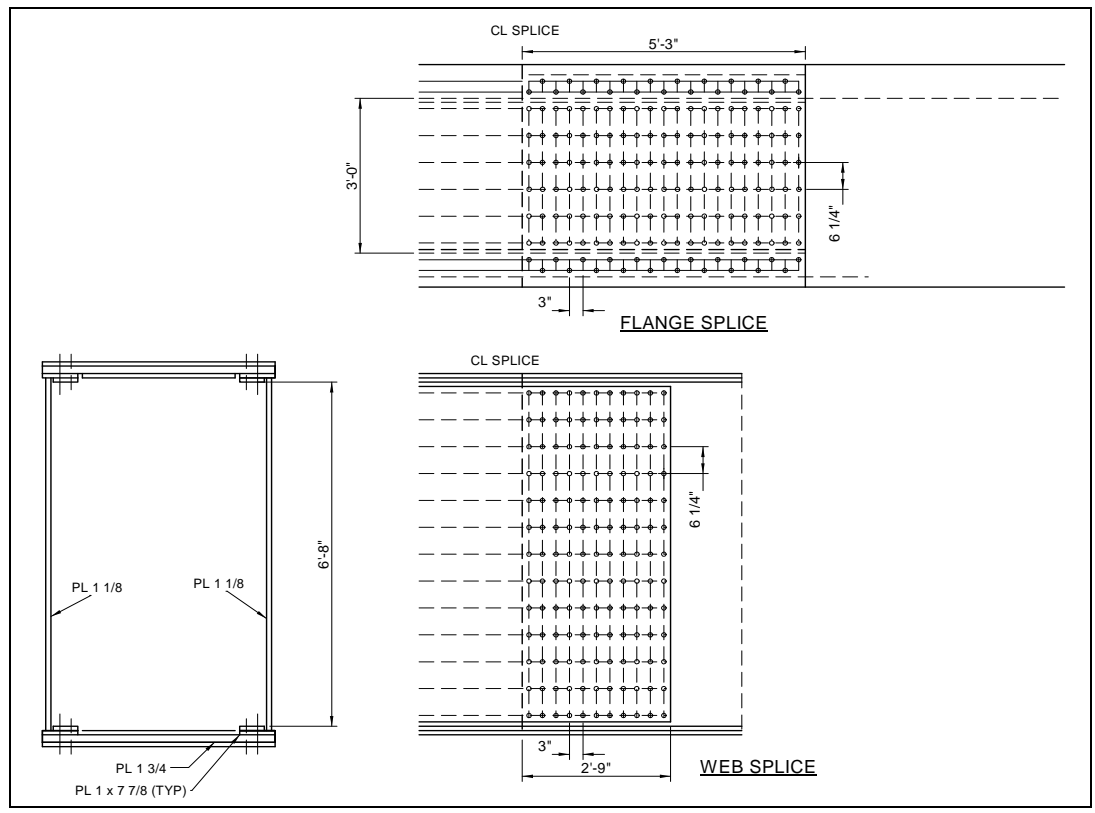

b. Bolted built-up box girder.

Figure 9. Examples of internally redundant members. 

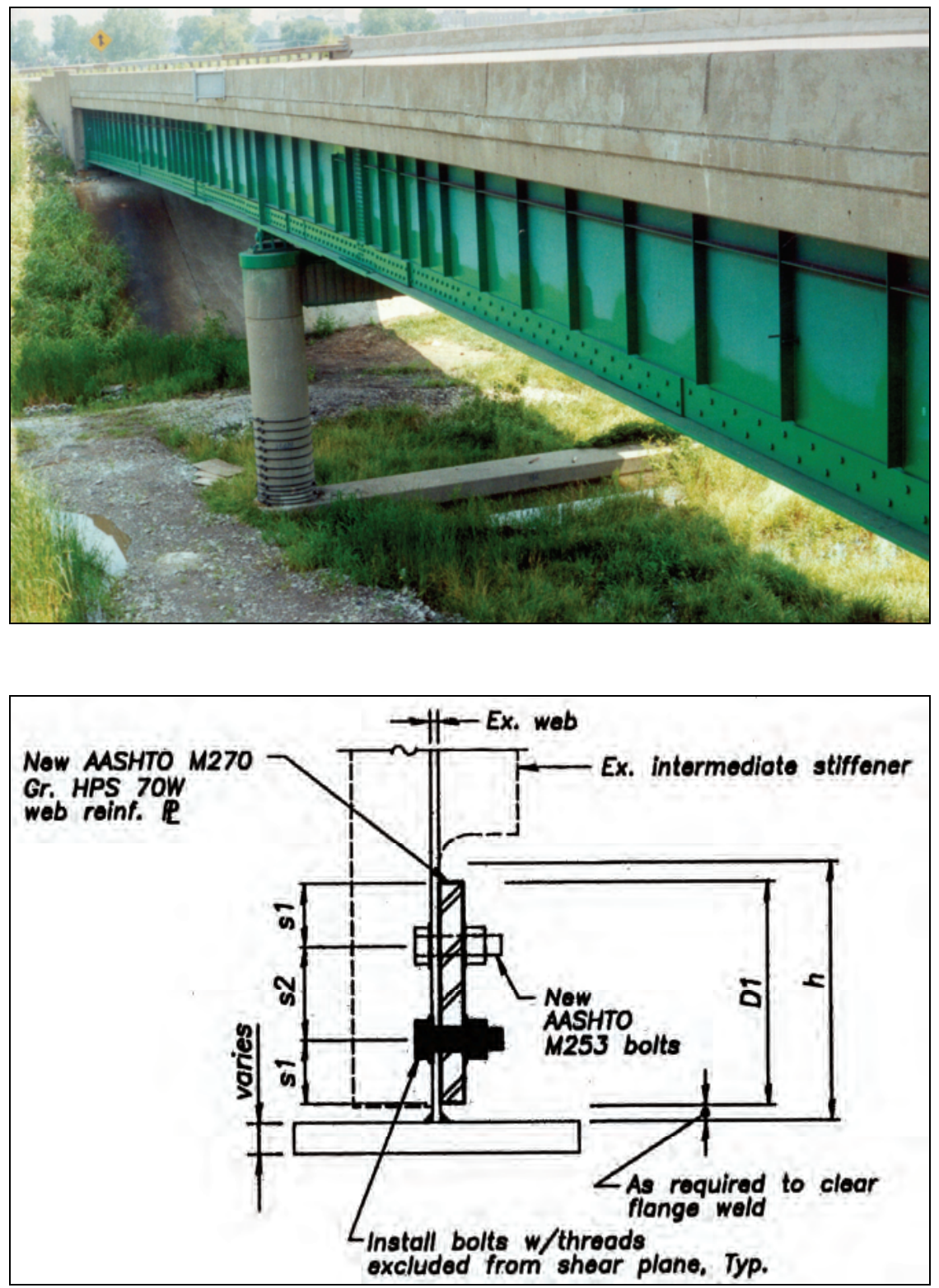

Figure 10. Retrofit redundancy plate bolted to web of existing two-girder superstructure. (Courtesy of Wiss, Janney, Elstner Associates.)

For example, the horizontally framed miter gates shown in Figure 1, the tainter gates shown in Figure 3, and the roller gates shown in Figure 5 clearly have load-path redundancy. If any one of the horizontal primary framing members should fracture, the structure might be able to redistribute the loading and possibly not collapse. This must be established by analysis under a specific load case, however. Even if collapse does not occur, they could still be fracture critical if the deformation caused by a fracture caused a loss of function of the structure. 
The two primary horizontal girders in the sector gate shown in Figure 2, the lift gates in Figure 4, and the bulkheads of Figure 6 are most likely fracture critical because fracture of one of these two girders would likely lead to collapse of the structure. Note that the secondary vertical members and the plating are redundant and therefore are not likely to be fracture critical.

Critical areas to be inspected are identified in the manual on inspection, evaluation, and repair of hydraulic steel structures (U.S. Army Corps of Engineers 2001). Note that these include some non-fracture-critical members and components.

\section{Fatigue and Fracture Control}

Fatigue and brittle fracture are listed in the engineering manual for design of hydraulic steel structures (U.S. Army Corps of Engineers 1994a) as two of the four possible failure modes to be considered for limit state design. A fracture control plan (FCP) includes everything that affects the potential for fracture, in-service inspection and maintenance as well as design, fabrication, and shop inspection (U.S. Army Corps of Engineers 1994a). The idea is that trade-offs can be made; for example, better toughness could be required for the steel and weld metal to compensate for relaxed in-service inspection standards, since better toughness would lead to a larger critical crack size that is easier to see and slower to develop.

The American Institute of Steel Construction (AISC) specifications (AISC 1999) are referred to for the fatigue design of hydraulic steel structures. The fatigue design provisions of AISC are essentially the same as those in the American Association of State Highway and Transportation Officials (AASHTO 2004) and the American Welding Society (AWS) Structural Welding Code D1.1(AWS 2000) and the AASHTO/AWSD1.5 Bridge Welding Code (AASHTO 2002). Section 12 of the AASHTO/AWS D1.5 is entitled AASHTO/AWS Fracture Control Plan (FCP) for Non-redundant Members (AASHTO 2002).

The differences between the provisions for the fabrication of fracture critical members (FCM) in Section 12 and the provisions for non-FCM elsewhere in AASHTO/AWS D1.5 primarily relate to more strict fabrication and shop-inspection requirements to control weld flaws and other crack-like defects in FCM. For example, for FCM, transverse groove 
welds are required to be inspected in the shop with both radiographic testing and ultrasonic testing, whereas only radiographic testing is required for non-FCM. In addition, the provisions for FCM include minimum Charpy V-notch (CVN) requirements for welds and base metals. Such restrictions on detailing, weld flaws, and CVN requirements result in an acceptably low probability of fatigue cracking and brittle fracture in new bridges.

Unfortunately, many of the hydraulic steel structures that are currently in service were designed and built before the implementation of these design and fabrication specifications. These structures may exhibit poor details that are susceptible to fatigue and fracture, low-toughness materials, and poor weld quality.

When the hydraulic structures that are now in service are inspected, the welds are often evaluated using ultrasonic testing according to AWS D1.1 (AWS 2000). Welds with defects and discontinuities that do not meet the standards of AWS D1.1 are supposed to be repaired and retested. It is then assumed in a structural evaluation that defects of these sizes were present in the welds at the time of the last inspection.

\section{Details Likely to Exhibit Deficiencies}

Welded and bolted (or riveted) details are likely to exhibit deficiencies in the fabrication process. The welded details could include welded attachments, seal welds, tack welds, and welds used in repairing riveted structures.

\section{Fatigue Cracks}

If some or the entire load on a structure is applied and then removed for more than 10,000 cycles, fatigue cracking is possible. If the load is applied in one direction and then in the opposite direction, fatigue can occur after as few as 2,000 cycles. If the repeated applied load causes plastic deformation, such as accidental or earthquake loading, then fatigue can occur after only a few cycles (low-cycle fatigue).

Fatigue cracks grow in the presence of tensile stress. Even if the applied loading is in compression, the tensile residual stress in the vicinity of a weld may be sufficient to allow the development of a fatigue crack. 
However, such a fatigue crack in a compression member cannot grow outside the zone of influence of the residual stress and therefore will arrest. Usually, these cracks in compression zones are not as important as cracks in a tension member, which can continue to grow.

The following is a brief overview of the categorization of fatigue details. Details are classified as A through E (and then E') in order of their susceptibility to fatigue, with the $E$ and $E^{\prime}$ details being the most susceptible. This susceptibility to fatigue is referred to as fatigue strength. Usually, there are few if any failures that have been attributed to details with fatigue strengths greater than Category C. Older structures have many Category $\mathrm{C}$ or even more severe details, and the most severe of these will usually govern the fatigue design. Therefore, only Category $\mathrm{C}$ and more severe details will be discussed in depth.

\section{Welded Joints}

The classification of the fatigue strength of welded joints depends on the orientation of the joint with respect to the primary stress direction. The direction of primary stresses in a member is usually clear, since the stresses are essentially uniaxial. However, some structures, such as large plate structures where there is two-way loading, may have multiaxial stress states. In multiaxial stress states, the primary stress direction can be taken as the principal stress direction. Some analysis may be required to determine the direction of principal stress.

Welded joints are considered transverse if the axis of the weld is perpendicular to the primary stress range (Fig. 11, 12, and 13). Unless there is a stress concentration from the configuration of the detail, transverse welds are typically Category C details if they are less than $51 \mathrm{~mm}$ ( 2 in.) long. If the attachments are between 51 and $101 \mathrm{~mm}$ (4.02 in.) long, they are considered Category D, and they are Category $\mathrm{E}$ if the attachments are greater than $101 \mathrm{~mm}$ (4.02 in.) long. Category E', which is slightly worse than Category E, applies if the attachment plates or the flanges exceed 25 $\mathrm{mm}$ (1.0 in.) in thickness. 


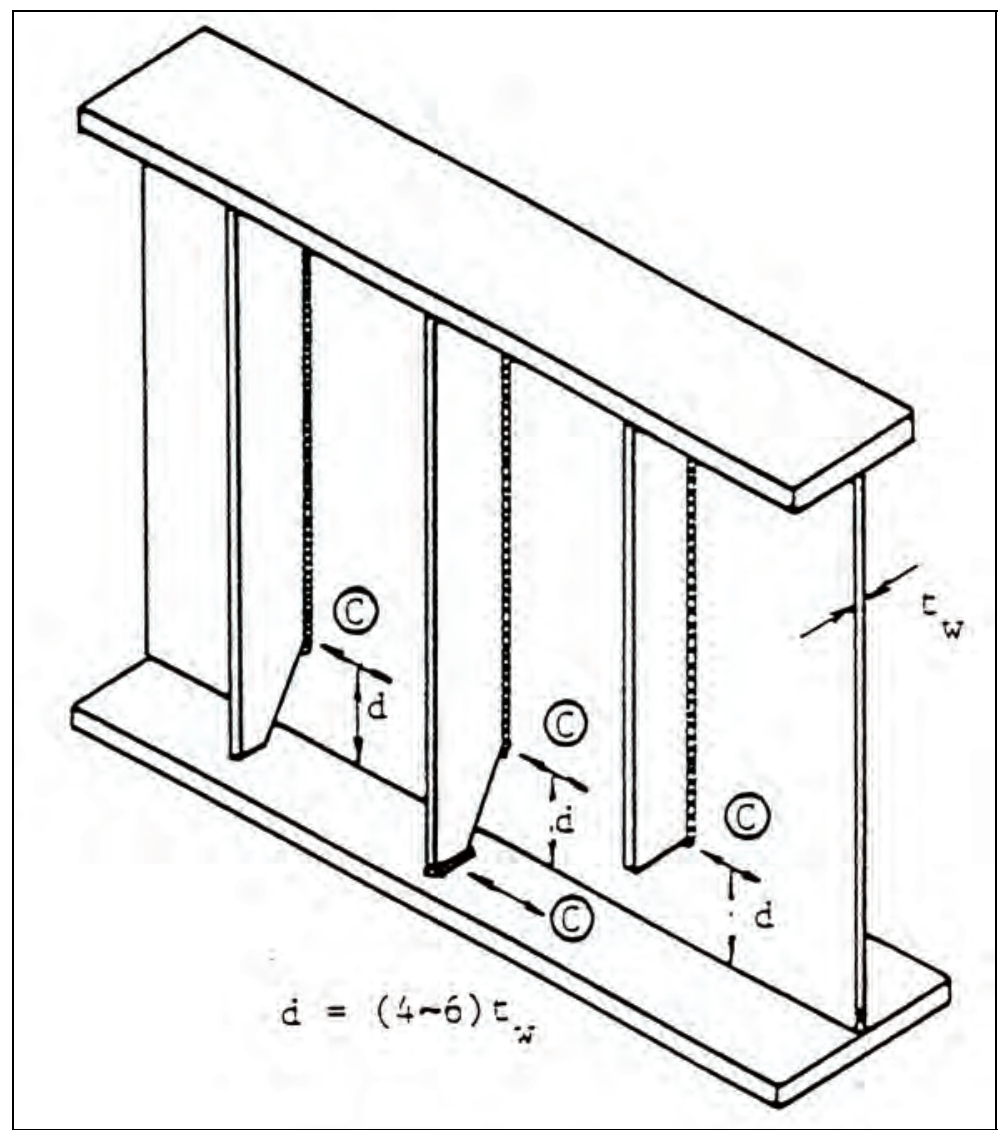

Figure 11. Category $C$ detail at the termination of a vertical weld used for attaching the transverse stiffener to the girder web for a web gap of four to six times the thickness of the web plate.

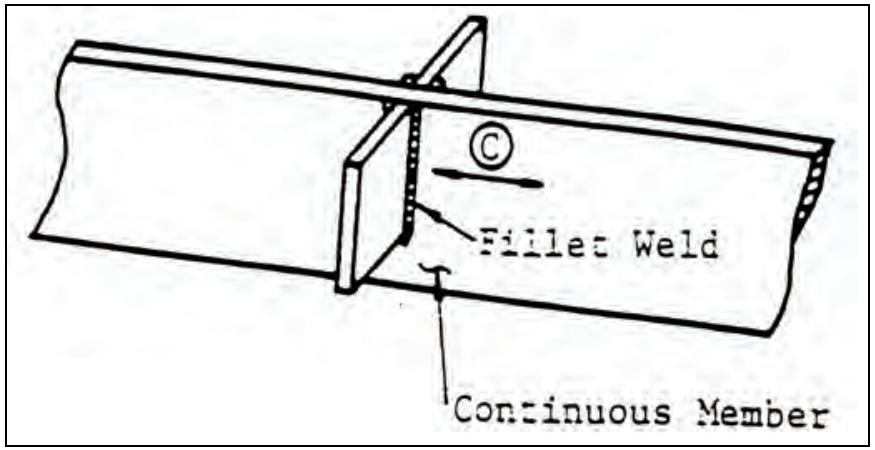

Figure 12. Category $\mathrm{C}$ detail at the toe of a transverse fillet weld. 


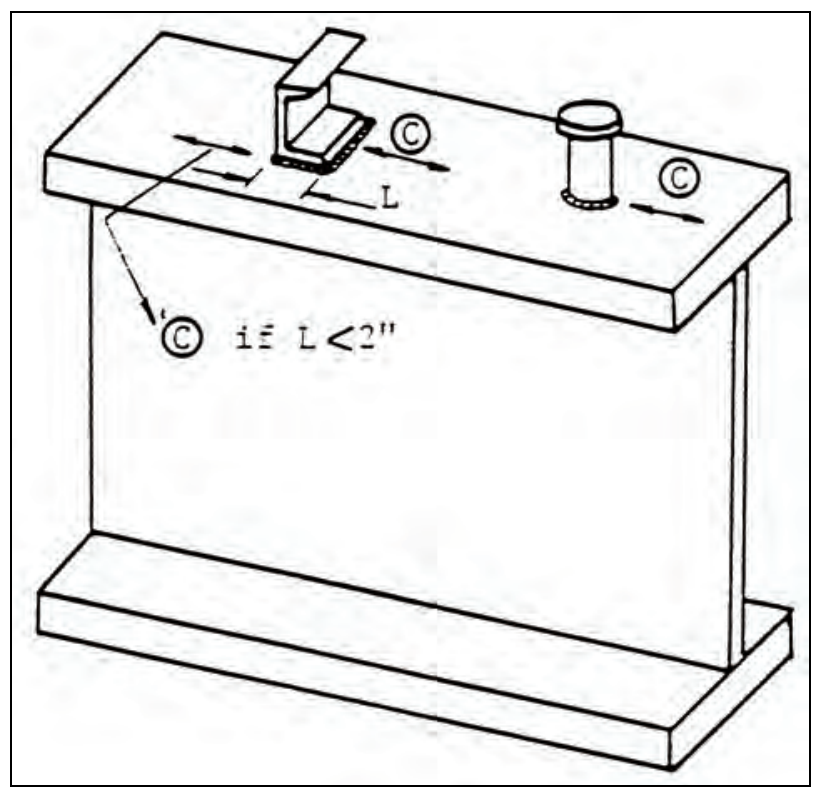

Figure 13. Category $\mathrm{C}$ detail for attachments perpendicular to a flange.

The cruciform joint where the load-carrying member is discontinuous (Fig. 14) is considered a Category $C$ detail because it is assumed that the plate transverse to the load-carrying member does not have any stress range. A special reduction factor for the fatigue strength is provided when the load-carrying plate exceeds $13 \mathrm{~mm}$ (0.05 in.) in thickness. This factor accounts for the possible crack initiation from the unfused area at the root of the fillet welds (as opposed to the typical crack initiation at the weld toe for thinner plates) (Frank and Fisher 1979).

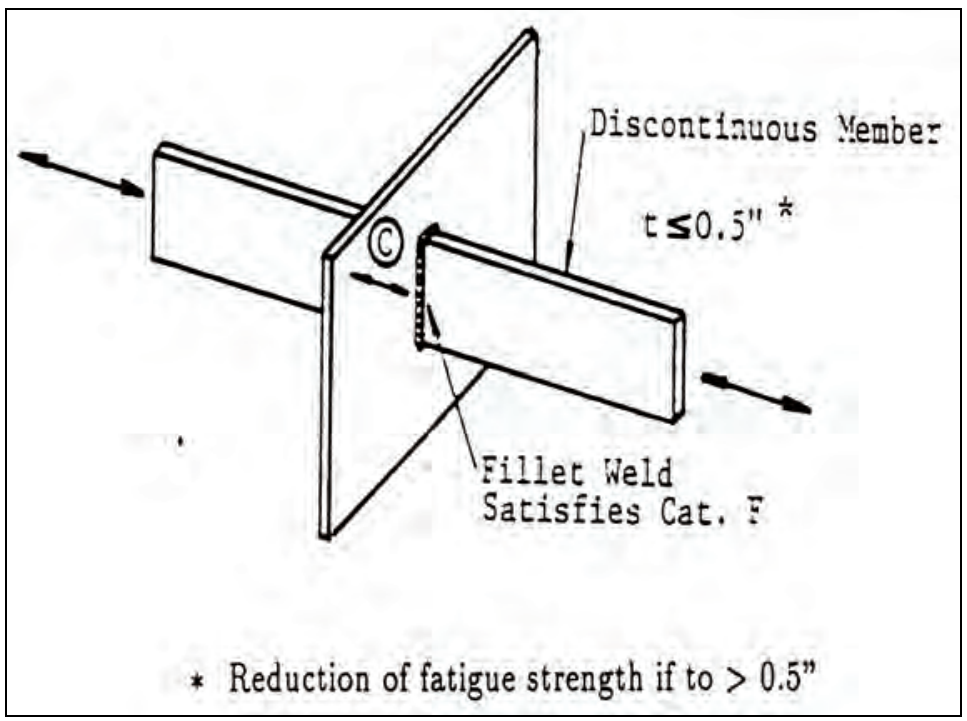

Figure 14. Category $\mathrm{C}$ detail for a cruciform joint. 
Full-penetration groove welded buttjoints subjected to nondestructive evaluation (NDE) such as ultrasonic or radiographic testing are also Category $\mathrm{C}$ details. If the reinforcement of these full-penetration butt joints is ground smooth, they become Category B details and are usually not a concern. Transverse groove welds with a permanent backing bar are reduced to Category D (Dexter and Kelly 1997, Kelly and Dexter 2003). One-sided welds with melt through (without backing bars) are also classified as Category D (Dexter and Kelly 1997, Kelly and Dexter 2003). Tests show that groove welds that contain large internal discontinuities that were not screened out by NDE had fatigue strengths comparable to Category E (Kober et al. 1994), regardless of backing bars. An example of a butt splice in a tension chord is shown in Figure 15. Figure 16 shows a Category C detail of a typical groove welded butt joint subjected to NDE and not ground flush.

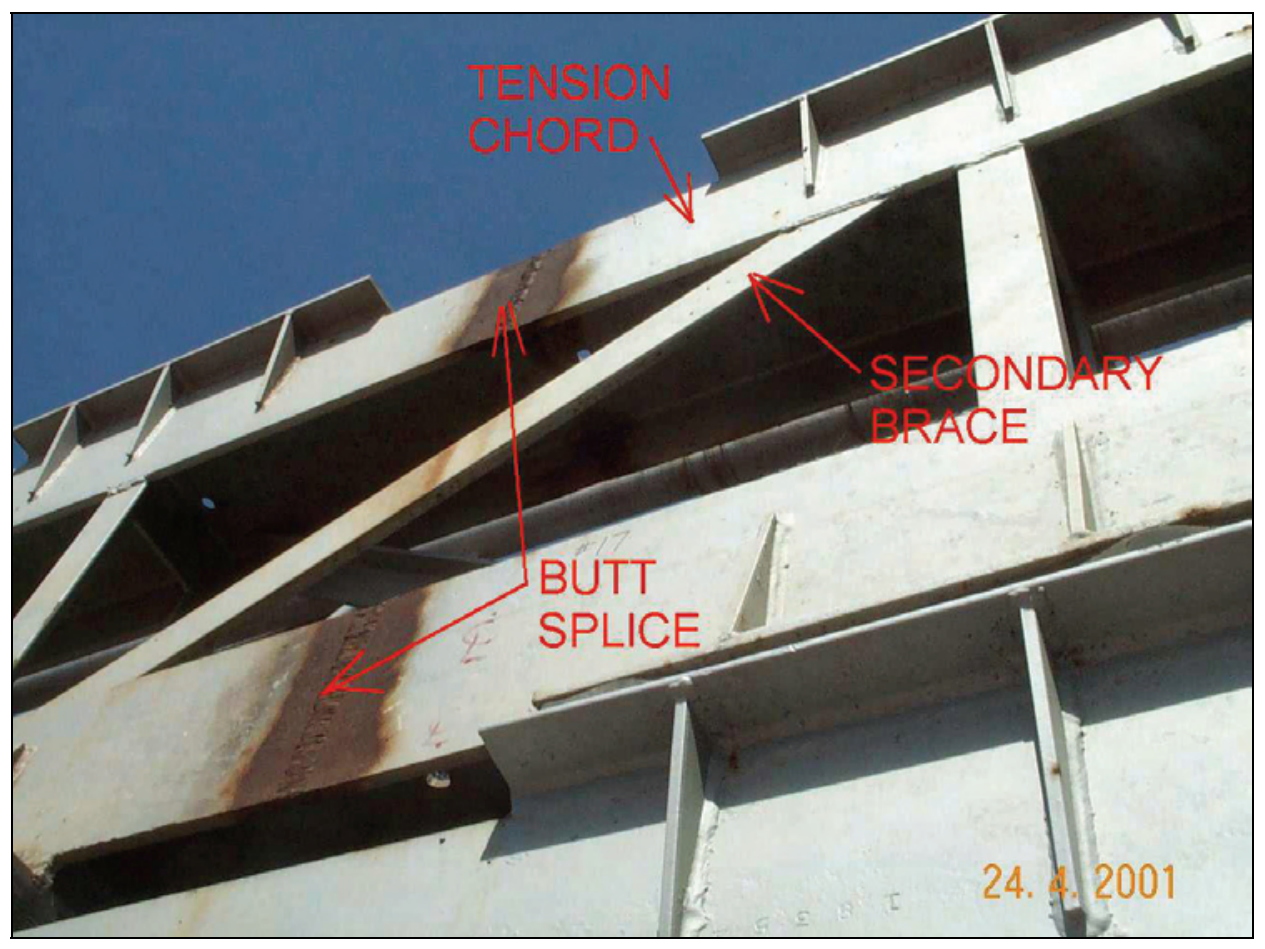

Figure 15. Example of a butt splice in a tension chord of a bulkhead.

Continuous longitudinal welds are Category B details and therefore are not expected to exhibit fatigue cracks. However, the termination of a longitudinal groove or fillet weld is more severe and is considered to be Category E, as shown in Figure 17. Figure 18 shows an example of a Category $\mathrm{E}$ detail at the termination of the longitudinal weld of a longitudinal 


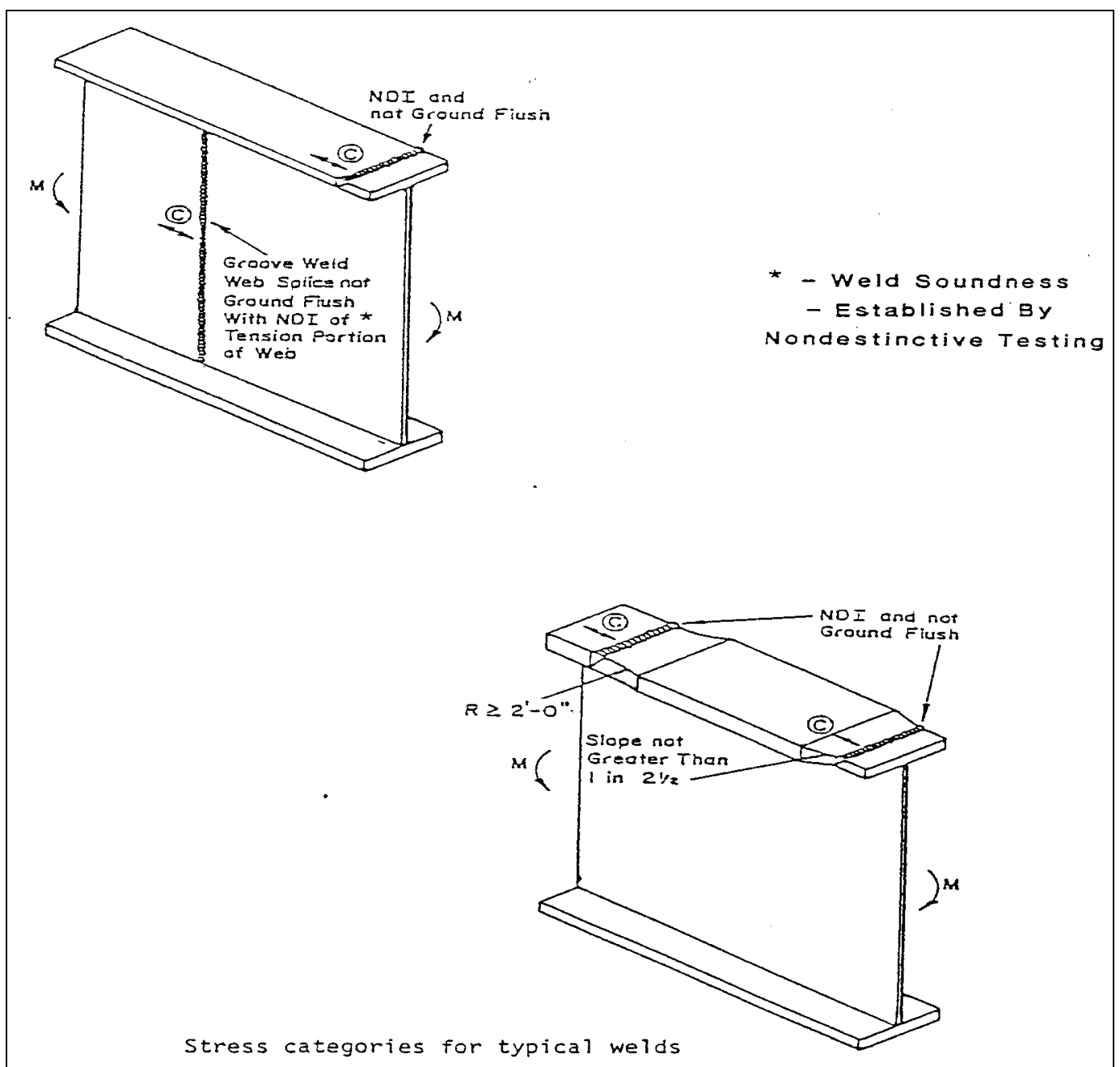

Figure 16. Category $C$ detail of a typical groove welded butt joint.

stiffener and the termination of a longitudinal weld of a gusset plate. Figure 19 shows two longitudinal stiffener details. Both details are Category E. However, crack initiation and propagation are likely to occur at the termination of the longitudinal stiffener located in a tensile stress field. The initial flaw at the weld toe at the termination of the detail will grow under fatigue to become a through-thickness crack before it propagates vertically in the web perpendicular to primary stresses as shown in Figure 20. Figures 21 and 22 show other examples of Category E details. The termination of full-penetration groove longitudinal welds can be better, but this requires a ground transition radius. If longitudinal welds must be terminated, it is better to extend the welds to a location along the structural member where the stress ranges are small or entirely in compression. 


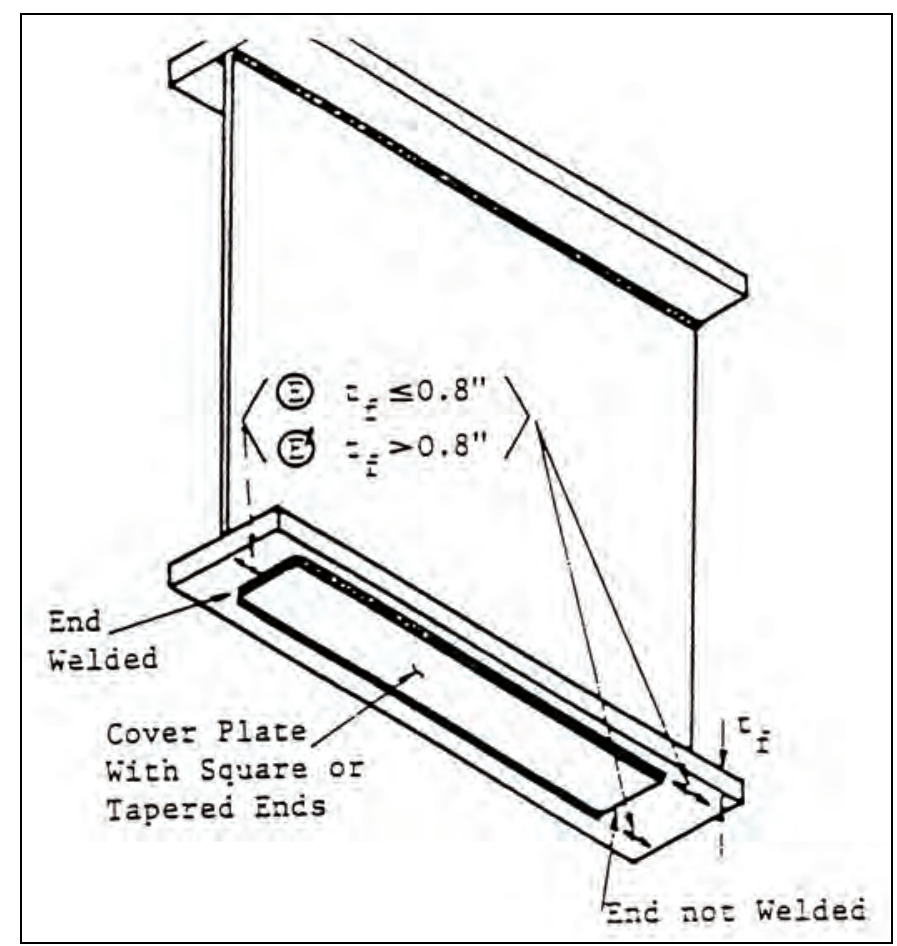

Figure 17. Category $\mathrm{E}$ detail at the termination of a longitudinal weld at cover plate detail.

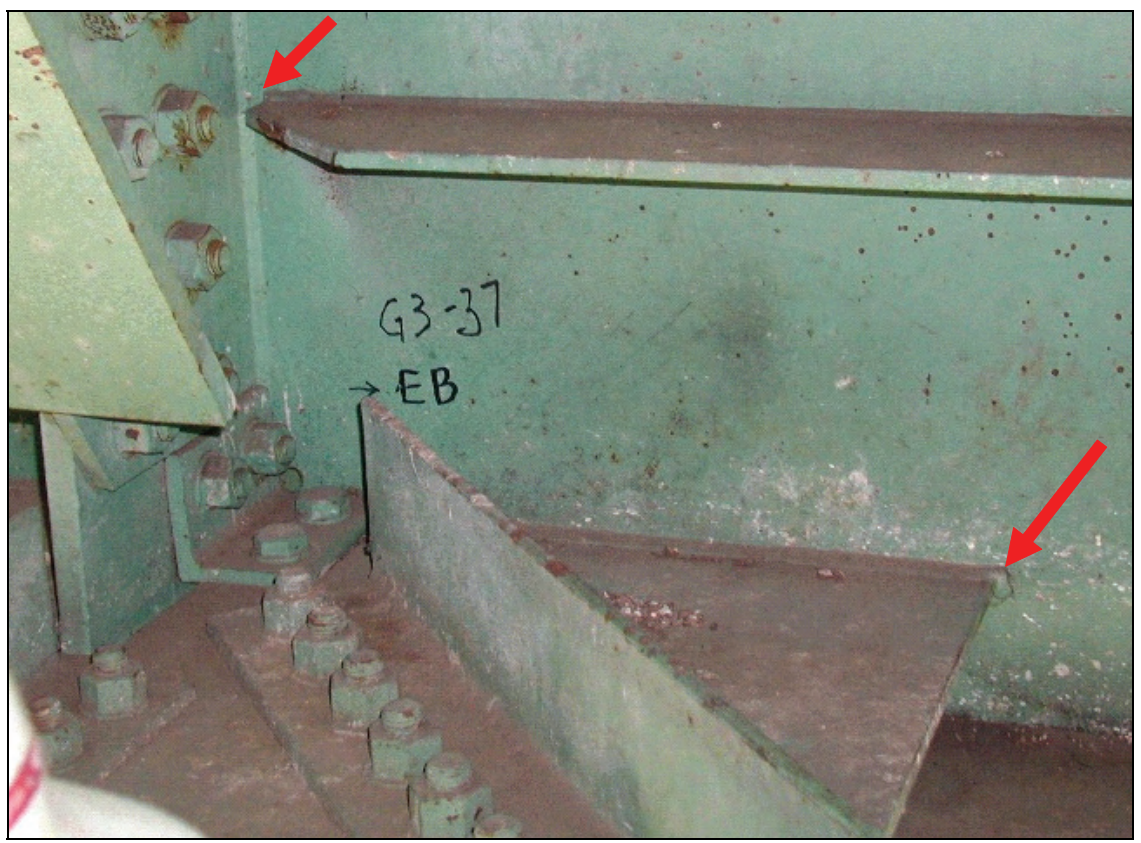

Figure 18. Category $\mathrm{E}$ detail at the termination of a welded longitudinal stiffener detail and at the termination of a welded gusset plate detail. 


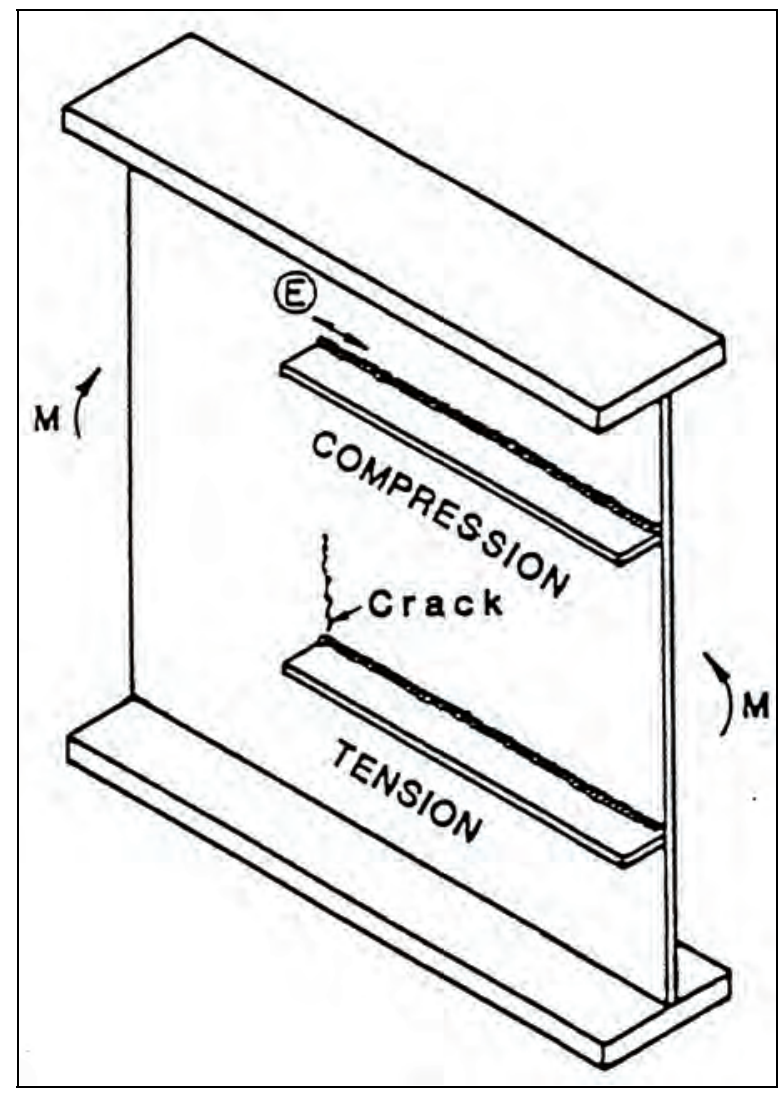

Figure 19. Crack location at the termination of a longitudinal stiffener detail in a tension stress field.

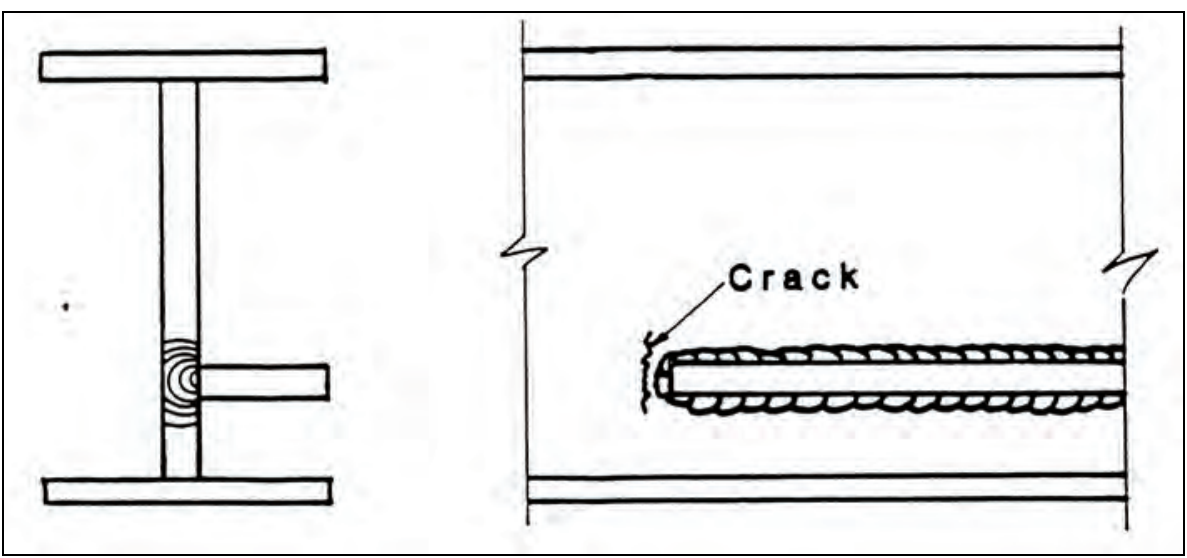

Figure 20. Through-thickness crack at the termination of a longitudinal stiffener detail. 


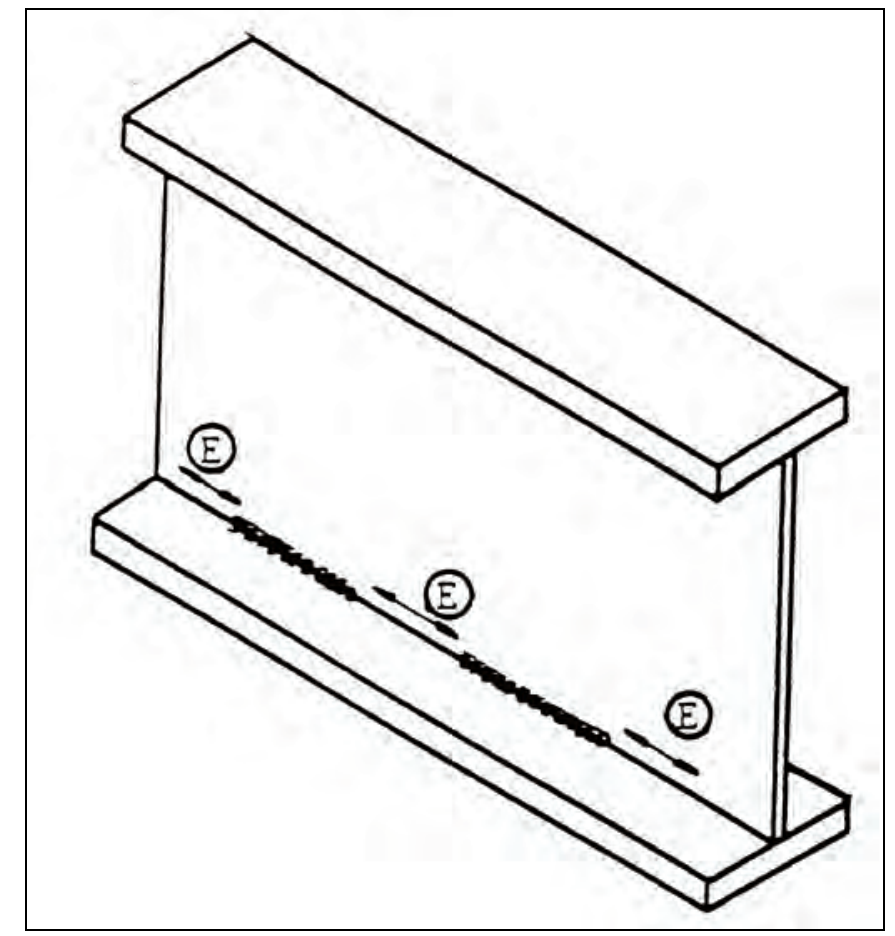

Figure 21. Category $E$ detail at the termination of longitudinal intermittent welds.

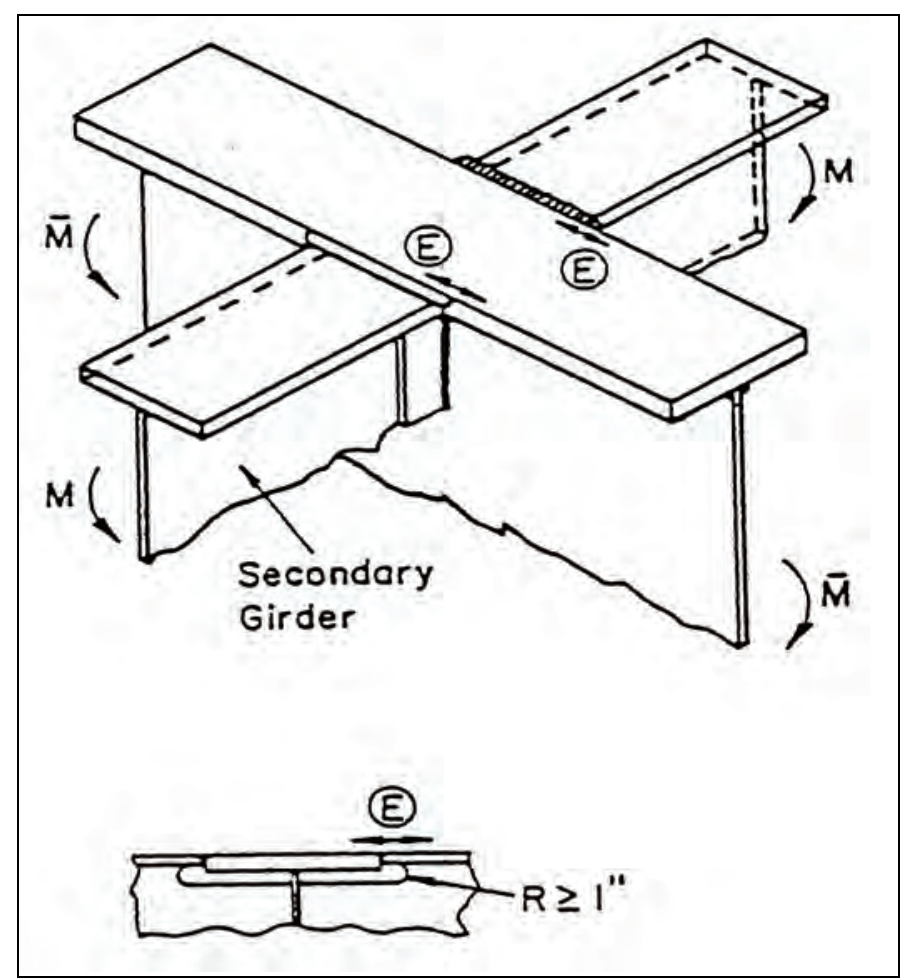

Figure 22. Category E detail at the termination of a longitudinal weld. 
Cope holes, cutouts, and snipes should be used for weld access and for avoiding intersecting welds. If the thermally cut surfaces have edges conforming to the ANSI smoothness of 1000, these may be considered Category D details, even if welds terminate at these details (Dexter and Kelly 1997, Kelly and Dexter 2003). A rougher cope hole may be treated as a Category E detail. If the steel at the thermally cut edge transforms to martensite, in some cases small cracks may occur that will propagate at even lower stress ranges. Figure 23 shows a poorly cut cope hole with a crack initiating from the cope. Figure 24 shows a crack initiating from a cope hole with a roughness not in confirmation with ANSI.

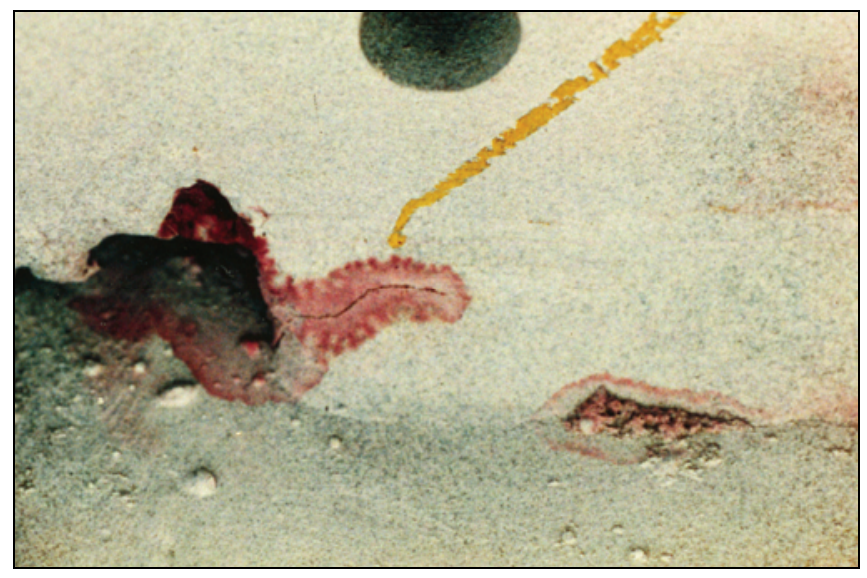

Figure 23. Crack initiating from a poorly cut cope hole.

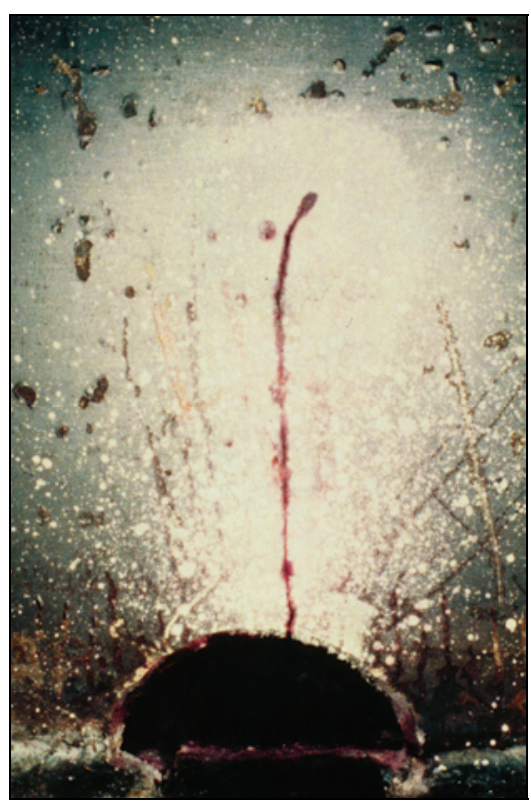

Figure 24. Crack initiating from a cope hole with a roughness not in confirmation with ANSI. 
As shown in Figure 25, attachments normal to flanges or plates that do not carry a significant load are rated Category C if they are less than $51 \mathrm{~mm}$ (2.0 in.) long in the direction of the primary stress range, Category D if they are between 51 and $101 \mathrm{~mm}$ (2.0- $4.0 \mathrm{in}$.) long, and Category E if they are greater than $101 \mathrm{~mm}$ (4.0 in.) long. If there is not at least $10 \mathrm{~mm}$ (0.4 in.) of edge distance, then Category $E$ applies for an attachment of any length. Category detail E' is slightly worse than Category $\mathrm{E}$, and it applies if the attachment plates or the flanges exceed $25 \mathrm{~mm}$ (1.0 in.) in thickness. Figures 26-28 show examples of Category E details of attachments normal to the flange of the primary carrying load member. In most other types of load-carrying attachments, there is interaction between the stress range in the transverse load-carrying attachment and the stress range in the main member. In practice, each of these stress ranges is checked separately. The attachment is evaluated with respect to the stress range in the main member, and then it is separately evaluated with respect to the transverse stress range. The combined multiaxial effect of the two stress ranges is taken into account by a relative decrease in the fatigue strength, i.e. most load-carrying attachments are considered Category E details.

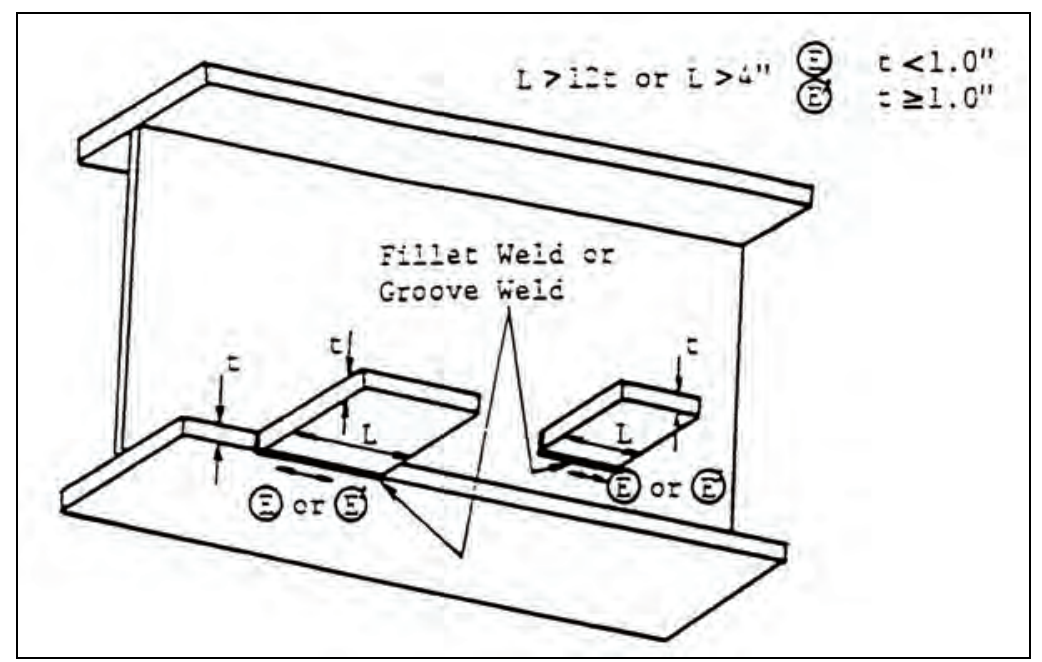

Figure 25. Category E detail for attachments normal to the flange and the web of a girder. 


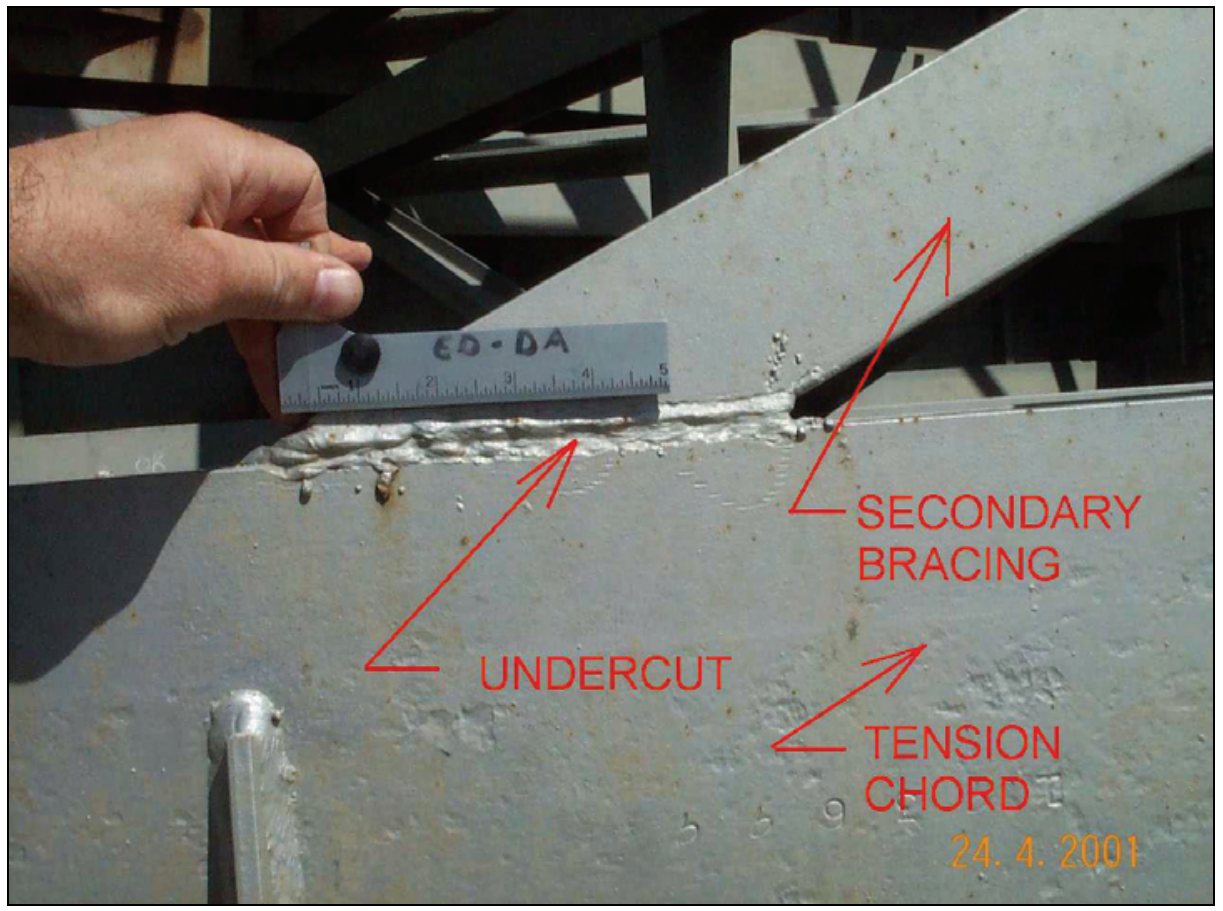

Figure 26. Category E detail for a diagonal member welded to a truss chord.

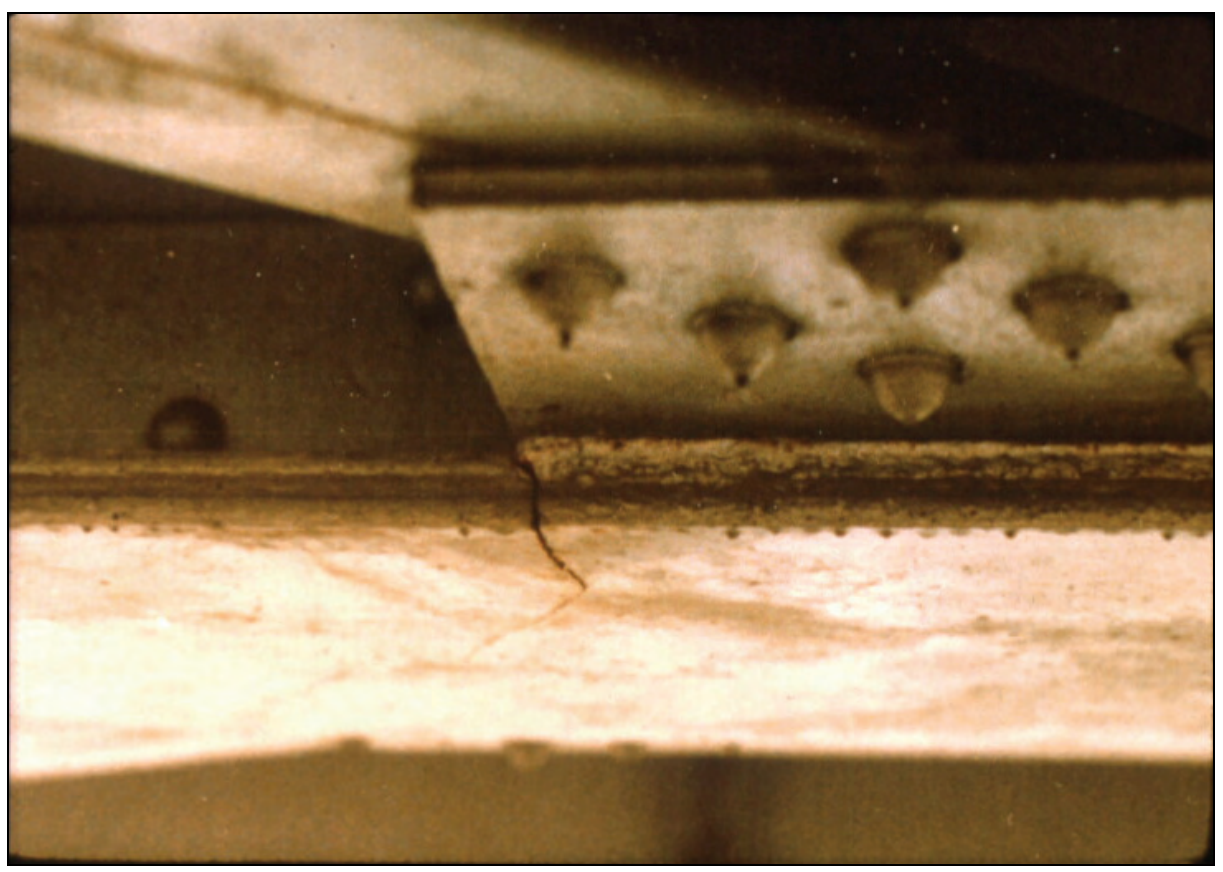

Figure 27. Category E detail and typical crack location for a gusset plate attachment normal to the flange of a girder. 


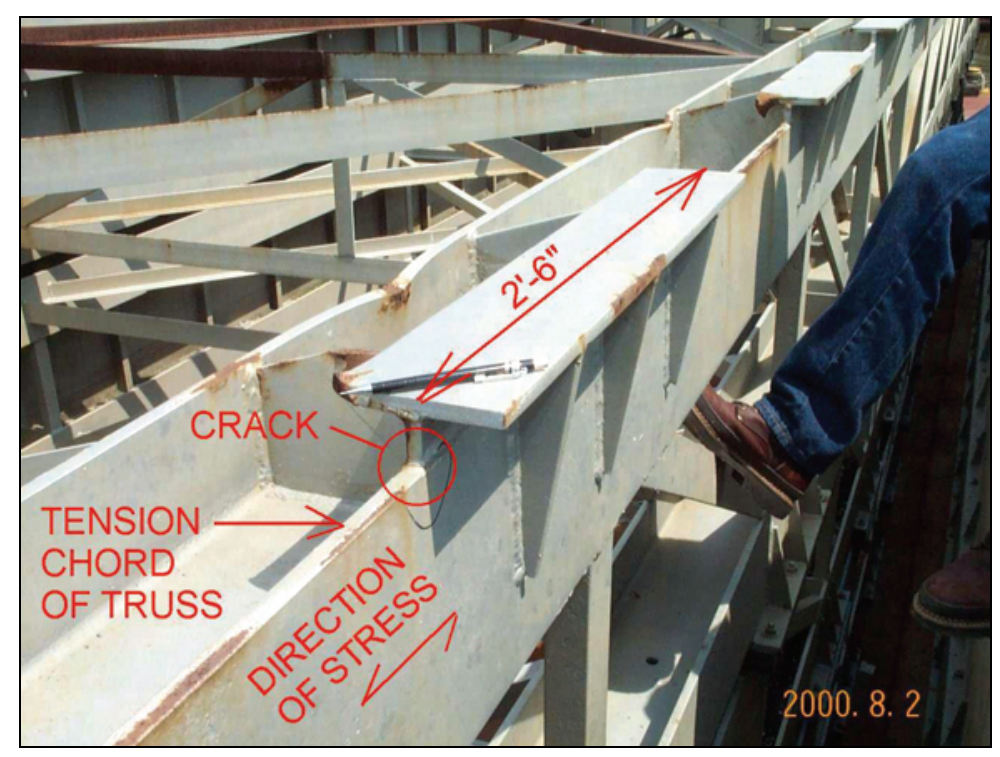

Figure 28. Category E detail of a longitudinal butt weld on a bearing pad attachment normal to the flange of a truss chord.

\section{Bolted Joints and Anchor Rods}

Small holes are considered Category D details (Fig. 29). Therefore, riveted and mechanically fastened joints (other than high-strength bolted joints) loaded in shear are evaluated as Category D in terms of the net section nominal stress (Fig. 30). Figure 31 shows a crack initiating at a riveted detail. High-strength A325 and A490 bolted joints that are properly pretensioned and loaded in shear are Category B details in terms of the net section nominal stress. Pin plates and eyebars are designed as Category E details in terms of the net section nominal stress.

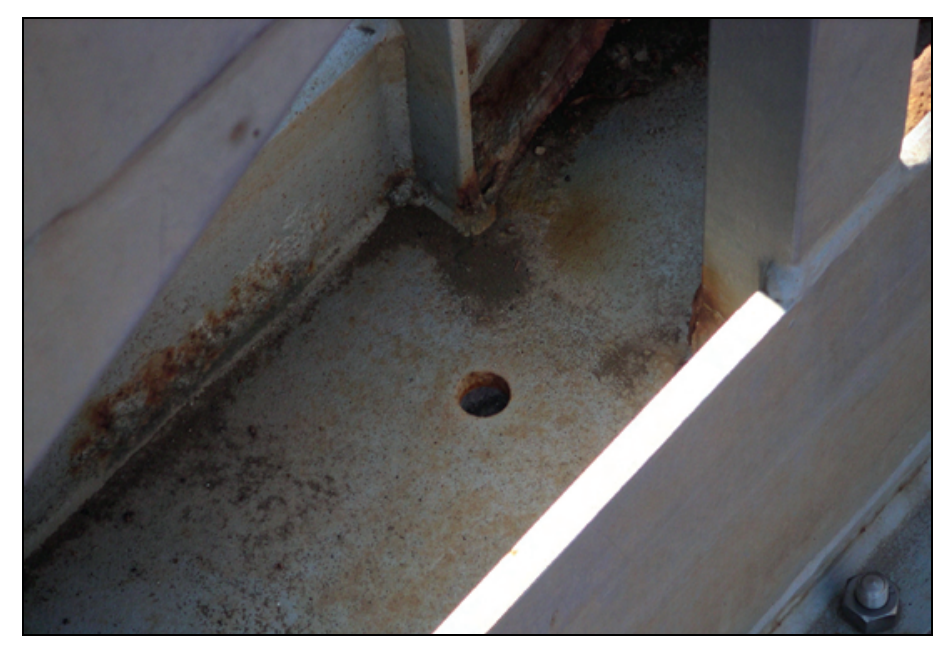

Figure 29. Category D detail of a drain hole. 


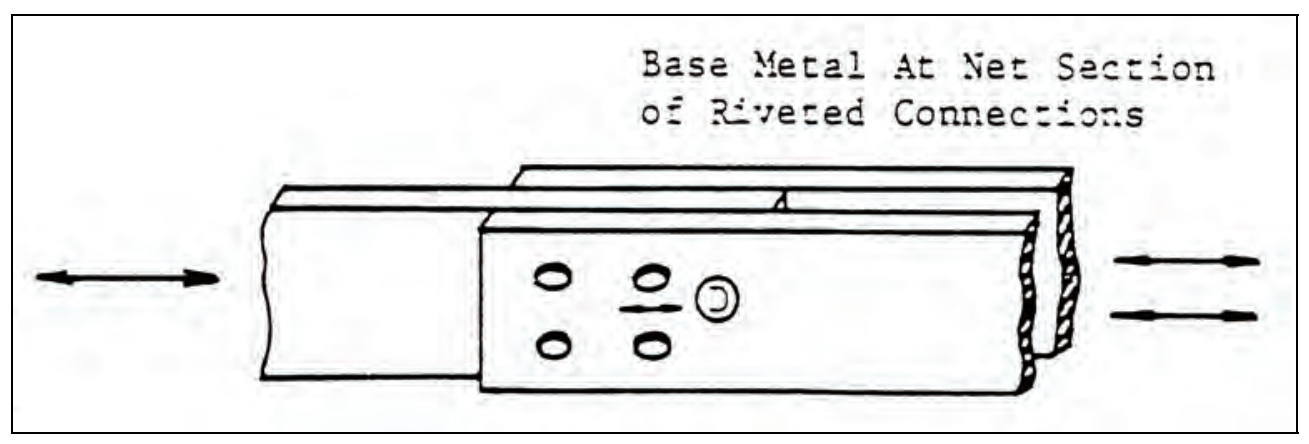

Figure 30. Category D riveted detail loaded in shear.

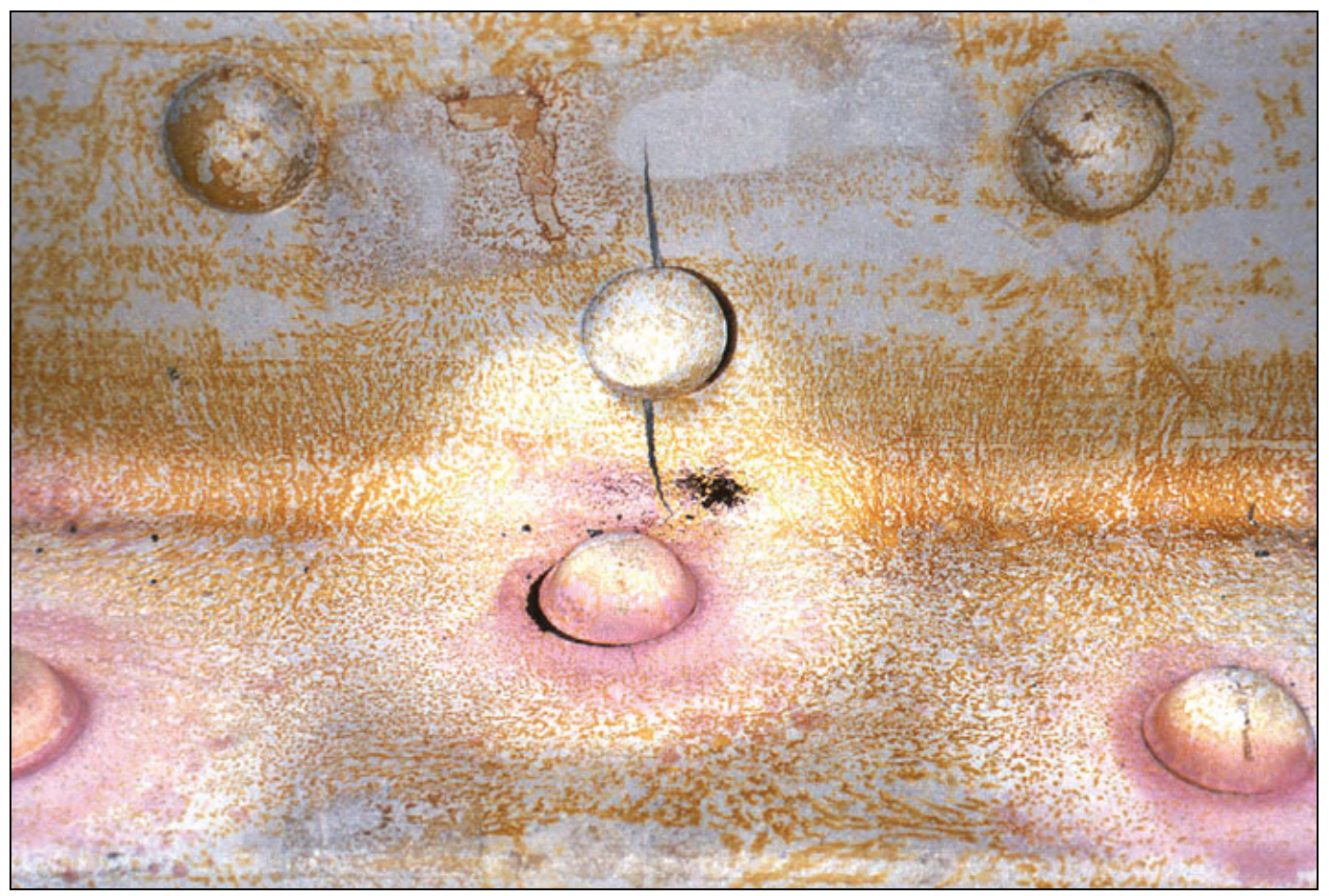

Figure 31. Crack initiating at a riveted detail.

Bolted joints loaded in direct tension are more complicated. Typically these provisions are applied to hanger-type or bolted flange connections where the bolts are pretensioned against the plies. In this case, the total fluctuating load is resisted by the area of the precompressed plies so that the bolts are subjected to only a fraction of the total load (Kulak et al. 1987). However, the analysis to determine this fraction is difficult. In the AISC specifications (AISC 1999), the designer may assume that the load range in the bolts is 20 percent of the total applied service load (dead plus live load). The total applied service load must include any prying load. Prying is very detrimental to fatigue, so it is best to minimize prying forces 
by using sufficiently thick plates (AISC 1999). In the AISC specifications (AISC 1999), the stress range in the bolts is calculated on the tensile stress area, $A_{\mathrm{t}}$, given by:

$$
\begin{gathered}
A_{\mathrm{t}}=\frac{\pi}{4}\left(d_{\mathrm{b}}-0.9382 P\right)^{2}(\mathrm{SI} \text { units }) \\
A_{\mathrm{t}}=\frac{\pi}{4}\left(d_{\mathrm{b}}-\frac{0.9743}{n}\right)^{2} \text { (English units) }
\end{gathered}
$$

where $d_{\mathrm{b}}$ is the nominal diameter (the body or shank diameter) (mm or in.), $\mathrm{P}$ is the pitch ( $\mathrm{mm} /$ thread), and $n$ is threads per inch.

Category E' is the lower bound for bolts in direct tension (Kuperus 1973, 1974). Anchor rods in concrete cannot be adequately pretensioned and therefore do not behave like hanger-type or bolted flange connections. In the double-nut configuration, they are pretensioned between nuts on either side of the base plate, but the part below the bottom nut is still exposed to the full load range. The data on anchor rods (Frank 1980, Dusel et al. 1984, Kaczinski et al. 1998) agree well with the bolt data, i.e. the lower-bound fatigue strength is Category $\mathrm{E}^{\prime}$. The constant amplitude fatigue limit (CAFL) for bolts and anchor rods is $48 \mathrm{MPa}$ (6.96 Ksi), which is much greater than the CAFL for other Category E' details.

\section{Effect of Corrosion}

Full-scale fatigue experiments have been carried out in moist air and therefore reflect some degree of environmental effect or corrosion fatigue. Full-scale fatigue experiments in seawater do not show significantly lower fatigue lives (Roberts et al. 1986), provided that corrosion is not so severe that it causes pitting. The fatigue lives seem to be more significantly influenced by the stress concentration at the toe of welds and the initial discontinuities. Therefore, these lower-bound S-N curves can be used for designing bridges in any natural environmental exposure, even near salt spray. However, pitting from severe corrosion may become a fatiguecritical condition and should not be allowed (Outt et al. 1984, Albrecht and Shabshab 1994). Severely corroded members may be treated as Category $E$ details (Albrecht and Shabshab 1994). 


\section{Welding Cracks}

Different types of cracks or flaws can occur during the welding process. These cracks could grow under cyclic loading and develop into fatigue cracks. The most significant defects are those that resemble cracks, such as lack-of-fusion defects, and cold overlap. Figure 32 shows a crack forming in a plate girder from a long lack-of-fusion defect. Porosities are another form of weld cracking. Porosity is the presence of cavities in the weld metal caused by the freezing in of the gas released from the weld pool during the solidification process. Porosity can take different forms, such as distributed (Fig. 33) or piping (Fig. 34). Hydrogen cracking is another form of weld crack, typically caused by exposing the weld to the environment, resulting in absorption of hydrogen from air into the work piece and causing internal cracks or voids in the steel. Figures 35 and 36 show examples of fatigue cracks forming from weld hydrogen defects.

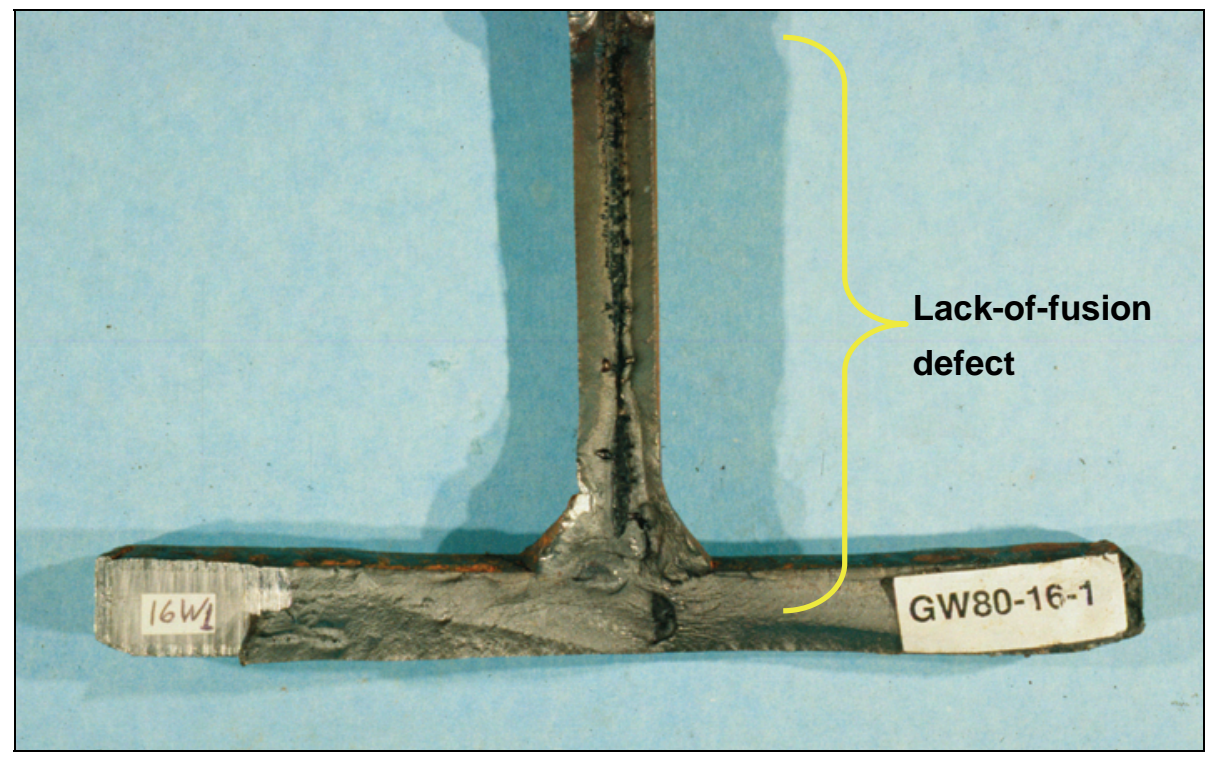

Figure 32. Crack forming from a lack-of-fusion defect. 


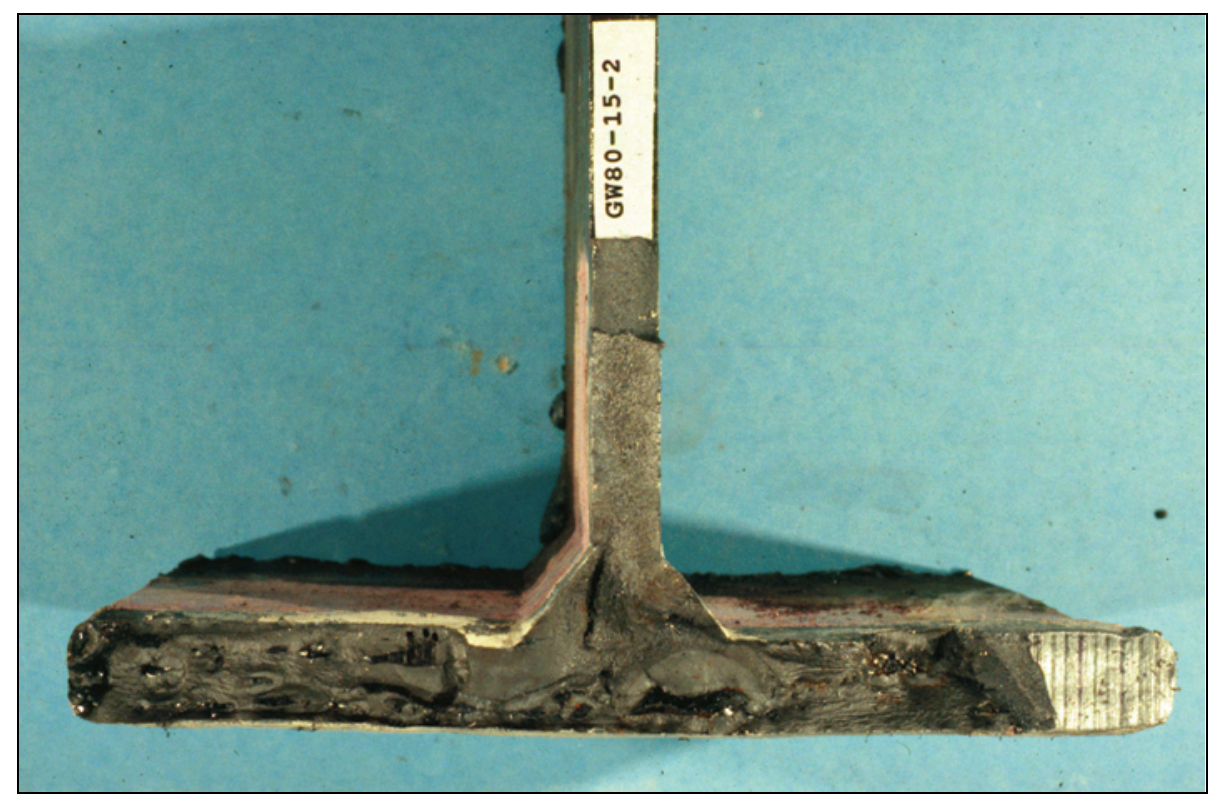

Figure 33. Several fatigue cracks forming from distributed porosities.

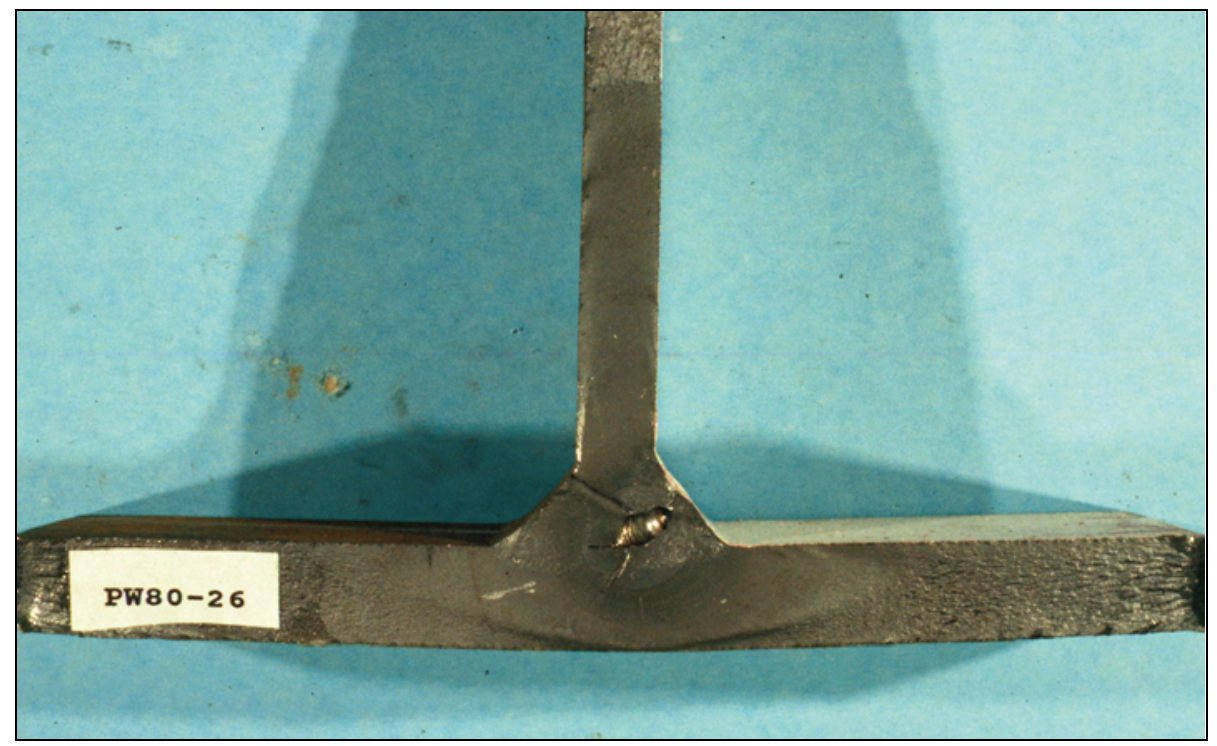

Figure 34. Fatigue crack forming from a piping porosity defect. 


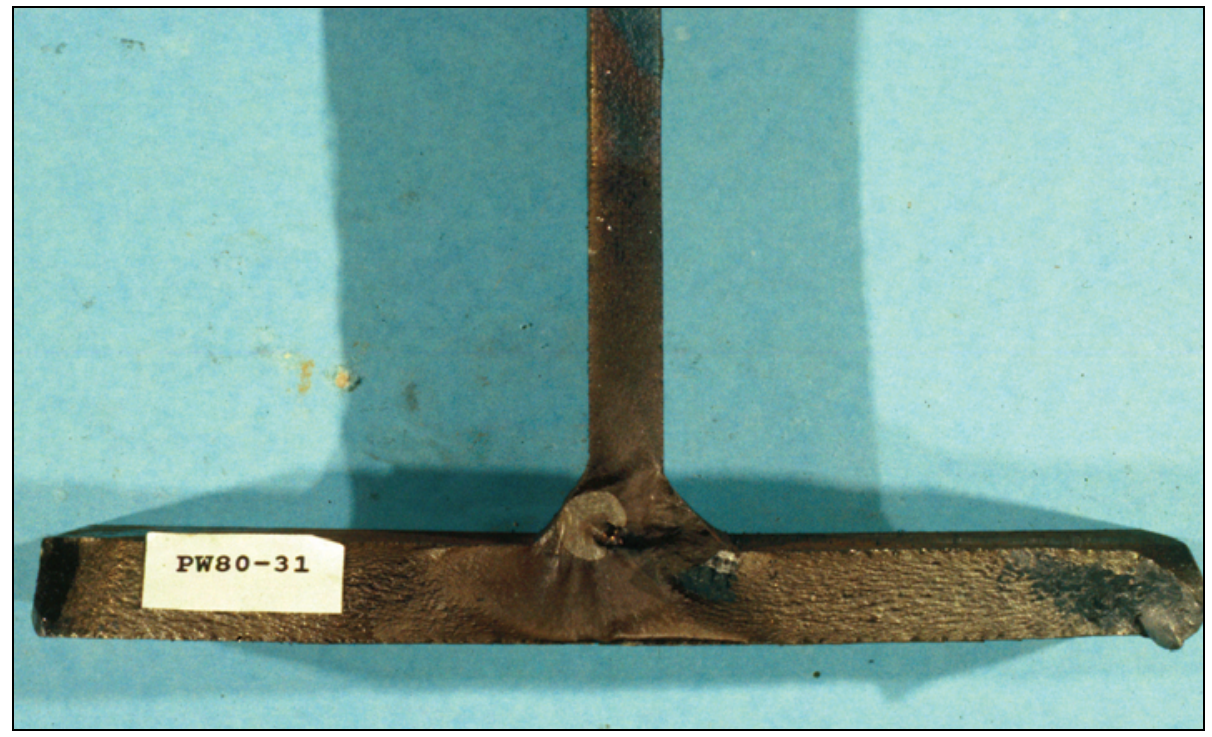

Figure 35. Hydrogen fisheye crack.

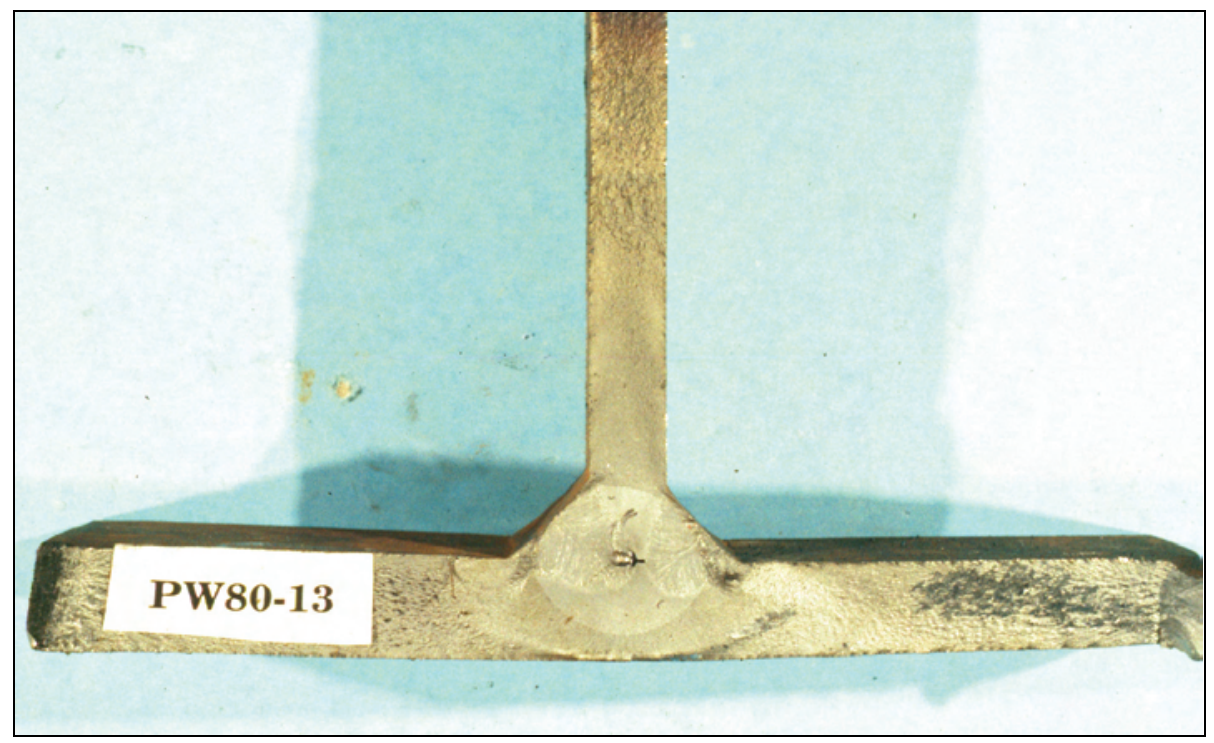

Figure 36. Another hydrogen fisheye crack.

\section{Intersecting Welds}

Details fabricated with intersecting welds are susceptible to fatigue cracking or sudden brittle fracture. In hydraulic steel structures, intersecting welds are often located at uncoped stiffeners and where diaphragm webs frame into girder webs and flanges (U.S. Army Corps of Engineers 2001). Areas of intersecting welds are known to exhibit entrapped slag in the weld root and weld toe. The entrapped slag results in a buried defect that could grow into a through-thickness crack under cyclic 
loading. After which, sudden failure of the welded connection could occur as a result of the high tri-axial state of stress resulting from the high level of constraint of the detail.

\section{Delaminations}

Delaminations often exist due to minimal cross rolling applied to plates during rolling coupled with high sulfur content $(0.025 \%)$, which typically results in a high proportion of longitudinally oriented manganese-sulfide inclusions. These inclusions manifest as separations in the throughthickness direction when subjected to tensile through-thickness stresses. Separations, which are often referred to as delaminations, are parallel to the plate surface and perpendicular to the fracture surfaces. Figures 37 and 38 show typical delaminations in steel members.

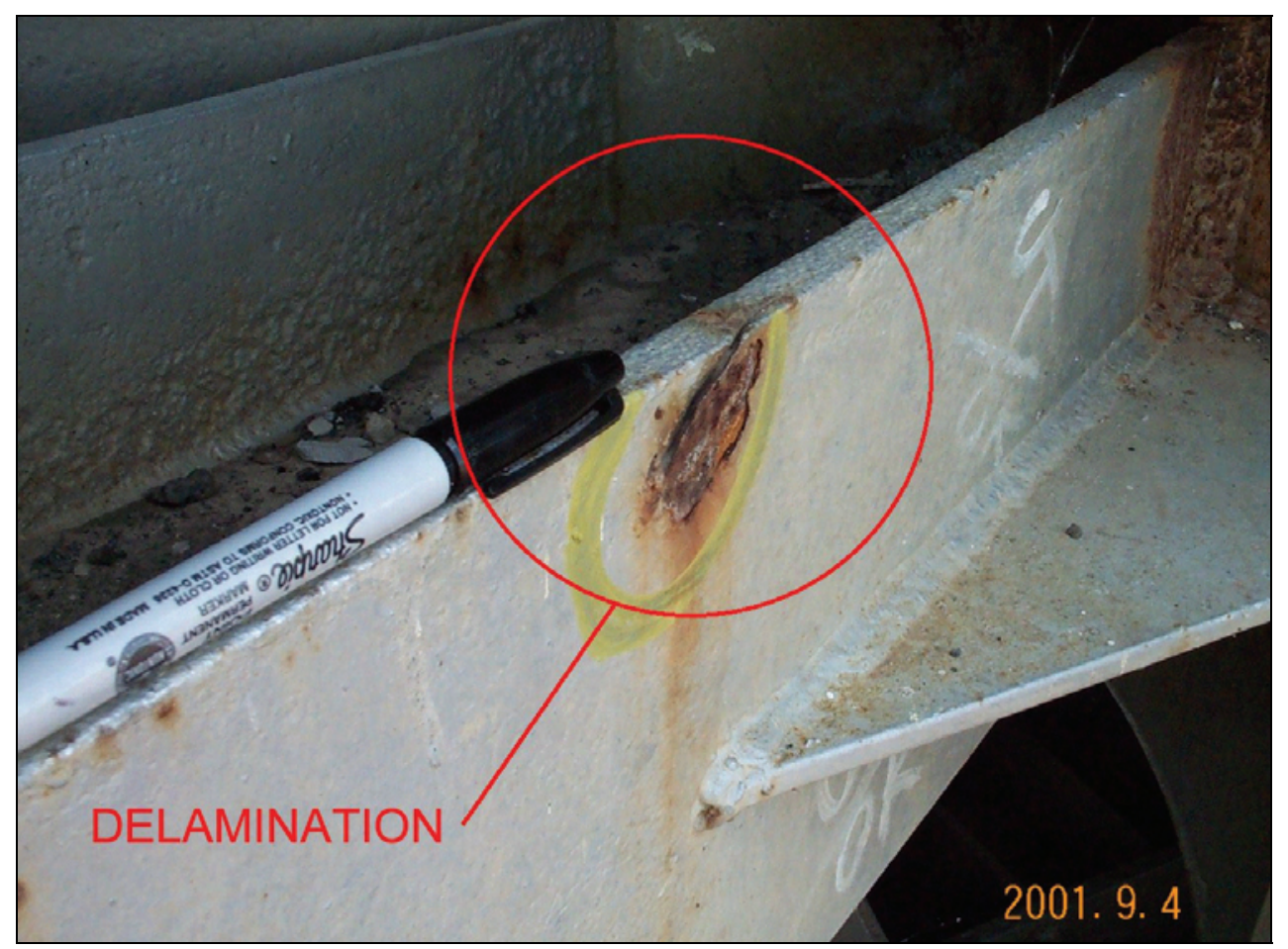

Figure 37. Delamination in a flange of a truss chord. 


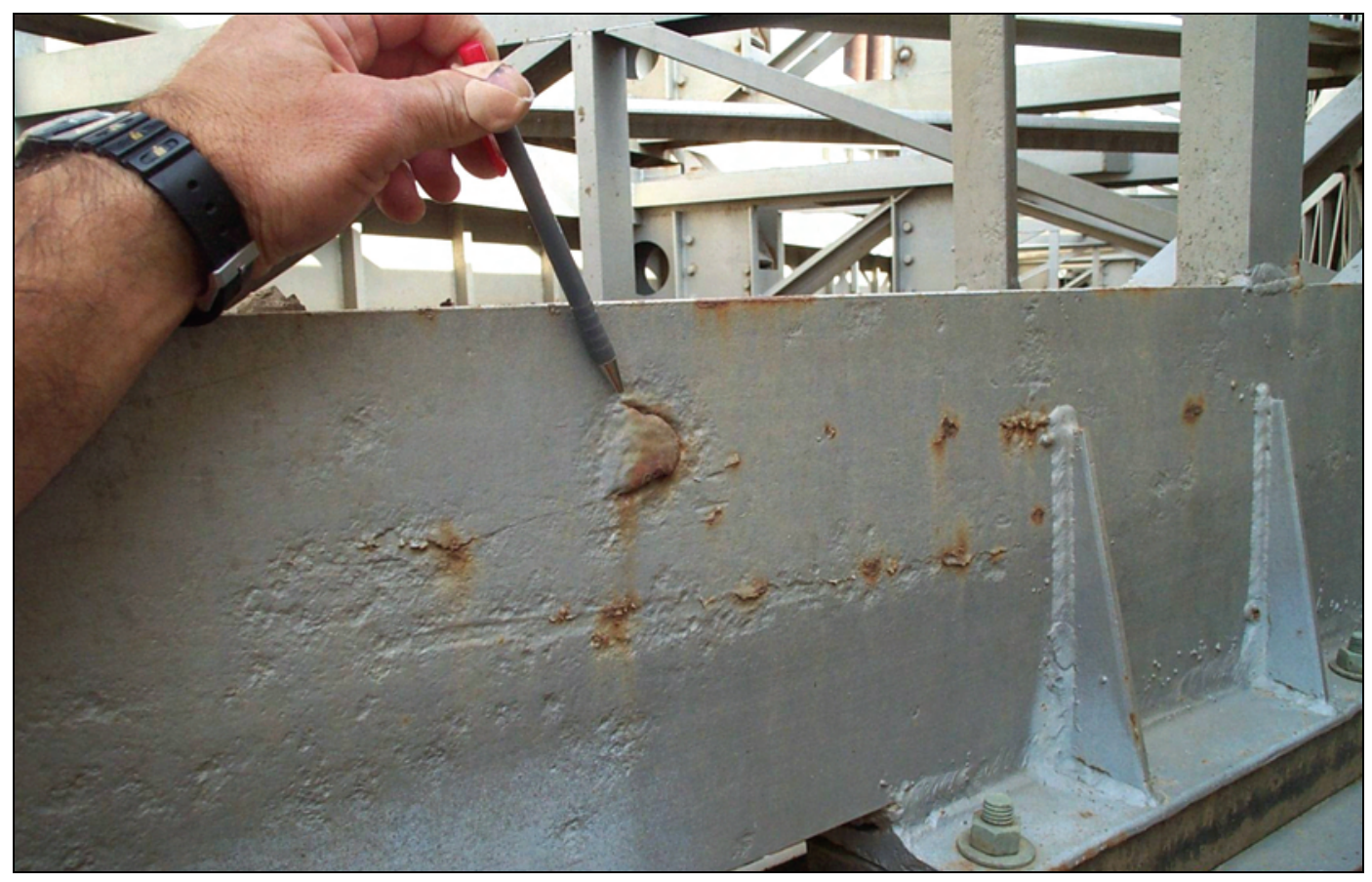

Figure 38. Pop out delamination.

\section{Workmanship Not Meeting Welding Code}

Figures 39-44 show examples of poor-quality workmanship, which might include gouges, weld spatter, poor weld profile, lack of penetration of weld, weld undercut, lack of fusion, or poorly cut holes. It is recommended that any gouges should be ground smooth (if perpendicular to primary stresses). If fatigue assessment is to be conducted on weld spatter, then the spatter can conservatively be treated like a shallow thumbnail crack. However, it is recommended that all weld spatters be removed and that all sharp edges be ground to a smooth radius of at least $3 \mathrm{~mm}$ (1/ $8 \mathrm{in}$.), or $6 \mathrm{~mm}$ (1/4 in.) if possible. Any defects at the toe of a poor vertical weld, such as the one shown in Figure 41, can be treated as surface cracks (if perpendicular to primary stresses). If a fatigue assessment results in an unacceptable defect size, then cracks or any deep undercuts at this location should be gouged out and rewelded. If the defect is less than $3 \mathrm{~mm}$ (1/ 8 in.) in depth, then hammer peening is recommended to remove the crack. Larger cracks would require gouging and welding. Lack-ofpenetration defects are not a major concern if they are not perpendicular to primary stresses. However, if they are perpendicular to primary stresses, they should be gouged out and rewelded. 
Holes with gouges or notches that are greater than $0.025 \mathrm{~mm}$ (0.001in.) deep (Fig. 44) should be drilled to a slightly larger diameter to provide a smooth surface at the inside of the hole. Alternatively, the gouges or notches can be removed by grinding the inside of the hole.

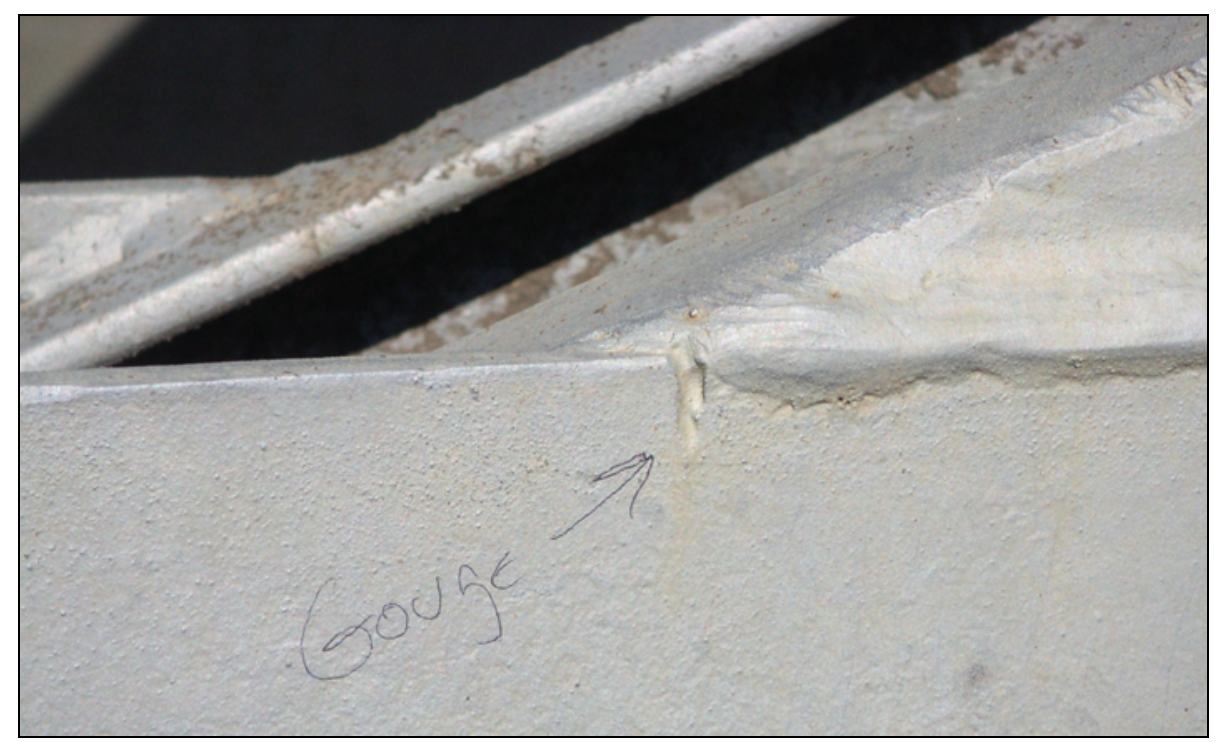

Figure 39. Gouge in a diagonal chord.

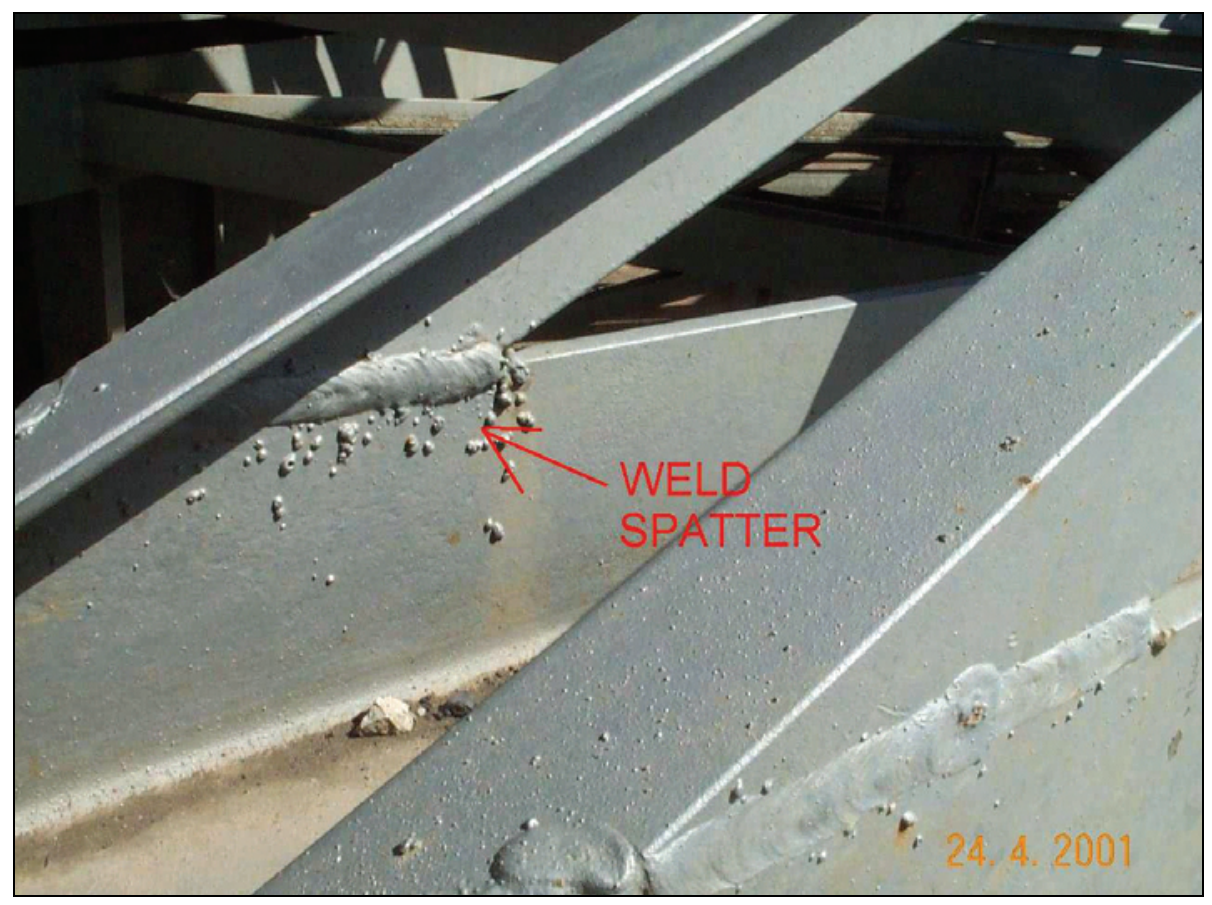

Figure 40. Weld spatter. 


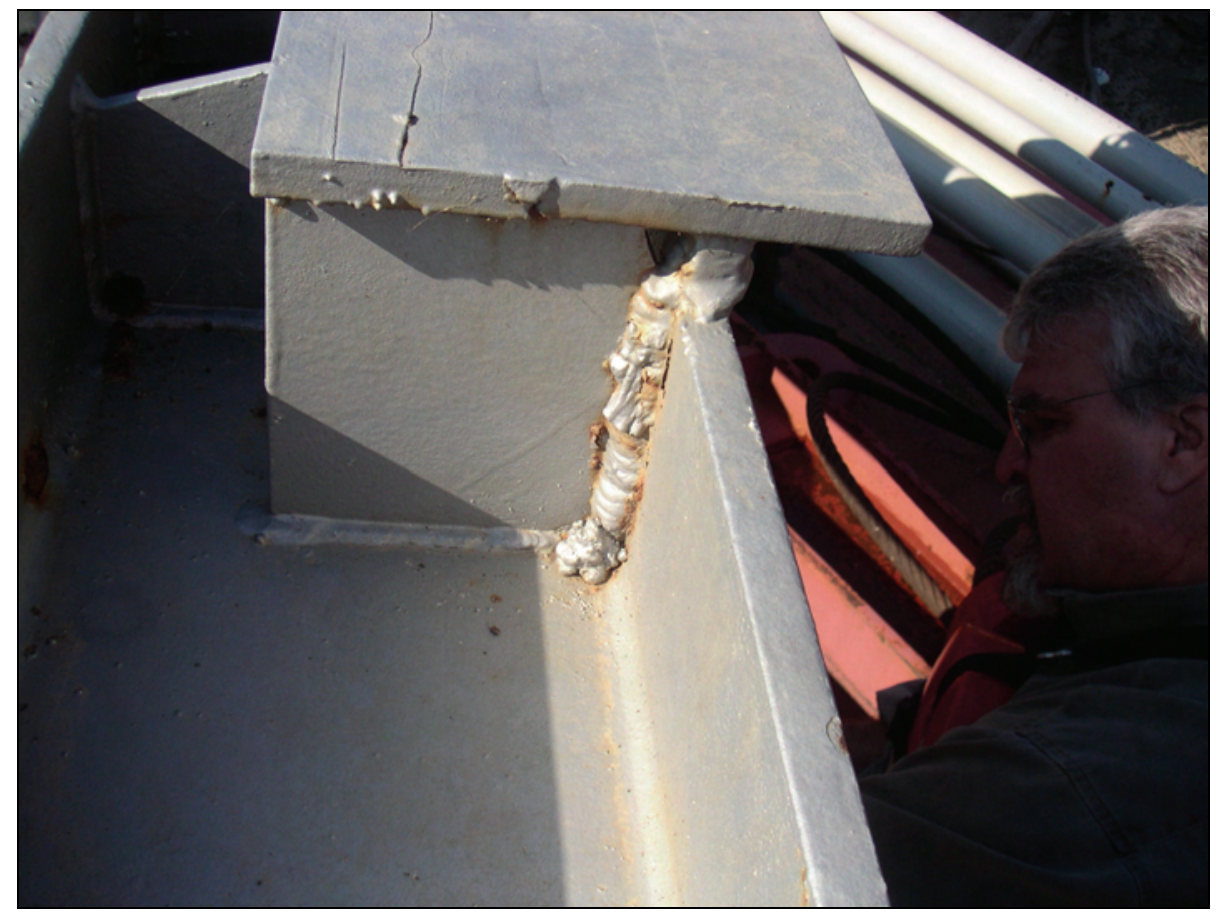

Figure 41. Poor vertical weld at a bearing pad attachment.

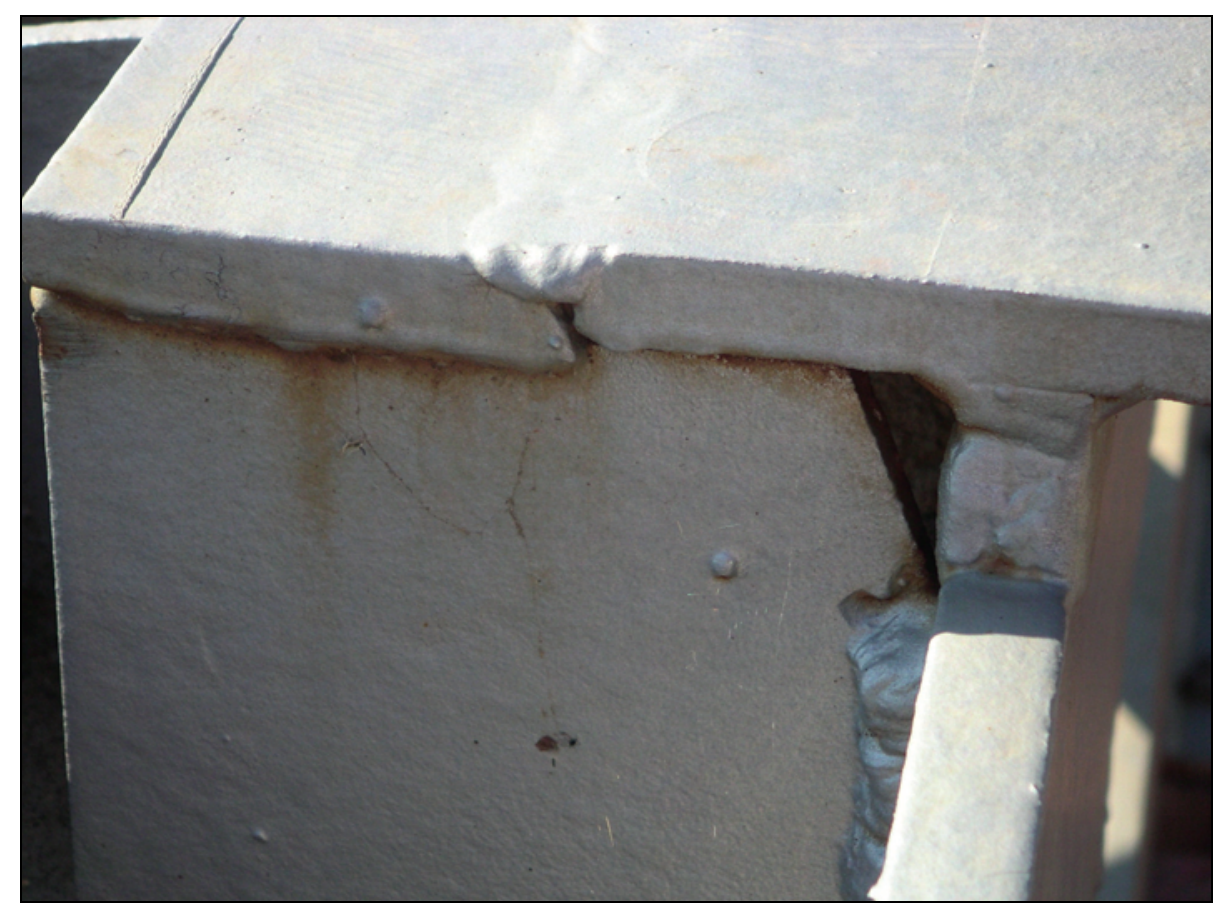

Figure 42. Lack of penetration in a longitudinal weld, which is not a serious concern. 


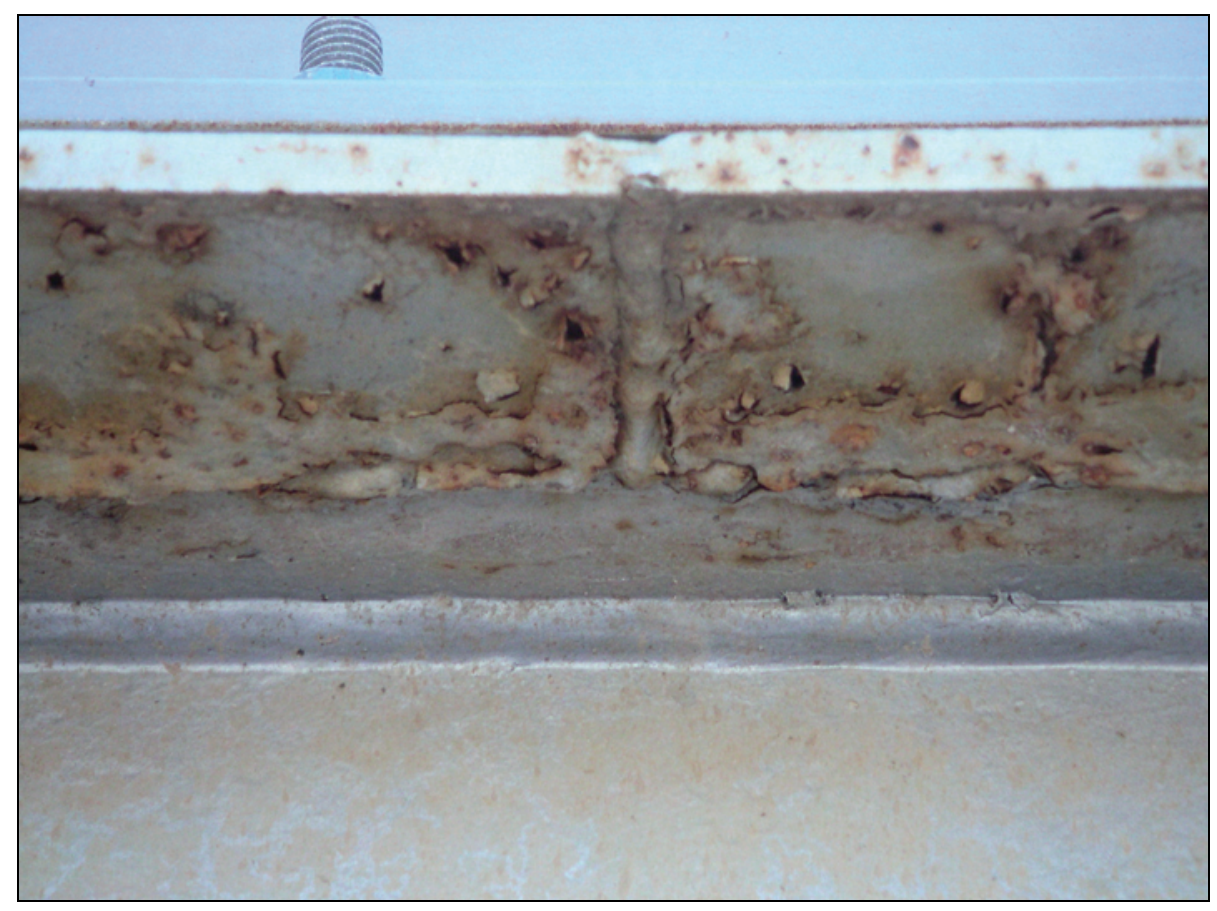

Figure 43. Lack of penetration in a transverse weld, which is a serious concern.

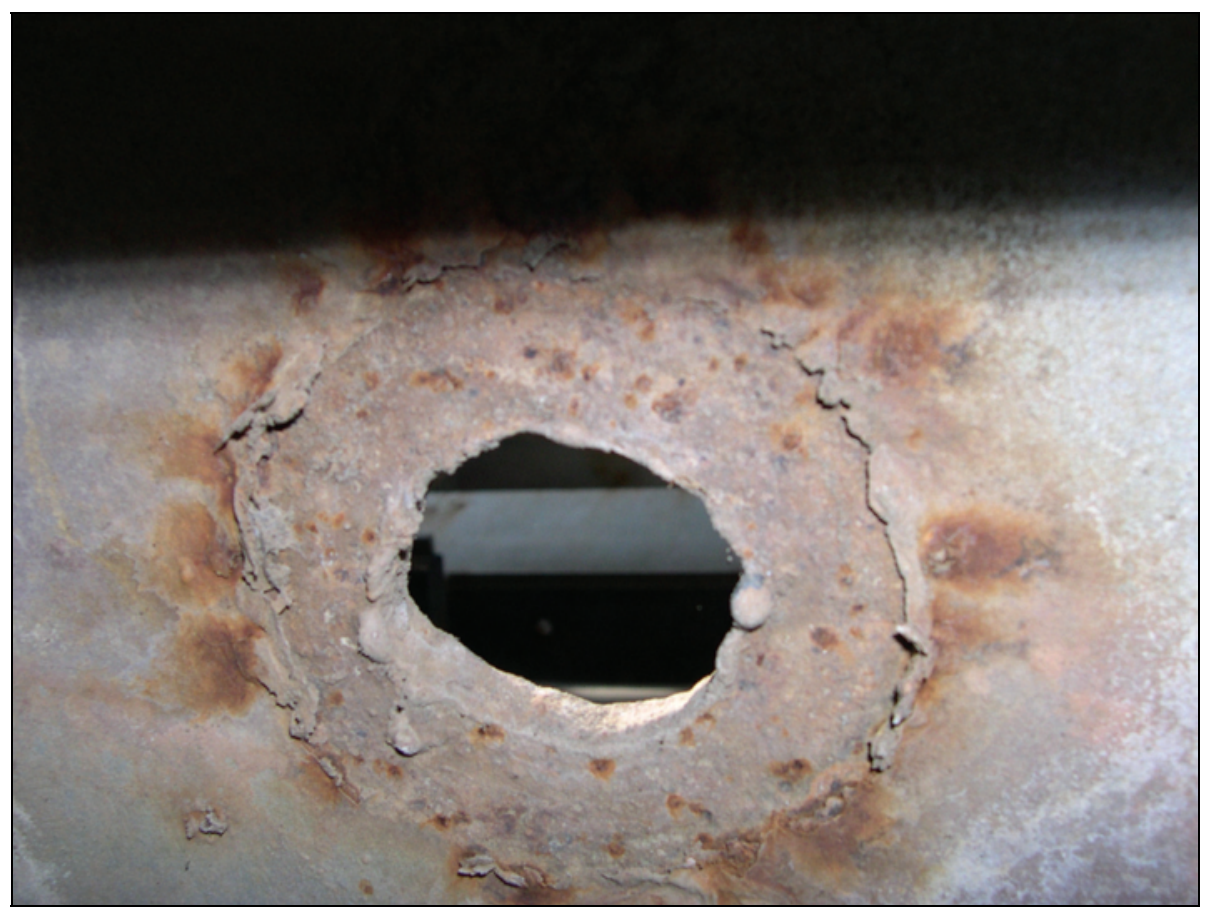

Figure 44. Poorly cut hole, which should be ground. 


\section{Corrosion and Coating Failure}

Figure 45 shows a corrosion crevice parallel to primary stresses. This condition is not serious unless smaller transverse notches branch off from the crevice in the direction perpendicular to primary stresses. On the other hand, great attention should be paid to corrosion crevices if they are oriented such that they are perpendicular to primary stresses, as shown in Figure 46. Evaluations of corrosion crevices should treat them as surface crack or edge cracks, depending on their location in the member.

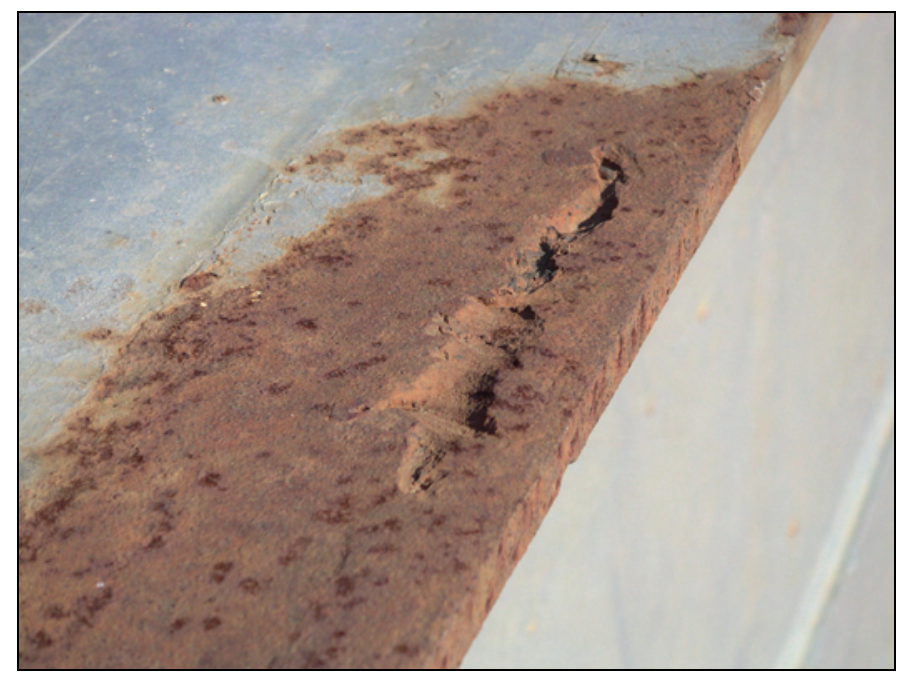

Figure 45. Crevice corrosion in the longitudinal direction in a bearing plate, which is acceptable.

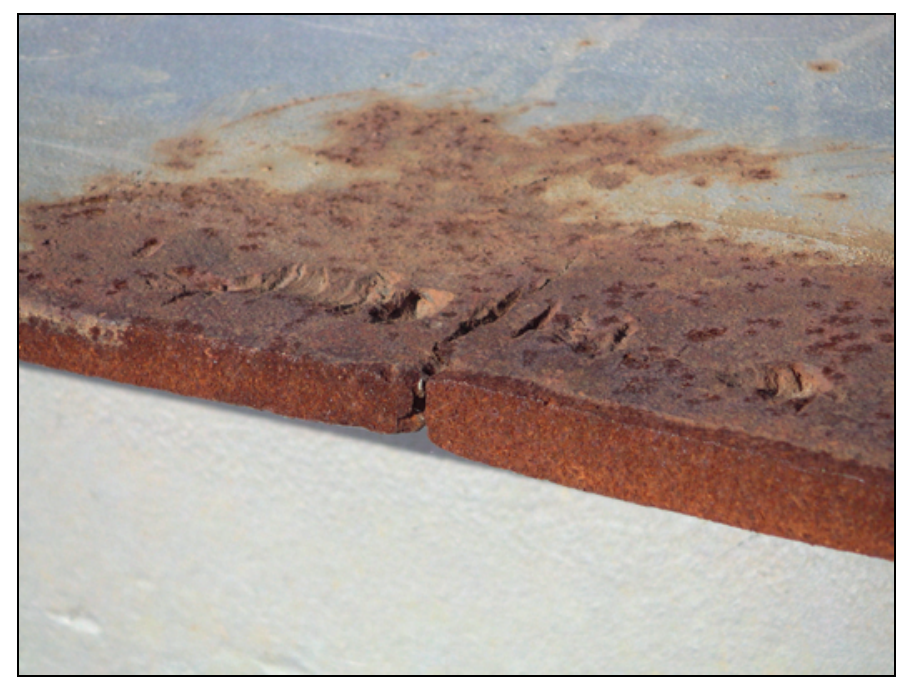

Figure 46. Crevice corrosion in the transverse direction in a bearing plate, which is a serious condition. 


\section{Fracture}

Fracture may be defined as rupture in tension or rapid extension of a crack, leading to gross deformation, loss of function or serviceability, or complete separation of the component (Anderson 1995, Dexter and Fisher 1997, AISC 1999). Since the scope of this guideline is limited to practical information, there are many interesting aspects of fracture that are not discussed. However, there are several good texts that can serve as starting points for more in-depth studies (Anderson 1995, Dexter and Fisher 1997, Barsom and Rolfe 1999).

It is urgent to assess the potential for fracture whenever there is a crack in any tension element (tension member or tension flange of flexural member). However, the occurrence of fatigue cracks does not necessarily mean that the structure is in danger (Fisher 1984, Dexter and Fisher 1997). In fact, in some redundant structures, a fatigue crack may stop propagating with no intervention at all, due to redistribution of stresses (Youngberg et al. 2003). Usually, however, a fatigue crack will propagate and eventually cause a fracture if not repaired in a timely manner (Fisher 1984, Dexter and Fisher 1997, Barsom and Rolfe 1999). Obviously, the development of a fatigue crack in a fracture-critical member should, in most cases, warrant closure of the structure until repairs can be made.

Details that have good fatigue resistance, Category $\mathrm{C}$ and better, are usually also optimized for resistance to fracture. Detailing rules for avoiding fracture are very similar to the common-sense rules for avoiding fatigue. For example, intersecting welds should always be avoided because of the probability of defects and excessive constraint. Intersecting welds, or even welds of too close proximity, have caused brittle fractures (e.g. Hoan Bridge in Wisconsin, SR 422 in Pennsylvania). Weld backing bars must usually be removed to achieve the needed resistance to both fatigue and fracture. Stress concentrations such as re-entrant corners should be avoided, and instead transition radii that are ground smooth and flush should be provided. This commonly occurs at copes in floorbeams at connections designed for vertical shear only.

The ends of butt welds are always a potential location of defects. It is important to use run-out tabs and to later grind the ends of the weld flush or to a radius. Fillet weld terminations should not be ground, as this will expose a very thin ligament near the weld root that will tear easily. 


\section{Fracture Assessment Procedures}

A fracture assessment is made using fracture mechanics principles (Fisher 1984, Anderson 1995, Dexter and Fisher 1997, Barsom and Rolfe 1999, BSI 1999). In the absence of other established procedures, an often-used reference is the British Standard, BS 7910: 1999, Guide on Methods for Assessing the Acceptability of Flaws in Metallic Structures (BSI 1999). There is presently no comparable United States standard, but BS 7910 is widely used by some U.S. industries (primarily the oil and gas industry).

A fracture assessment requires some knowledge of the fracture toughness of the steel and/ or weld metal, which may be estimated from the Charpy energy, or CVN (Barsom and Rolfe 1999, Dexter et al. 2004). Unlike fatigue, the susceptibility to fracture is strongly dependent on the type of material and even the particular heat of steel or lot of weld metal (Anderson 1995, Barsom and Rolfe 1999, Dexter 2004, Dexter et al. 2004). The CVN may be obtained from the mill reports for the steel and from the certifications for the weld metal, if good records exist. If lacking such specific information, the CVN for the steel plate and weld metal may be assumed to be at least as large as the minimum specified values, which can be found in the ASTM A709 specification for bridge steels. For older structures, or for cases when the assumed minimum values are not sufficient, it may be necessary to drill a core and get a sample of the steel, then make and test some Charpy specimens. A minimum of three specimens should be tested from each plate or structural shape.

\section{Causes for Fracture Other than Fatigue}

As mentioned previously, fracture in bridges is typically almost always a result of fatigue cracking. However, if a detail and material are particularly susceptible to fracture, failure will usually occur as the loads are applied for the first time during or soon after construction. An example is the fracture that occurred when the Caltrans Workers Memorial Bridge (previously known as the Bryte Bend Bridge) was under construction in 1970. The fracture, shown in Figure 47, was attributed to use of lowtoughness A514 steel (ENR 1970) at a point where transverse bracing member was welded along the edge of the primary tension flange of a tub girder, creating a stress concentration at the reentrant corner. A514 steel, marketed under the name of T1 steel, is quenched and tempered with a minimum specified yield stress (MSYS) of 690 MPa (100 Ksi). 


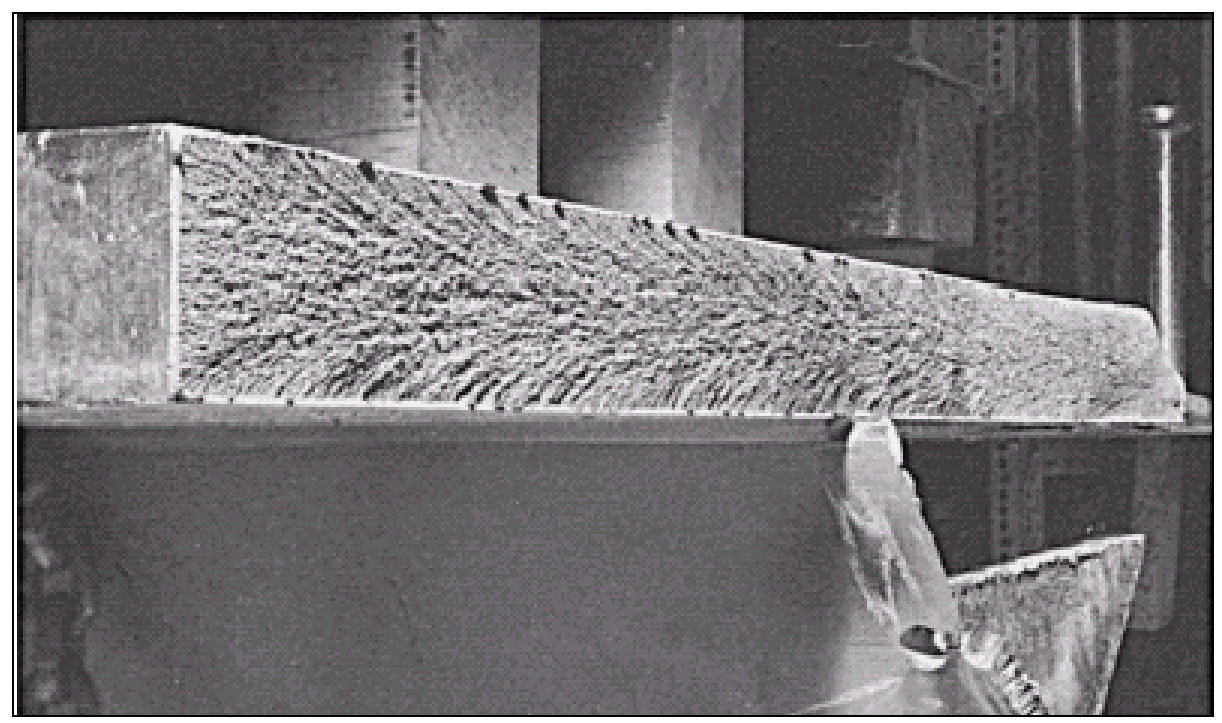

Figure 47. Brittle fracture of flange of tub girder of Bryte Bend Bridge while under construction.

It is also possible that fracture can occur in service directly without apparent fatigue crack growth. For example, at poor details that are highly constrained, such as the intersection point of two or three welds, fracture may occur in service directly from small crack-like weld discontinuities, such as the fractures that originated at shelf plate details in the Hoan Bridge in Milwaukee in December 2000 (Wright et al. 2001) (Fig. 48) or the SR 422 failure (Connor et al. 2004). Highly constrained details are of concern if the detail in question is under tensile stresses. If in doubt, a detailed non-linear finite element analysis should be conducted (Mahmoud et al. 2005) to investigate the state of stress and to determine the triaxiality demand as shown in equations (2) and (3).

$$
\begin{gathered}
T_{2}=\frac{\sigma_{1}}{\sigma_{\text {eff }}}=\frac{\sigma_{\text {max }}}{\sigma_{\text {eff }}} \\
\sigma_{\text {eff }}=\sqrt{\frac{1}{2}} \sqrt{\left(\sigma_{1}-\sigma_{2}\right)^{2}+\left(\sigma_{2}-\sigma_{3}\right)^{2}+\left(\sigma_{1}-\sigma_{3}\right)^{2}}
\end{gathered}
$$

where $\sigma_{\text {eff }}$ is effective stress and $T_{2}$ is the triaxiality factor.

Repair and retrofit of these shelf-plate details are discussed in special directives from FHWA and are not discussed further in this report. 

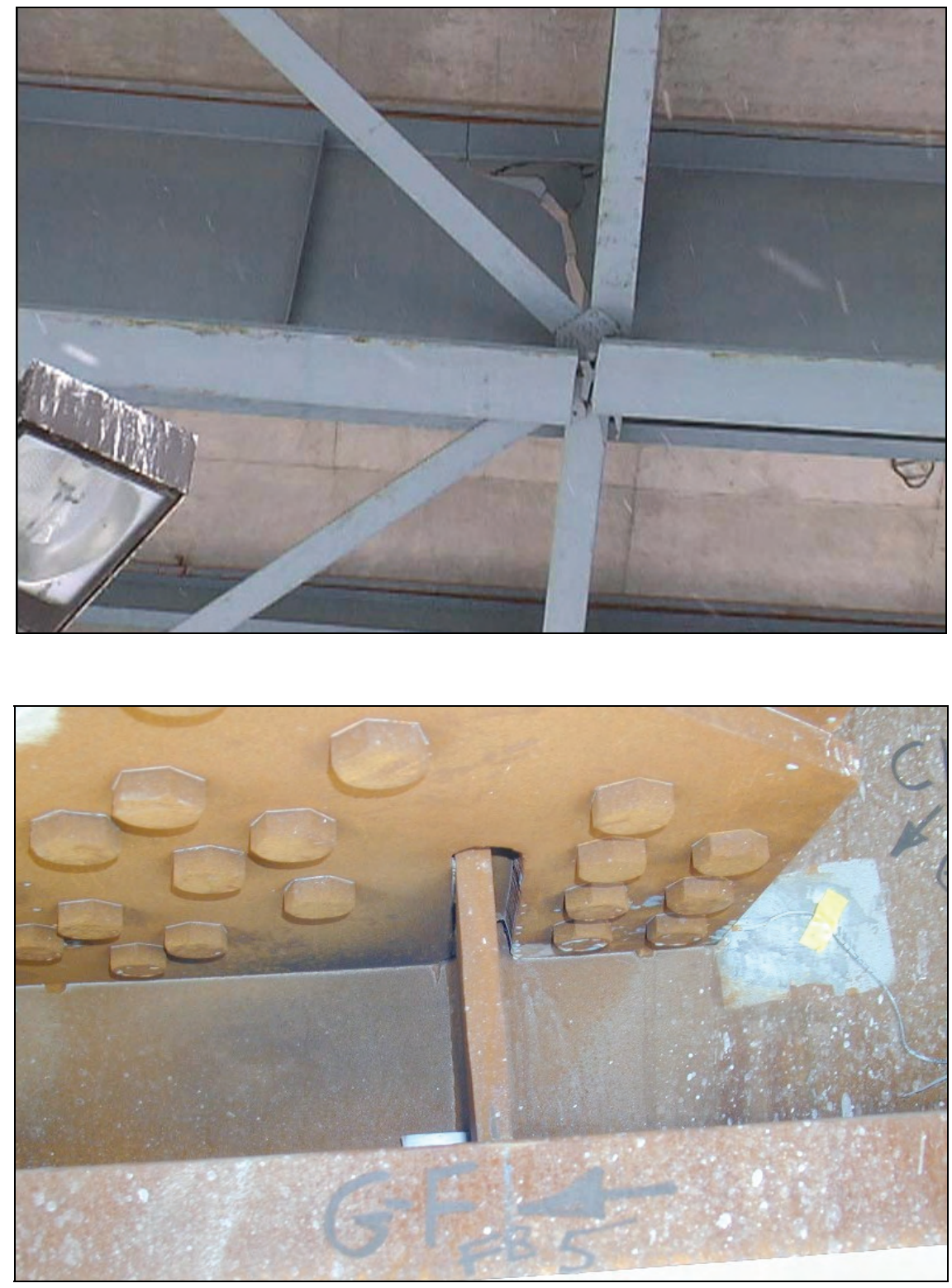

Figure 48. Fractured girder of the Hoan Bridge in Milwaukee and a critical shelf plate detail featuring intersecting welds.

Sub-critical crack propagation in bridge elements may also occur by stress corrosion cracking, although this is a concern only for very high-strength steels, i.e. steels with yield strengths much greater than $100 \mathrm{ksi}$. Stress corrosion cracking involves electrochemical dissolution of metal along active sites under the influence of tensile stress (Anderson 1995, Barsom and Rolfe 1999). As hydrogen is liberated in the process, this failure mechanism may also involve hydrogen cracking. Stress corrosion cracking can be distinguished from fatigue cracking by examining the fracture 
surface under a light microscope. Stress corrosion cracking has occurred in prestressing cables (Vehovar 1998) and in A490 bolts that were out of specification (Kulak et al. 1987).

\section{Specification of CVN for Fracture Resistance}

Fracture behavior depends strongly on the type and strength level of the steel or filler metal. In fact, the fracture resistance of each type of steel or weld metal varies significantly from heat to heat and from lot to lot. Although fracture toughness can be measured directly in fracture mechanics tests (Paris and Erdogan 1963, Anderson 1995, Barsom and Rolfe 1999), the usual practice is to characterize the toughness of steel in terms of the impact energy absorbed by a Charpy V-notch (CVN) specimen (Barsom and Rolfe 1999). Because the Charpy test is relatively easy to perform, it will likely continue to be the measure of toughness used in steel specifications.

Since it is not directly related to the fracture toughness, CVN energy is often referred to as notch toughness. The notch toughness is still very useful, however, since it can often be correlated to the fracture toughness and then used in a fracture mechanics assessment (Dexter and Fisher 1997, Barsom and Rolfe 1999, BSI 1999). Figure 49 shows a plot of the CVN energy of A588 Grade 50 [350 MPa (50 Ksi) yield strength] structural steel at varying temperatures. These results are typical for ordinary hotrolled structural steel.

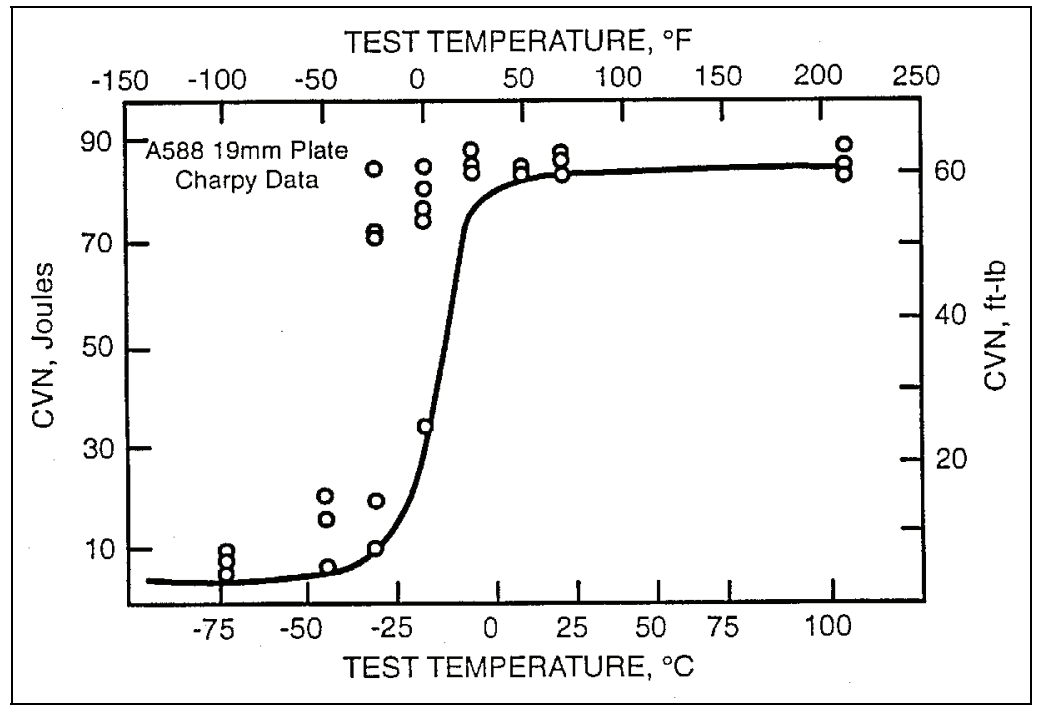

Figure 49. Charpy energy transition curve for A709 Grade 50 structural steel. 
The fracture limit state includes phenomena ranging from brittle fracture of low-toughness materials at service load levels to ductile tensile rupture of a component. The transition between these phenomena depends on temperature, as reflected by the variation of $\mathrm{CVN}$ with temperature as shown in Figure 49. The transition is a result of changes in the underlying micro-structural fracture mode.

Brittle fracture on the so-called lower shelf in Figure 49 is associated with cleavage of individual grains on select crystallographic planes. Brittle fracture may be analyzed with linear-elastic fracture mechanics theory because the plastic zone at the crack tip is very small. At the high end of the temperature range, the so-called upper shelf, ductile fracture is associated with the initiation, growth, and coalescence of micro-structural voids, a process requiring much energy. The net section of plates or shapes fully yields and then ruptures with large slanted shear lips on the fracture surface.

Transition-range fracture occurs at temperatures between the lower and upper shelves and is associated with a mixture of cleavage and shear fracture. Large variability in toughness at constant temperature and large changes with temperature are typical of transition-range fractures.

AASHTO specifications for bridge steel and weld filler metal require minimum CVN values at specific temperatures. As shown in Figure 49, the typical lower-shelf CVN is about $10 \mathrm{~J}$. Therefore, when a minimum CVN of $20 \mathrm{~J}$ or more is specified at some temperature, the most important result is that the lower shelf of the Charpy curve will start at a temperature lower than the specified temperature. In fact, this indicates that the lower shelf of a structure loaded statically or at intermediate strain rates such as traffic loading on a bridge is even lower, a phenomenon known as the temperature shift (Barsom and Rolfe 1999). Because of the temperature shift, the temperature at which the $\mathrm{CVN}$ requirement is specified may be greater than the lowest anticipated service temperature.

As long as the material is not on the lower shelf at service temperature, brittle fracture will not occur as long as large cracks do not develop. It almost does not matter what the specified CVN value is as long as it is at least $20 \mathrm{~J}$

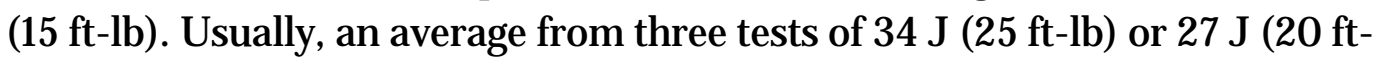
$\mathrm{lb})$ is specified at a particular temperature. The greater the value of the 
average CVN requirement, the more certain that the material is well above the lower shelf, but there may be a greater premium to be paid with diminishing increases in certainty.

Table 1 lists, as an example, values of impact energy presently required for base metal in fracture-critical members for the three temperature zones into which the U.S. is divided. (Non-fracture-critical members typically require only $20 \mathrm{~J}$ at the same temperatures). The complete table is found in the LRFD specifications. For example, 50-mm- (2.0-in.-) thick flange plates of grade $345 \mathrm{~W}$ steel for a fracture-critical bridge to be built at a site where the lowest anticipated service temperature (LAST) is $-15^{\circ} \mathrm{C}$ must have the minimum impact energy for zone 1 , which is $34 \mathrm{~J}$ at $21^{\circ} \mathrm{C}$.

Table 1. Minimum Charpy impact test requirements for fracture-critical members.

\begin{tabular}{|c|c|c|c|c|c|}
\hline $\begin{array}{l}\text { ASTM A709 } \\
\text { Steel Grade }\end{array}$ & $\begin{array}{l}\text { Plate Thickness } \\
(\mathrm{mm})\end{array}$ & $\begin{array}{l}\text { Joining } \\
\text { Method* }\end{array}$ & $\begin{array}{c}\text { Zone } 1 \\
\text { LAST }=-18^{\circ} \mathrm{C} \\
\left(\mathrm{J} @{ }^{\circ} \mathrm{C}\right)\end{array}$ & $\begin{array}{c}\text { Zone } 2 \\
\text { LAST = -34 }{ }^{\circ} \mathrm{C} \\
\left(\mathrm{J} @{ }^{\circ} \mathrm{C}\right)\end{array}$ & $\begin{array}{c}\text { Zone } 3 \\
\text { LAST }=-51^{\circ} \mathrm{C} \\
\left(\mathrm{J} @{ }^{\circ} \mathrm{C}\right)\end{array}$ \\
\hline $250 F$ & Up to 100 & $M \& W$ & $34 @ 21$ & $34 @ 4$ & $34 @-12$ \\
\hline \multirow{3}{*}{$\begin{array}{l}345 F \\
345 W F\end{array}$} & Up to 50 & $M \& W$ & $34 @ 21$ & $34 @ 4$ & $34 @-12$ \\
\hline & Over 50 to 100 & $M$ & $34 @ 21$ & $34 @ 4$ & $34 @-12$ \\
\hline & Over 50 to 100 & W & $41 @ 21$ & $41 @ 4$ & $41 @-12$ \\
\hline HPS-485WF & Up to 100 & $M \& W$ & $48 @-23$ & $48 @-23$ & $48 @-23$ \\
\hline \multirow{3}{*}{$\begin{array}{l}\text { 690F, } \\
690 W F\end{array}$} & Up to 65 & $M \& W$ & $48 @-1$ & $48 @-18$ & $48 @-34$ \\
\hline & Over 65 to 100 & $M$ & $48 @-1$ & $48 @-18$ & $48 @-34$ \\
\hline & Over 65 to 100 & W & $68 @-1$ & $68 @-18$ & Not permitted \\
\hline
\end{tabular}

* $\mathrm{M}=$ Mechanically Fastened, $\mathrm{W}=$ Welded

Metallurgical Factors Affecting the Toughness of Structural Steel and Weld Metal

The transition phenomenon shown in Figure 49 is a result of changes in the underlying microstructural fracture mode. There are at least three types of fracture with distinctly different behaviors.

- Brittle fracture is associated with cleavage, which is transgranular fracture on select crystallographic planes on a microscopic scale. This type of fracture occurs at the lower end of the temperature range, although the brittle behavior can persist up to the boiling point of water in some low-toughness materials. This part of the temperature range is called the lower shelf because the minimum toughness is 
nearly constant up to the transition temperature. Brittle fracture is sometimes called elastic fracture because the plasticity that occurs is negligible, so the energy absorbed in the fracture process is also negligible.

- Transition-range fracture occurs at temperatures between the lower shelf and the upper shelf and is associated with a mixture of cleavage and fibrous fracture on a microstructural scale. Because of the mixture of micromechanisms, transition-range fracture is characterized by extremely large variability. Fracture in the transition region is sometimes referred to as elastic-plastic fracture because the plasticity is limited in extent but has a significant impact on the toughness.

- Ductile fracture is associated with a process of void initiation, growth, and coalescence on a microstructural scale, a process requiring substantial energy. It occurs at the higher end of the temperature range, which is referred to as the upper shelf because the toughness levels off and is nearly constant for higher temperatures. Ductile fracture is sometimes called fully plastic fracture because there is substantial plasticity across most of the remaining cross section ahead of a crack. Ductile fracture is also called fibrous fracture because of the fibrous appearance of the fracture surface, or shear fracture because of the usually large slanted shear lips on the fracture surface.

Unfortunately, these terms are often used ambiguously. For example, fracture in the transition region is often called brittle or ductile, depending on the relative toughness. Some materials go through a transition but still exhibit relatively low toughness on the upper shelf, despite a lack of cleavage and a fibrous fracture appearance. One example of such a lowupper-shelf material is the weld metal used for some girth welds in nuclear pressure vessels that has been embrittled by irradiation. A fracture in such a material at upper-shelf temperatures appears to be a fibrous fracture but may be referred to as brittle because of the lack of ductility.

Smooth specimens of structural steel or an associated filler metal will typically always fail in a totally ductile, fully plastic manner, even at low temperatures. For brittle or transition-range fractures to occur, the principal stress must exceed a critical cleavage stress, which is not related to and is much higher than the ultimate strength measured in a smooth tensile test. Therefore, brittle or transition-range fractures typically only occur when the stress is raised locally by the presence of a notch or crack. 
In general, fracture toughness has been found to decrease with increasing yield strength of a material, suggesting an inverse relationship between the two properties. In practice, however, fracture toughness is more complex than implied by this simple relationship, since steels with similar strength levels can have widely varying levels of fracture toughness. That similar materials with the same strength level can also possess widely different fracture properties indicates that the metallurgical condition of the material has a significant influence on its fracture toughness.

The metallurgical condition of steel is controlled through its composition and processing, the combination of which can develop different strength and toughness characteristics. Composition influences fracture toughness through the development of microstructural constituents and their relative proportions. Most alloy elements are added to steels to increase strength and consequently are detrimental to fracture toughness. Of the usual alloy elements added to structural steels (carbon, manganese, molybdenum, vanadium, and niobium), carbon has the most deleterious influence on toughness. Recognition of this has led to the development of microalloyed steel compositions such as ASTM A572 that employ only small amounts of alloying elements. Newer microalloyed structural steels have since been developed with reduced carbon ( $<0.15 \mathrm{wt} \%)$ and alloy contents, often combined with thermo-mechanical controlled processing, to produce a fine-grained, low-carbon microstructure with high fracture toughness. ASTM A913 shapes produced by the quenching and self tempering process is an example of these new steels.

Nickel is unique as an alloy element in that it increases both strength and toughness and is frequently added to steel and weld metal (1.0- $2.0 \mathrm{wt} \%)$ for this purpose. (Nickel alloying is only one method for improving toughness.) Unintentional or residual alloy elements in steel, such as sulfur, phosphorus, and nitrogen, can have a deleterious effect on fracture toughness. However, improved steel-making practices in use today have reduced these elements to where they have only small effects on toughness. Sulfur in steel exists in the form of sulfide inclusions, which tend to reduce energy absorption in CVN tests but have less influence on the ductile-brittle transition temperature of steel. Lamellar tearing, at one time a major problem in welded fabrication, caused primarily by poor through-thickness properties in plate steels with high sulfide inclusion 
content, has also been reduced by controlling sulfur levels to less than 0.01 ut. \% in steel.

Grain size is another factor that has a significant effect on fracture toughness. Grain refinement is unique in metallurgical processing in that it increases fracture toughness and strength simultaneously. A simple explanation for this behavior is that the larger concentration of grain boundaries in fine-grained steel provides both an impediment for plastic flow (and hence increased strength) and obstacles for microcracks to negotiate, requiring increased expenditure of fracture energy. In general, finer microstructural constituents such as bainite and tempered martensite produce greater fracture resistance than coarser constituents such as ferrite and pearlite. This is why quenched and tempered steels generally have superior toughness to as-rolled or normalized steels. Cooling rates largely determine the grain size of steels as well as the type of microconstituents developed. Thicker sections tend to have coarser grain sizes, coarser microconstituents, and lower toughnesses than thinner sections. The large-grain-size ferrite-pearlite microstructure existing at the core region of as-rolled jumbo shapes is the primary reason for the low fracture toughness measured in this area. Segregation of alloy elements to the core region resulting in alloy enrichment also contributes to low toughness.

Microalloyed steels contain elements added specifically to control ferrite grain size, e.g. niobium (Columbium) and vanadium. Aluminum, added as a deoxidizer, also limits ferrite grain size and serves as a denitrifier as well.

The effect of composition and microstructure on weld metal toughness follows much the same trends as wrought steel. Toughness is still dictated by the development of desirable fine microconstituents and fine grain size. In general, weld metal toughness is usually as good as or superior to plate or shape toughness, largely because of the lower carbon and inherent fine grain structure and finer microconstituents that result from the high cooling rates associated with most welding processes. Only in slowcooling, high-heat-input weld processes does the resulting grain size have a detrimental effect on the weld fracture toughness. The low toughness of electroslag welds can be attributed to the coarse grain size and coarse microconstituents developed during the slow cooling of welds deposited with this very-high-heat-input process. 
More often, weld toughness is influenced by the incorporation of undesirable elements such as oxygen and nitrogen in the weld pool, which reduces toughness. Controlling these elements is the role of the shielding gas and/ or flux used in the weld process. Fluxes contain deoxidizers such as silicon and aluminum for this purpose.

The region with lowest fracture toughness in weldments is usually the base metal adjacent to the weld nugget that has been heated to high temperature but below the melting point of the base metal. This region, called the heat-affected zone (HAZ), is composed of several subregions with structures and properties reflecting the highest temperature reached in that area during welding. Like weld metal, the microconstituents developed in the HAZ are influenced by the cooling rate of the weld and consequently are affected by welding procedure (i.e. heat input, preheat). The subregion nearest the weld fusion line, called the coarse-grained HAZ (CGHAZ), is heated to temperatures where rapid grain growth can occur and, in the case of some steels, hard martensite microstructures can develop. These are often termed local brittle zones (LBZs) in low carbon steels. The next subregion beyond the CGHAZ is called the fine-grained HAZ (FGHAZ) and, as the term suggests, is a region heated to a lower temperature where lessened grain growth can occur. For most wrought steels the resulting grains are smaller than the unaffected base metal grain size and constitute a grain-refined region with superior strength and toughness compared to the base metal. In most weldments, the CGHAZ region will have a lower fracture toughness than found in the unaffected base metal and a lower toughness than found in most weld metals because of the coarse grain size and the hard and brittle phases developed in this region. This is not the case, however, in all weldments. In weldments where the weld metal has a low fracture toughness, such as produced with E70T-4 electrodes, the CGHAZ may have equal or superior toughness compared to the weld metal and will not be the region of the weldment most susceptible to fracture.

\section{Linear Elastic Fracture Mechanics}

Linear elastic fracture mechanics (LEFM) can be used where there is relatively little plastic deformation around the crack tip. It is applicable to high-cycle fatigue crack growth, which typically occurs when applied stresses are well below the yield stress of the steel. LEFM is also usually 
applicable to brittle fracture, which often occurs at applied stress levels less than the yield stress.

The principle of LEFM is dictated by the stress-intensity factor $K$, which describes the magnitude of the stress field at the crack tip by relating it to the applied gross-section stress acting remotely from the crack plane and the crack length. The stress-intensity factor has units of MPa-m $\mathrm{m}^{1 / 2}$ in SI units and ksi-in ${ }^{1 / 2}$ in English units, although solutions have been obtained for $K$ for various geometrical configurations and loadings, many of which can be found in handbooks. $K$ can also be found from finite-element analysis or other numerical methods.

The solution for the stress-intensity factor for a through-thickness crack in an infinite panel with an applied tensile stress is discussed here, for example. The general solution for $K$ was derived for a through-thickness crack in an infinite plate and is described by equation (3):

$$
K=\sigma \times \sqrt{\pi \times a}
$$

where $\sigma$ is the applied tensile stress and $a$ is the crack half-length.

\section{Relating Charpy Test to Fracture Toughness}

The critical stress intensity factor, $K_{\mathrm{C}}$, is a structural element's capacity to resist fracture and has the same units as the stress intensity factor, $K$. It is often estimated from correlations with the result from a CVN test, because the CVN is much cheaper to perform and requires less material than a fracture mechanics test, and all test laboratories are equipped for the CVN test. A widely accepted correlation for the lower shelf and lower transition region between $K_{\mathrm{C}}$ and CVN is described by equation (4):

$$
\begin{aligned}
& K_{c}=11.5 \times \sqrt{C V N} \\
& K_{c}=15.5 \times \sqrt{C V N}
\end{aligned}
$$

where for Equation $4 \mathrm{a} C V N$ is given in $\mathrm{J}$ and $K_{\mathrm{c}}$ is given in $\mathrm{MPa}-\mathrm{m}^{1 / 2}$, while for Equation $4 \mathrm{~b} C V N$ is given in $\mathrm{ft}-\mathrm{lb}$ and $K_{\mathrm{c}}$ is given in ksi-in. ${ }^{1 / 2}$. 
Figure 50 shows some $K_{\mathrm{c}}$ data for a variety of brittle materials that have caused fractures of steel structures in the past (Dexter and Fisher 1997). Data from the web/ flange core region of a W14x605 "jumbo" wide flange column section are shown. This material in the core region of jumbo sections made in the past had unusually low toughness and caused several fractures in the early 1970s when these shapes were used as tension chords in trusses. The lower-bound CVN energy for the core region ranges from 4 to $14 \mathrm{~J}$ ( 3 to $10 \mathrm{ft}-\mathrm{lb}$ ). Using the correlation of equation (4), the scatterband for the predicted $K_{\mathrm{c}}$ therefore ranges from 23 to $43 \mathrm{MPa}-\mathrm{m}^{1 / 2}$ (21 to 39 $\left.\mathrm{Ksi}^{-} \mathrm{in}^{1 / 2}\right)$.The scatterband for $K_{\mathrm{C}}$ based on the Charpy data is shown in Figure 50 with some measured $K_{\mathrm{c}}$ data from fracture mechanics tests. These data show that the correlation of equation (4) is conservative, since the actual $K_{\mathrm{c}}$ ranges between 45 and $50 \mathrm{MPa}-\mathrm{m}^{1 / 2}$ (41 and $45.5 \mathrm{Ksi}$-in. ${ }^{1 / 2}$ ).

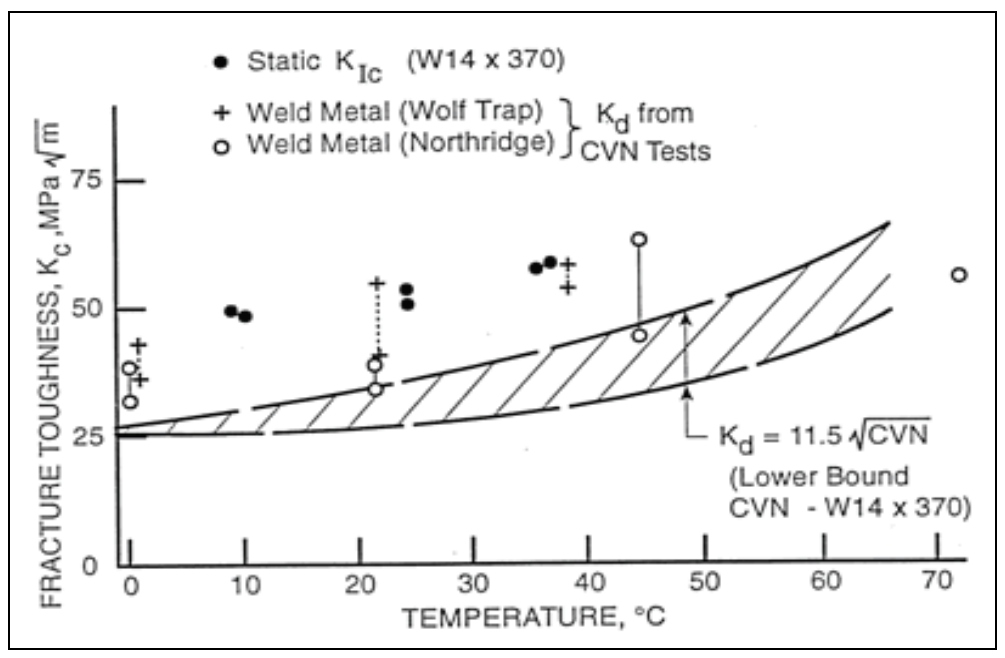

Figure 50. Fracture toughness data for a number of brittle materials that have caused fractures in the past, suggesting a lower-bound fracture toughness of about $50 \mathrm{MPa}^{1 / 2}$ (45.5 Ksi-in. $\left.{ }^{1 / 2}\right)$ for the most brittle structural steel and weld metal.

Also shown in Figure 50 are some $K_{\mathrm{c}}$ data calculated using equation (4) from the CVN data measured for several brittle welds that have caused fractures in the past (Dexter and Fisher 1997). One example is the brittle, self-shielded, flux-cored arc welds that were used in moment frame connections prior to the Northridge earthquake in 1994. Another example is the brittle welds that caused a fracture of a steel box section supporting a roof at the Wolf Trap outdoor performing arts center in Virginia in J anuary 1986. It happens that the values of CVN and $K_{\mathrm{c}}$ for these brittle welds also fall within the scatterband for "lower-shelf" brittle-fracture- 
prone materials. The lower bounds of the $\mathrm{CVN}$ and $K_{\mathrm{C}}$ data are not sensitive to temperature or strain rate because these materials do not undergo a transition at temperatures of interest. This similarity in the data suggests that there may be a "lower-bound" value of the fracture toughness that can be assumed for brittle ferritic weld metal, structural steel, and the heat-affected zone (HAZ). The lower-bound fracture toughness reflects the worst effects of temperature and strain rate. For these conditions and materials, the lower-bound fracture toughness was about $50 \mathrm{MPa}-\mathrm{m}^{1 / 2}$ $\left(45.5\right.$ Ksi-in. $\left.^{1 / 2}\right)$.

\section{Plastic Collapse}

Failure of structural components is defined by either the fracture of a component or by plastic collapse, whichever occurs first. Full plastic collapse cannot occur until sufficient plastic hinges have formed or a yield path to the free boundaries for a mechanism have developed (Burdekin 2002). Fracture assessment methods are typically based on critical fracture parameters, such as the stress intensity factor $K, J$-integral, or crack tip opening displacement (CTOD) value. Relatively thin steel plates typically fail by ductile tearing at service temperatures. In this case, the critical condition for maximum crack size is based on net section plastic collapse rather than critical values of $K, J$, or CTOD. 


\section{Fracture Assessment}

\section{General Assessment Procedures}

Procedures for assessing the significance of defects in welded connections has been established in may countries such as BS 7910 and R6 in the United Kingdom, SINTAP in Europe, and API 579 and MPC in the U.S. Fitness-forpurpose analyses are used in these codes for a variety of critical welded steel structures, including pipelines, offshore structures, and ships to assess their vulnerability to fracture. Of the most use in the codes listed above is the widely accepted British Standard, BS 7910: 1999, Guide on Methods for Assessing the Acceptability of Flaws in Metallic Structures (BSI 1999). BS 7910 is widely used by some U.S. industries and is based on accepted fracture mechanics principles used in several other U.S. codes and standards.

The fracture assessment for Mode I loading used in the fitness-for-purpose evaluation is described below. The assessment method is the same as is documented in BS 7910. The intent here is to list the assessment method in a simplified way. A complete description of the assessment method could be found in BSI (1999).

BS 7910 offers three levels of fracture assessment. Level 1 uses a simplified assessment method. The simplification of the analysis arises from the conservative assumptions that could be made with regard to material properties and/ or applied stresses. Level 2 is a normal assessment route, typically used in general applications. The method is geared towards preventing plastic collapse of the structure under evaluation. Level 3 is usually used for ductile materials that exhibit stable tearing. It allows a tearing resistance analysis to be performed. Because of the complexity associated with the application of Level 3 assessment, only Levels 1 and 2 will be discussed below. If the assessment with a particular level shows that a flaw size is unacceptable, then the analysis could be improved by conducting the analysis at a higher level. If the assessment of a flaw was conducted using Level 3 and the flaw size was unacceptable, then finite element analysis could be used as a more accurate assessment. However, there is no safety factor inherent in the finite element analysis, and if such route is chosen, then a risk analysis should be conducted. 
The calculations in BS 7910 are based on linear elastic fracture mechanics (LEFM). The calculations involve the stress intensity factor $(K)$, which characterizes the stress field at notches or cracks. Crack-like notches and weld defects are idealized as cracks, and the term "crack" will be used to include crack-like notches and weld defects. The applied $K$ is determined by the size of the crack and the nominal gross-section stress remote from the crack. Solutions for $K$ for a variety of geometries can be found in BS 7910 (Annex M). In general, the applied stress intensity factor is given as:

$$
K=F_{\mathrm{C}} \times F_{\mathrm{S}} \times F_{\mathrm{w}} \times F_{\mathrm{g}} \times \sigma \sqrt{\pi a}
$$

where:

$$
\begin{aligned}
F_{\mathrm{C}}= & \text { factor for the effect of crack shape } \\
F_{\mathrm{S}}= & \text { factor, equal to 1.12, that is used if a crack originates at a free } \\
& \text { surface } \\
F_{\mathrm{W}}= & \text { correction for finite width, which is necessary because the } \\
& \text { basic solutions were generally derived for infinite or semi- } \\
& \text { infinite bodies } \\
F_{\mathrm{g}}= & \text { factor for the effect of non-uniform stresses, such as a stress } \\
& \text { concentration or bending stress gradient. }
\end{aligned}
$$

\section{Modes of Loading}

Fracture mechanics problems can be described in terms of three modes of loading, mode I, II, and III as illustrated in Figure 51. Mode I, also known as the opening mode, is the most common in civil structures and is associated with crack faces moving apart when the load is acting perpendicular to the crack plane. Mode II is called the sliding mode (inplane shear). Mode III is called the tearing mode.

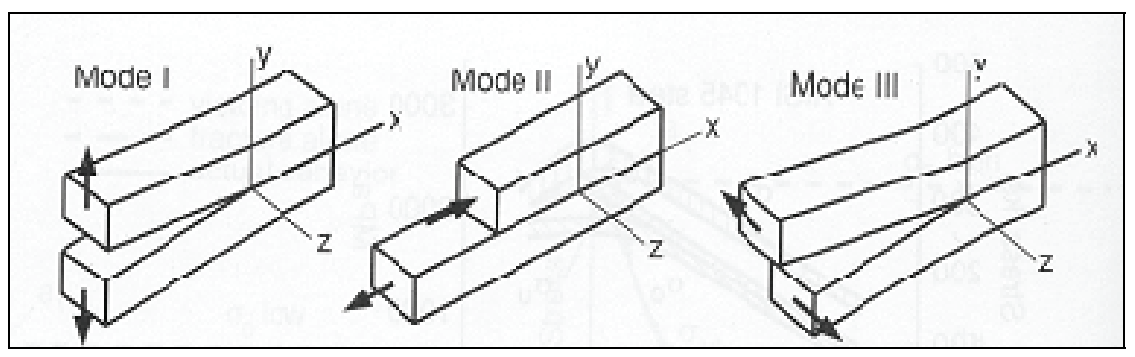

Figure 51. The three modes of loading. 
Crack propagation in the majority of civil structures is usually under Mode I loading. However, extension of cracks under Mode II or Mode III is not uncommon and is likely to happen when the structure is subjected to nonsymmetrical loading. In Hydraulic water structures, the non symmetrical loading could for example result from uneven settlement of the gate supports. It is important to emphasis that this guideline is developed for the assessment of cracks under Mode I loading. The $K$ solutions for different crack geometries under Mode I loading are listed below.

\section{Center Crack}

The $K$ solution for a wide plate with a small through crack subject to uniform tensile stress is:

$$
K=\sigma \sqrt{\pi a}
$$

where $\sigma$ is the nominal gross-section stress remote from the crack and $2 a$ is the total overall crack length.

Figure 52 shows a through-thickness crack geometry with crack length $2 a$, plate thickness $t$, and plate width $2 W$.

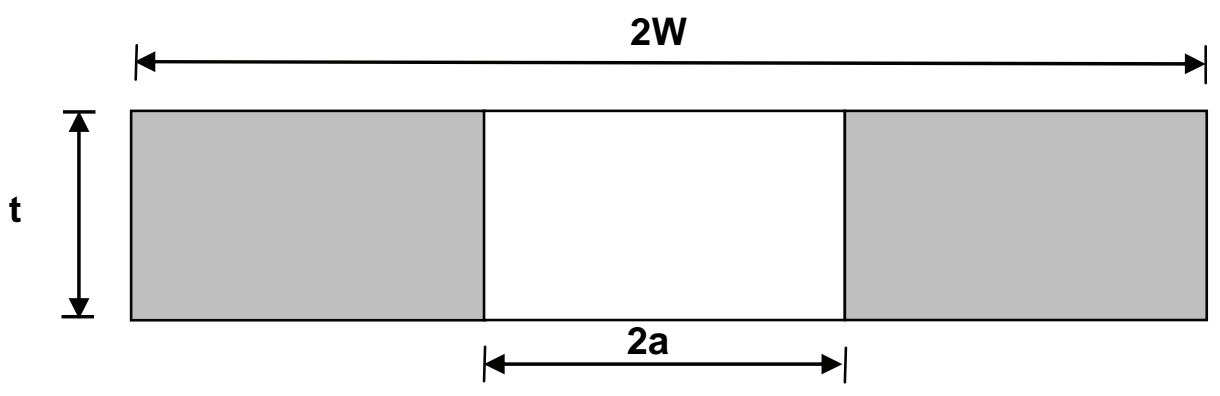

Figure 52. Through-thickness crack geometry.

For this geometry, $F_{\mathrm{c}}$ and $F_{\mathrm{s}}$ are equal to $1.0 . F_{\mathrm{g}}$ is also equal to 1.0 , since there is no bending or other stress gradient. If the total width of the panel is given as $2 W, F_{\mathrm{w}}$ for this crack geometry can be approximated by the secant formula:

$$
F_{\mathrm{w}}=\sqrt{\sec \frac{\pi a}{2 W}} .
$$


Generally the formula gives a value for $F_{\mathrm{w}}$ value that is close to 1.0 and can be ignored for $a / W$ less than a third. For $a / W$ of about 0.5 , the secant formula gives $F_{\mathrm{w}}$ of about 1.2. The secant formula is reasonably accurate for $a / W$ values up to 0.8 . For assessing fracture with BS 7910, the stress should be a combination of applied stress and residual stress.

Equation (5) could be applied to through-thickness cracks (such as delaminations) as well as to long incomplete-penetration or lack-of-fusion defects that are essentially continuous along the weld and normal to the applied stresses.

\section{Example of Flaws Idealized as Center Cracks}

Double-Bevel Groove Welds

Double-bevel groove welds are commonly used in many welded connections. As the name implies, a double-bevel groove weld is made by introducing bevel grooves in the two pieces to be attached. The grooves are then filled with weld metal, resulting in positive attachments between the two pieces. However, as Figure 53a shows, a crack-like condition forms as a result of the incomplete penetration of the weld. This crack-like condition could propagate under fatigue and result in a fracture of the attachment if the crack length reaches a critical size. The "crack" could then be idealized as a center crack with length $2 a$ in a plate with finite width $2 w$, as shown in Figure 53b. The value of $2 w$ is taken to be equal to the thickness $(t)$ of the base metals being attached. The material properties to be used in the assessment should be those of the weld metal, since propagation of the crack would be in the weld metal.

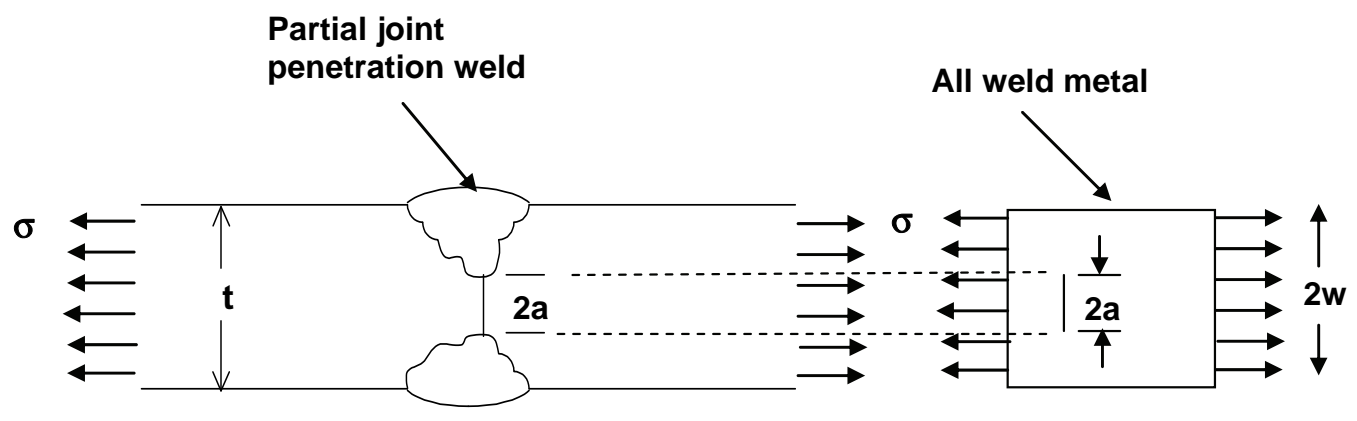

a. Partial joint penetration weld.

b. Idealization as a center crack.

Figure 53. Incomplete penetration in a double-bevel groove weld idealized as a center crack. 
Figure 54 shows a typical incomplete joint penetration in a double-bevel groove weld. The figure shows the original crack-like condition resulting from the incomplete joint penetration in the welding process. The original crack-like condition propagated under fatigue and entered the weld metal zone. If a fatigue or fracture assessment is to be made on the condition shown in the figure, then the total crack length should be included (i.e. the original defect plus the extended crack).

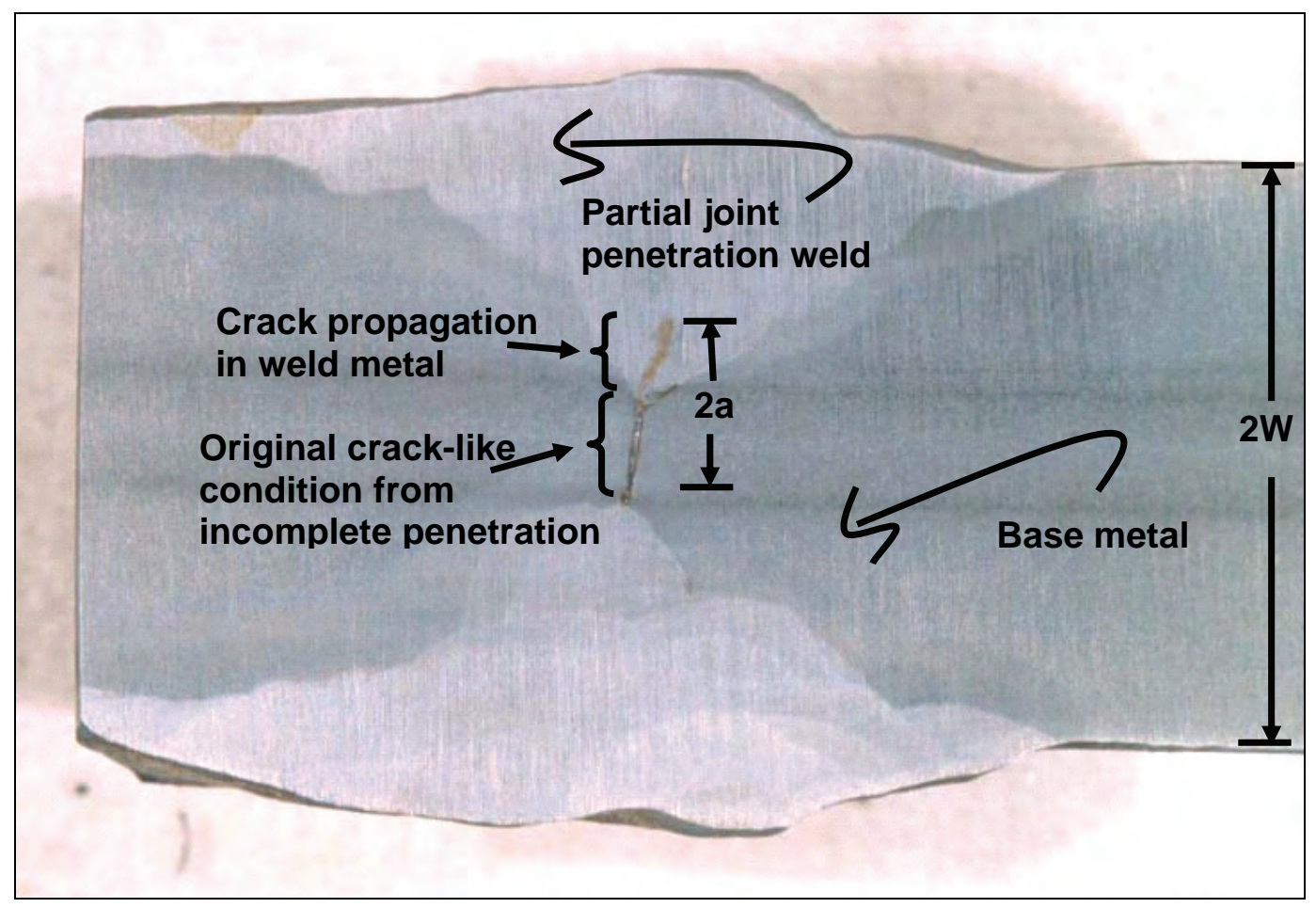

Figure 54. Partial joint penetration weld with a crack-like condition resulting from incomplete joint penetration.

\section{Backing Bar}

Another type of crack-like condition that can be idealized as a centercracked panel is a backing bar with a fillet, as shown in Figure 55. In this case, the unfused area of the backing bar creates a crack-like notch with one tip in the root of the fillet weld and one tip at the root of the groove weld. The crack is asymmetrical, but since the connection is subjected to uniform tension, the crack can be analyzed as if it were in a symmetrical, center-cracked panel. 


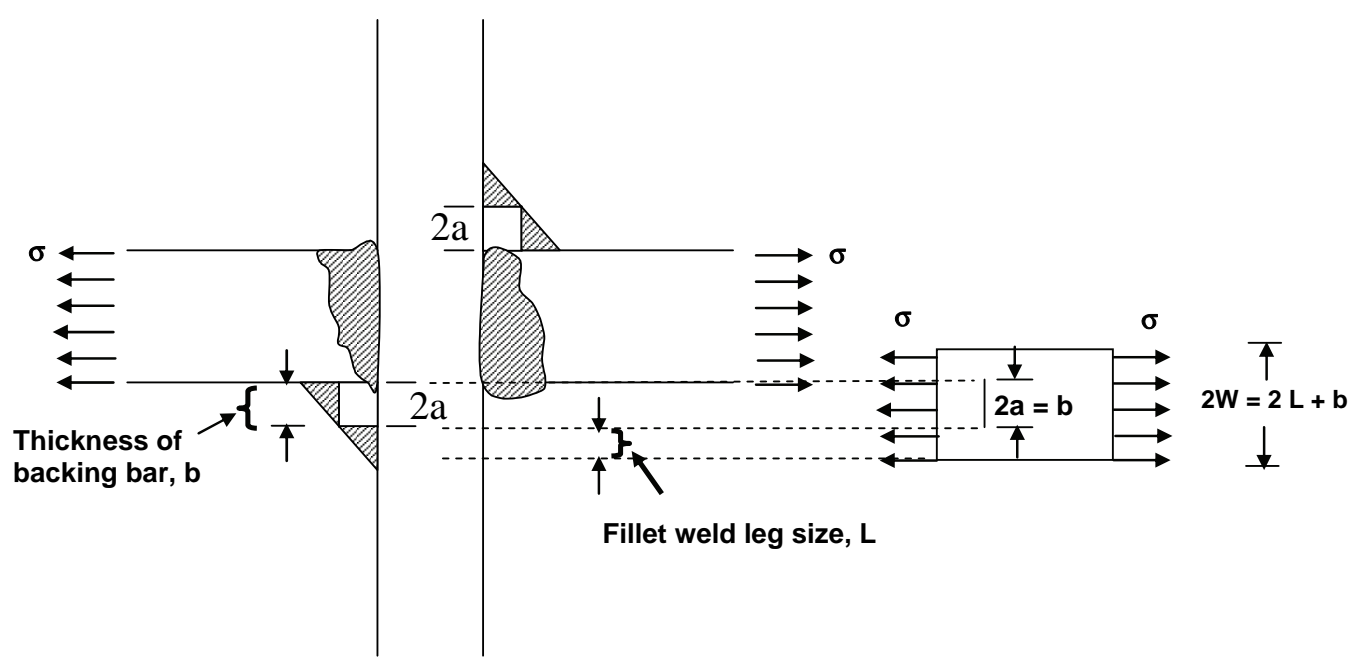
a. Crack-like condition in a backing bar detail.
b. Idealization as a center crack.

Figure 55. Incomplete penetration in a double-bevel groove weld idealized as a center crack.

Figure 55 shows a backing bar detail that existed in a tied arch bridge. Similar backing bar details are common in many steel structures. The backing bar was left in place after the completion of the welding process. The existence of the backing bar created a lack-of-fusion defect, which, if large enough, could propagate under fatigue and enter the web of the tie.

\section{Butt Weld and the Idea of Resolving Flaws}

Butt welds are also known to contain flaws resulting from the welding process. Flaws could be present on an inclined plan as shown in Figure 56. However, flaws grow in the direction perpendicular to primary stresses. The idea of resolving flaws is simply finding the length of the flaw $(2 a)$ by resolving the original length $(L)$ on the inclined plan into a component on a plan perpendicular to the primary stresses.

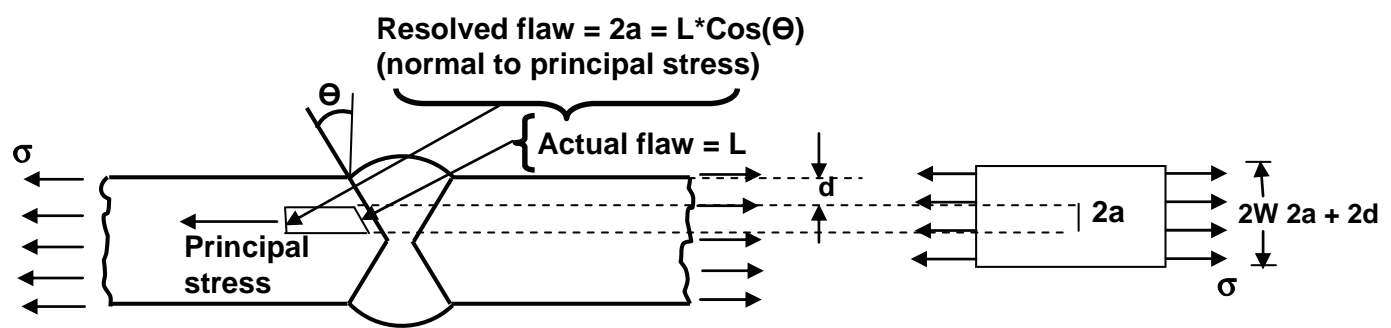

Figure 56. Butt weld with an inclined flaw resolved into a component perpendicular to the direction of the primary stresses. 


\section{Edge Crack}

The stress intensity factor for an edge crack in an infinitely wide plate is

$$
K=1.12 \sigma \sqrt{\pi a}
$$

where $\sigma$ is the remote gross-section nominal stress and $a$ is the depth of the edge crack or crack-like notch.

Figure 57 shows edge crack geometry with crack length $a$, plate thickness $t$, and plate width $2 W$.

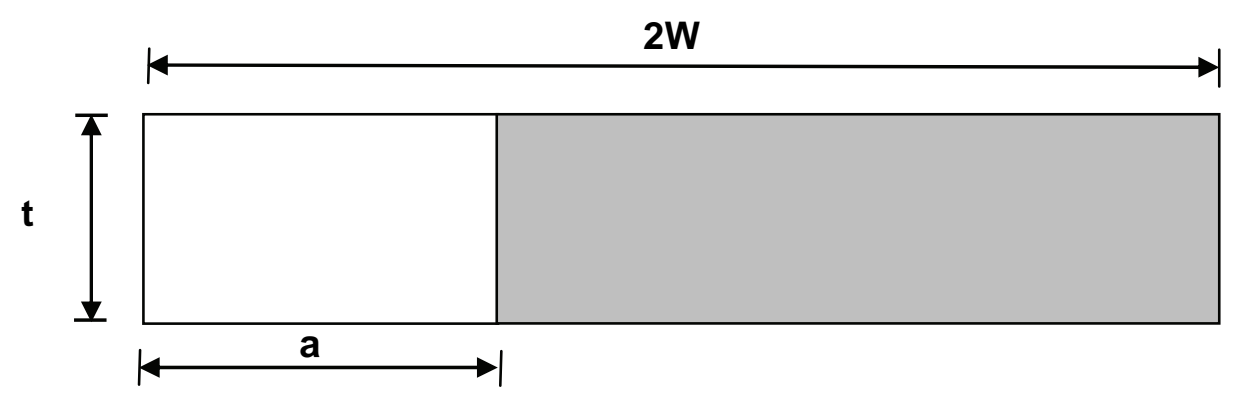

Figure 57. Edge crack geometry.

The edge crack equation is treated like half of a center crack [i.e. equation (6), where $a$ is the total length for the edge crack]. The $F_{\mathrm{s}}$ value of 1.12 is applied to account for the free edge, which is not restrained as it is in the center-crack geometry. The formula for $F_{\mathrm{w}}$ is more complicated than equation (7); however, for very small values of $a / W, F_{\mathrm{w}}$ can be taken as 1.0. Equation (7) could be applied to a through-thickness crack at the edge of a plate or the depth of a very long surface crack along the surface of a plate.

\section{Example of Idealization of an Edge Crack}

\section{Edge Crack in Tension Chord at Bearing Pad Detail}

Figure 58 shows an edge crack forming at the end of the attachment of the bearing pad to the tension chord. Such cracks will be nearly perpendicular to the primary stress direction and can penetrate into the tension chord. This crack could be idealized as an edge crack as shown in Figure 58, where $t$ is the thickness of the chord flange, $a$ is the crack depth in the chord flange, and $2 W$ is the total width of the chord flange. 


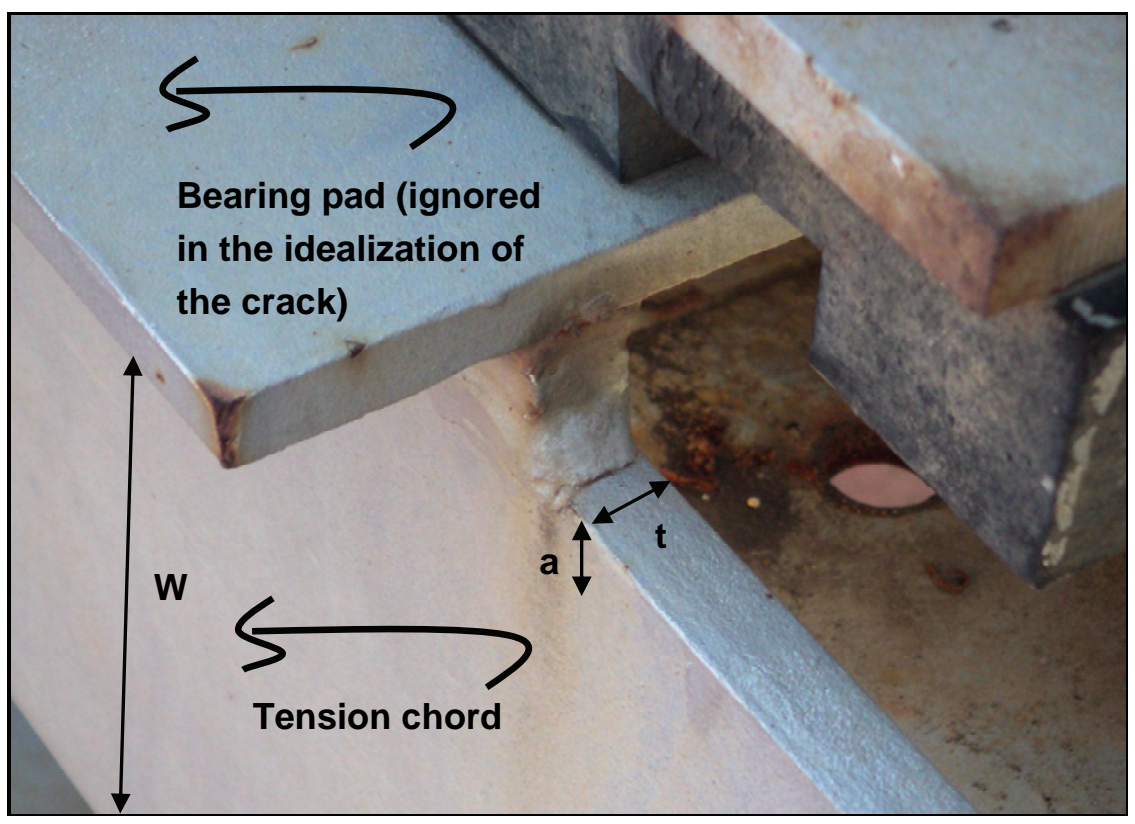

Figure 58. Shallow edge cracks or undercut at the termination of a longitudinal butt weld on a bearing pad attachment.

\section{Buried Penny-Shaped Crack}

Buried defects will be modeled as penny-shaped cracks as shown in Figure 59. This model is conservative for any defect that is circumscribed by the circular cracks normal to the stresses. Often, the increased accuracy accrued by using the relatively complex elliptical formula is not worth the effort, and the circumscribed penny-shaped or circular crack is always conservative. The stress intensity factor for the penny-shaped crack in an infinite body is given as

$$
K=\frac{2}{\pi} \sigma \sqrt{\pi a}
$$

where $\sigma$ is the remote gross-section nominal stress and $a$ is the radius of the circular crack.

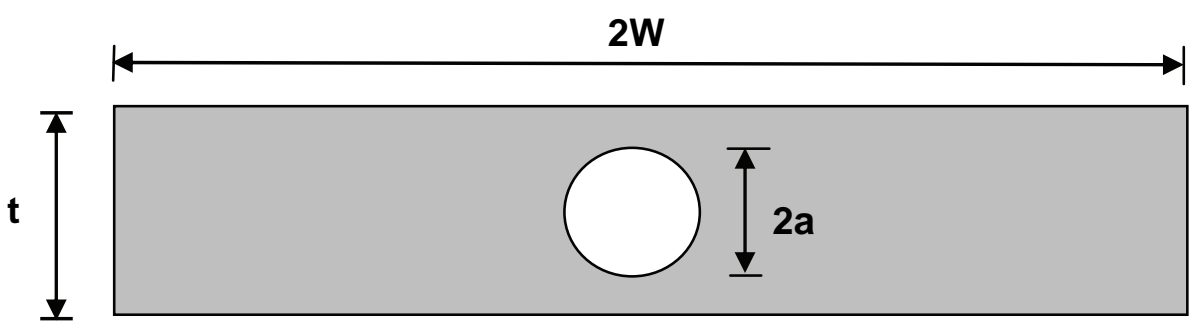

Figure 59. Buried penny-shaped crack geometry. 
In terms of equation (3), the crack shape factor $F_{\mathrm{c}}$ in this case is $2 / \pi$, or 0.64 . For the case of an infinitely thick plate, $F_{\mathrm{w}}=1$. The crack shape factor $F_{\mathrm{c}}$ is more favorable (0.64) for buried cracks, as opposed to an $F_{\mathrm{s}}$ value of 1.12 for edge cracks, and the defect size is equal to $2 a$ for the buried crack and only $a$ for the edge crack. These factors explain why edge cracks of a given size are much more dangerous than buried cracks of the same size. For all crack geometries specified above, fracture will not occur if the calculated stress intensity factor value is less than the fracture toughness of the material:

$$
K_{\text {max }} \leq K_{\text {IC }} .
$$

\section{Level 1 Assessment}

As described in BS 7910, Level I is a simplified assessment route. It is usually used when information on material properties and applied stresses is limited.

\section{Applied Stress and Residual Stress}

The maximum tensile stress $\sigma_{\max }$ should take into consideration the values of the stress components where

$$
\sigma_{\max }=S C F \times \sigma_{\text {nominal }}+\sigma_{\text {secondary }}
$$

where

$$
\begin{aligned}
S C F= & \text { factor that accounts for the stress concentration at welds } \\
& \text { and/or holes } \\
\sigma_{\text {nominal }}= & \text { applied nominal stress } \\
\sigma_{\text {secondary }}= & \text { secondary tensile stresses such as residual stresses. }
\end{aligned}
$$

Tensile uniform residual stresses from the welding processes should be assumed and taken to be equal to the yield strength of the material. If the structure was subjected to post-weld heat treatment, the level of residual stresses can be estimated using stress relaxation tests. If test data are not available, then an estimate can be used in accordance with BS 5500 . 


\section{Stress Concentrations at Welds and Holes}

Local structural discontinuities such as holes, notches, and sharp corners (including welds) usually decay over distances of less the $20 \%$ of the hole or notch radius, or $20 \%$ of the thickness. If the flaw lies in that $20 \%$ region, then a specified $S C F$ value should be multiplied by the nominal stress as shown in equation 5.

For cracks originating at a hole, an $S C F$ value of 3 should be used. For sharp corners, the $S C F$ factor is infinite. If a crack existed in such a location, then a stress intensity magnification factor is used to account for the high magnitude of the stress concentration. Note that stress concentration factors at weld toes do not contribute to plastic collapse.

\section{Assumed Lower-Bound Fracture Toughness or Material Testing}

The data plotted in Figure 50 are characteristic of the most brittle steel and weld metals that have ever been used, so a minimum fracture toughness of $50 \mathrm{MPa}-\mathrm{m}^{1 / 2}$ (45.5 Ksi-in. ${ }^{1 / 2}$ ) can be conservatively assumed for the hydraulic structural steel, weld metal, and heat-affected zone. Using equation (4), it can be shown that $50 \mathrm{MPa}-\mathrm{m}^{1 / 2}$ (45.5 Ksi-in. $\left.{ }^{1 / 2}\right)$

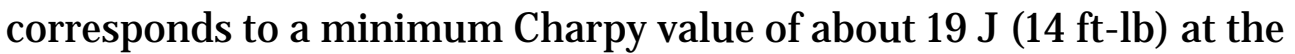
lowest anticipated service temperature. So long as data are available, it is prudent to assume that the minimum fracture toughness is $50 \mathrm{MPa}-\mathrm{m}^{1 / 2}$ (45.5 Ksi-in. $\left.{ }^{1 / 2}\right)$.

\section{Using the Level I Failure Assessment Diagram to Calculate the Maximum Tolerable Defect Size}

Level 1 uses the Failure Assessment Diagram (FAD) for assessing flaw sizes. The vertical axis of the diagram represents $K_{\mathrm{r}}$ or $\left(\delta_{\mathrm{r}}\right)^{0.5}$, and the horizontal axis of the diagram represents $S_{\mathrm{r}}$ as shown in Figure 60. A flaw size is acceptable when the calculated values of $K_{\mathrm{r}}$ or $\left(\delta_{\mathrm{r}}\right)^{0.5}$ and $S_{\mathrm{r}}$ for a given flaw size fall inside the FAD. The vertical values of the diagram can be obtained from equations (12) through (15), while the horizontal axis can be calculated from equations (16) and (17). The procedure in BS 7910 has a built-in factor of safety of two with respect to crack size. The safety factor is imposed by not allowing $K_{\mathrm{r}}$ (the ratio of the applied $K$ to the $K_{\mathrm{c}}$ ) to exceed 0.707 . 


$$
\begin{array}{cc}
K_{\mathrm{r}}=\frac{K_{\mathrm{I}}}{K_{\mathrm{mat}}} & \\
\delta_{\mathrm{r}}^{0.5}=\left(\frac{\delta_{\mathrm{I}}}{\delta_{\text {mat }}}\right)^{0.5} & \text { for } \frac{\sigma_{\max }}{\sigma_{\mathrm{Y}}} \leq 0.5 \\
\delta_{\mathrm{I}}=\frac{K_{\mathrm{I}}^{2}}{\sigma_{\mathrm{Y}} E} & \text { for } \frac{\sigma_{\max }}{\sigma_{\mathrm{Y}}}>0.5 .
\end{array}
$$

The value of $K_{\mathrm{I}}$ to be used in equation (6), (8), or (9) is calculated using equation (3), and the value of $K_{\text {mat }}$ to be used in equation (6) is as defined above. The value of $\delta_{\text {mat }}$ is the fracture toughness of the material, which can be obtained by using the CTOD test or by conservatively estimating the value. $\sigma_{\max }$ is the maximum applied tensile stress value, and $\sigma_{Y}$ is the yield strength of the material.

$$
S_{\mathrm{r}}=\frac{\text { Load }}{\text { Collapse Load }} .
$$

If membrane tension loads are applied, then the "Load" is defined as the tension load applied to the member. The "Collapse Load" is the average of the loads that correspond to the yield and ultimate strength of the material. In the case of members in tension, stress values could be used where the nominal stress $\sigma_{\text {nom }}$ is substituted for the Load and $\left(\sigma_{\mathrm{Y}}+\sigma_{\mathrm{u}}\right) / 2$ for the Collapse Load.

If moment is applied instead of membrane loads, then the Load is defined as the applied moment and the Collapse Load is defined as the plastic moment $M_{\mathrm{p}}$, where

$$
M_{\mathrm{P}}=\sigma_{\mathrm{Y}} \times Z
$$

such that $\sigma_{\mathrm{Y}}$ is the yield strength of the material and $Z$ is the section modules. 
A flaw size is acceptable if the calculated $K_{\mathrm{r}}$ or $\left(\delta_{\mathrm{r}}\right)^{0.5}$ is less than 0.707 and $S_{\mathrm{r}}$ is less than 0.8 , that is, if a calculated assessment point lies inside the rectangular area bounded by the horizontal and vertical assessment lines and the horizontal and vertical axes.

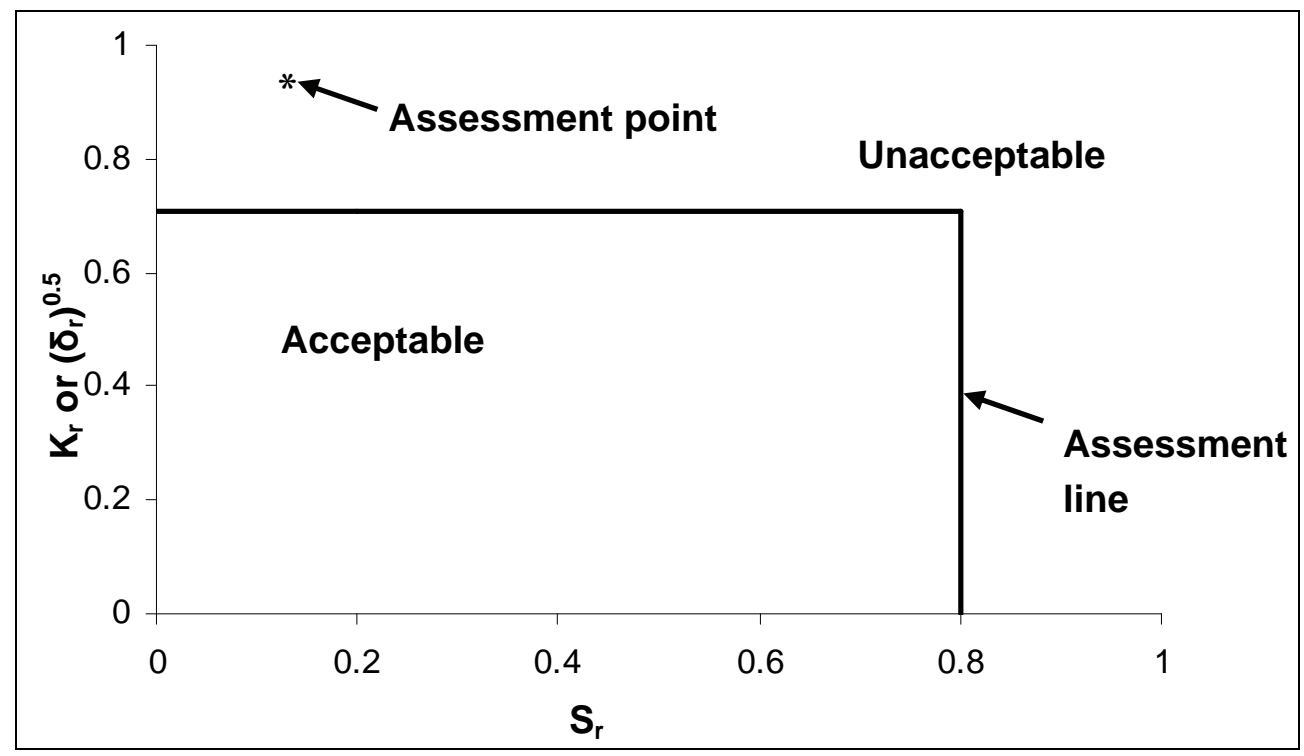

Figure 60. FAD used in Level 1A.

\section{Level 2 Assessment}

Level 2 is used in general applications and is aimed at preventing plastic collapse of the structure under evaluation.

\section{Applied Stress and Residual Stress}

Similar to Level 1, nominal and secondary stresses should be taken into account, using equation (6) to calculate the maximum tensile stress $\sigma_{\max }$ used in the evaluation. $S C F$ accounts for stress concentration at welds and/ or holes, $\sigma_{\text {nominal }}$ is the applied nominal stress, and $\sigma_{\text {secondary }}$ is the secondary stresses such as residual stresses.

Unlike Level 1, a non-uniform residual stress distribution can be used to take advantage of the beneficial effect of the compressive residual stresses that could be present around the flaw, depending on the location of the flaw with respect to the weld. When transverse residual stresses (i.e. perpendicular to the weld length) are considered, then the magnitude of the residual stresses is given by 


$$
\sigma_{\mathrm{R}}^{\mathrm{T}}=\sigma_{\mathrm{Y}}\left[\begin{array}{l}
1.0-0.917\left(\frac{a}{t}\right)-14.533\left(\frac{a}{t}\right)^{2}+83.115\left(\frac{a}{t}\right)^{3} \\
-215.45\left(\frac{a}{t}\right)^{4}+244.16\left(\frac{a}{t}\right)^{5}-96.36\left(\frac{a}{t}\right)^{6}
\end{array}\right]
$$

where $a$ is the flaw size and $t$ is the thickness of the structural component under consideration.

If the structure was subjected to post-weld heat treatment, the level of residual stresses could be estimated using stress relaxation tests.

\section{Stress Concentrations at Welds and Holes}

Local structural discontinuities such as holes, notes, and sharp corners (including welds) usually decay over distances of less the $20 \%$ of the hole or notch radius, or $20 \%$ of the thickness. If the flaw lies in that $20 \%$ region, then a specified $S C F$ value should be multiplied by the nominal stress as shown in equation (5).

For cracks originating at a hole, an $S C F$ value of 3 should be taken. For sharp corners, the $S C F$ factor is infinite. If a crack existed in such a location, then the stress intensity magnification factor is used to account for the high magnitude of the stress concentration. Note that stress concentration factors at weld toes do not contribute to plastic collapse.

\section{Material Sampling, Confidence, and Testing to Estimate Fracture Toughness}

Fracture toughness tests are to be carried out on samples welded using the same welding process. Tests should take into consideration the orientation of the flaw in the structure, the temperature under which the structure is operating, the degree of constraint, and the rate of loading. Using BS 7910, the fracture toughness values $K_{\text {mat }}$ and $\delta_{\text {mat }}$ may be taken as the minimum of three similar test results. All three results have to be consistent and either show brittle fracture or tearing up to the maximum load. Confidence in the results is measured by the degree of scatter in the data. More test data are required if there is excessive scatter in the results $K_{\text {mat }}$ and $\delta_{\text {mat. }}$. Such scatter is evident when: 
- The minimum result of $K_{\text {mat }}$ is less than $70 \%$ of the average of three results, or

- The maximum value is more than 1.4 times the average of three and/ or when the minimum CTOD result is less than $50 \%$ of the average of three, or

- The maximum is twice the average of three.

If more tests are conducted, then fracture toughness values equivalent to the minimum of three tests could be used (Table 2).

Table 2. Fracture toughness values equivalent to the minimum of three results.

\begin{tabular}{|l|l|}
\hline Number of fracture toughness results & Equivalent value \\
\hline 3 to 5 & Lowest \\
\hline 6 to 10 & Second lowest \\
\hline 11 to 15 & Third lowest \\
\hline
\end{tabular}

\section{Use of Nondestructive Testing to Refine Estimates of Defect Size}

Various nondestructive methods exist and can be used to better estimate the actual size of embedded defects. Ultrasonic testing utilizes ultrasonic waves to detect voids, cracks, or geometric changes in the material. Methods such as time-of-flight diffraction (TOFD) and linear phase array (LPA) are typically used as nondestructive ways of measuring the size of defects. Background on nondestructive testing can be found in the literature and will not be discussed further.

\section{Using the Level II Failure Analysis Diagram to Calculate the Maximum Tolerable Defect Size}

Similar to the Level 1FAD, Level 2 uses the Failure Assessment Diagram (FAD) for the assessment of flaw sizes. The vertical axis of the diagram represents $K_{\mathrm{r}}$ or $\left(\delta_{\mathrm{r}}\right)^{0.5}$, and the horizontal axis of the diagram represents $L_{r}$, as shown in Figure 61. A flaw size is acceptable when the calculated values of $K_{\mathrm{r}}$ or $\left(\delta_{\mathrm{r}}\right)^{0.5}$ and $L_{\mathrm{r}}$ for a given flaw size fall inside the FAD. The vertical values of the diagram $\left[K_{\mathrm{r}}\right.$ or $\left.\left(\delta_{\mathrm{r}}\right)^{0.5}\right]$ can be obtained from equation (19), while the value of $L_{\mathrm{r}}$ on the horizontal axis can be calculated from 
equation (20). The cutoff in the FAD is to localized plastic collapse, where $L_{\mathrm{r}}=L_{\mathrm{r} \max }$ (i.e. $L_{\mathrm{r}}$ should not be taken less than $L_{\mathrm{r} \max }$ ):

$$
\begin{gathered}
\left(\delta_{\mathrm{r}}\right)^{0.5} \text { or } K_{r}=\left(1-0.14 L_{\mathrm{r}}^{2}\right)\left[0.3+0.7 \exp \left(-0.65 L_{\mathrm{r}}^{6}\right)\right] \\
L_{\mathrm{r}}=\frac{\sigma_{\mathrm{applied}}}{0.5\left(\sigma_{\mathrm{y}}+\sigma_{\mathrm{u}}\right)} \\
L_{\mathrm{rmax}}=\frac{\left(\sigma_{\mathrm{y}}+\sigma_{\mathrm{u}}\right)}{2 \sigma_{\mathrm{y}}} .
\end{gathered}
$$

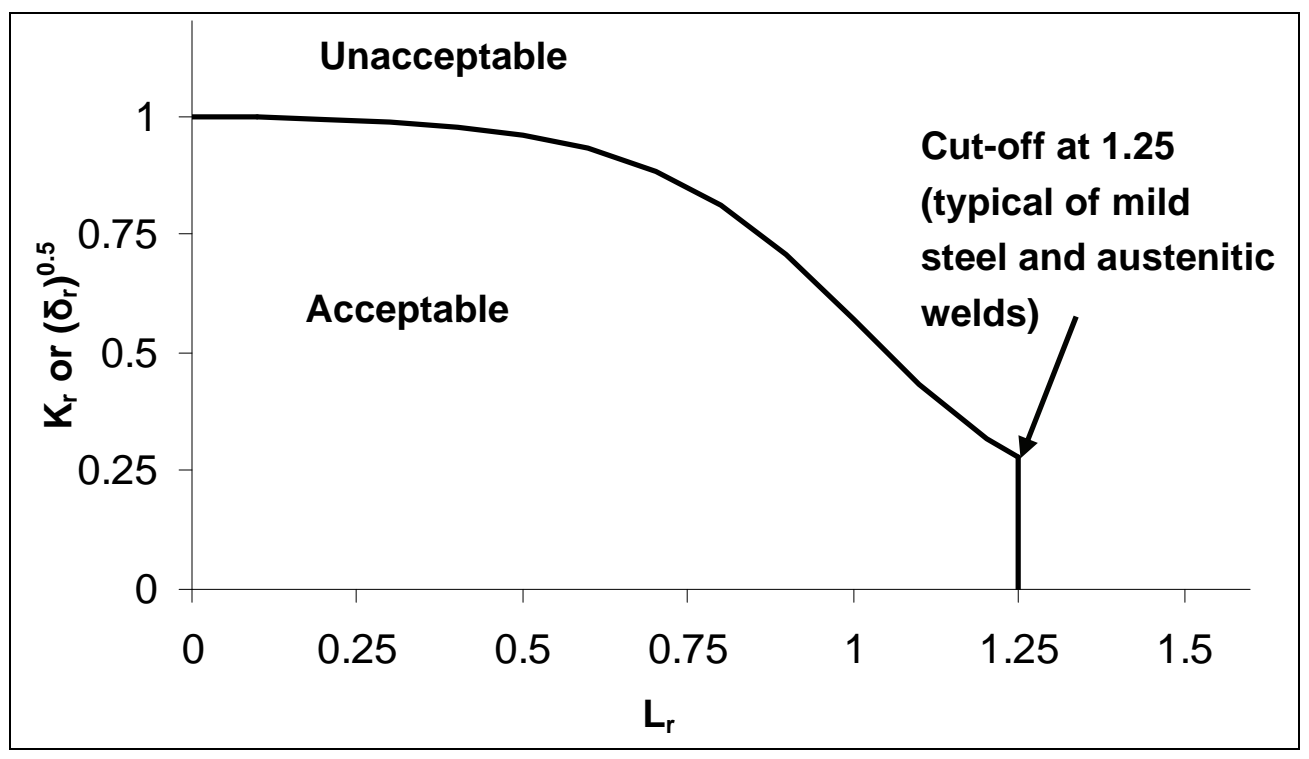

Figure 61. FAD used in Level 2A. 


\section{Fatigue Crack Growth Analysis}

Generally, the relationship relating the range in the stress intensity factor $\Delta K$ to fatigue crack growth rate $(\mathrm{d} a / \mathrm{d} N)$ is observed to be sigmoidal on a log-log scale. The curve representing the relationship consists of the three regions shown in Figure 62. In Region I, at low $\Delta K$ values where $\Delta K<\Delta K_{\text {th }}$, the crack growth is insignificant. $\Delta K_{\text {th }}$ is a threshold stress intensity factor range blow which crack growth will not occur. For steel, $\Delta K_{\text {th }}$ could be taken as $3 \mathrm{MPa}-\mathrm{m}^{1 / 2}$ (2.75 Ksi-in. $\left.{ }^{1 / 2}\right)$. In Region III the crack growth is very rapid. Relationships have been developed by researchers to express the growth rate in that region. However, the relationship representing the growth rate in Region II could be applied up to failure (including Region III). The central portion of the curve (Region II), which applies to the crack most of the time, is represented by a straight line. Paris and Erdogan (1963) expressed the straight-line portion using equation (22), also known as the Paris Law:

$$
\frac{\mathrm{d} a}{\mathrm{~d} N}=C \times(\Delta K)^{m}
$$

where $a=$ crack size

$N=$ number of cycles

$C=$ experimentally determined coefficient

$\Delta K=$ stress intensity factor range

$m=$ material constant. 


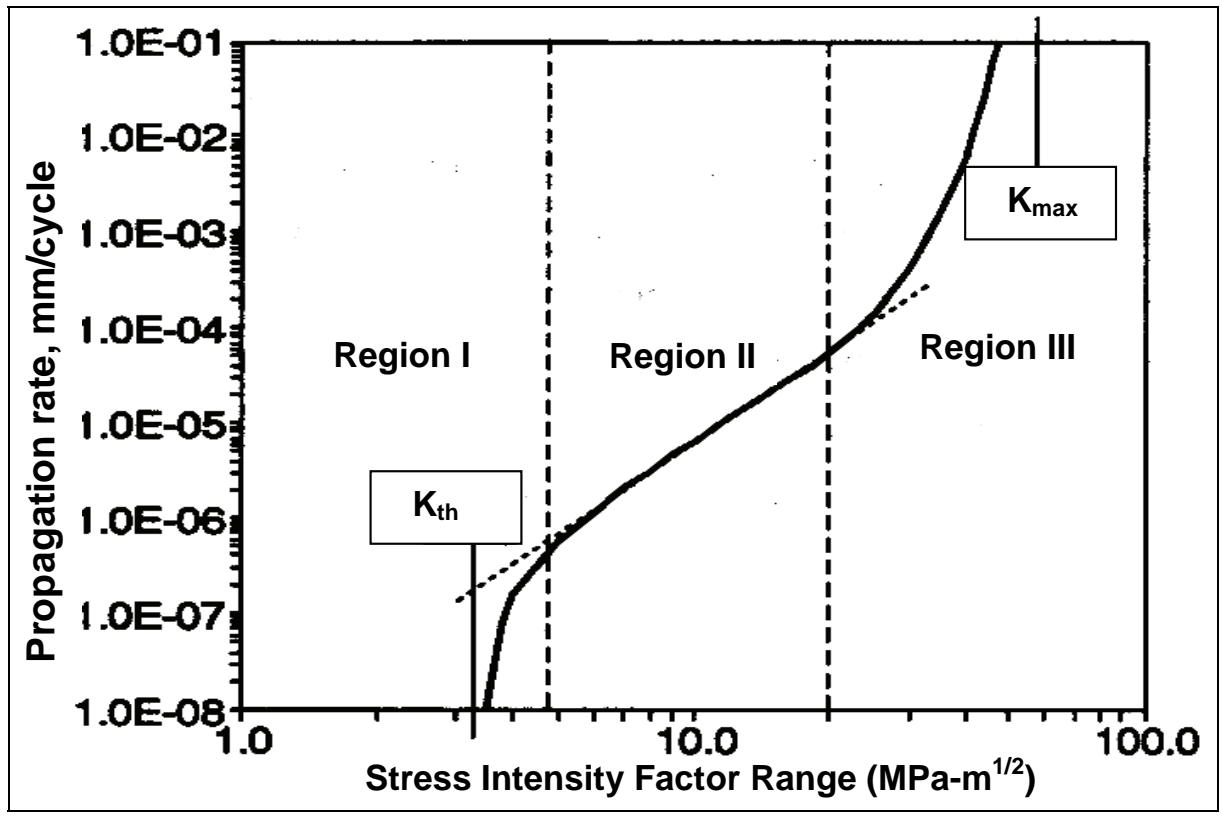

Figure 62. Typical plot of fatigue life.

The experimentally determined coefficient $C$ is intended to represent a conservative upper bound to the data that have been published. The value of $C$ and $m$ for steel in a marine environment used in the BS 7910 are equal to $7.28 \times 10^{-11}$ and 3, respectively, for $a$ in meters (in.) and $K$ in MPa-m $\mathrm{m}^{1 / 2}$ (Ksi-in. ${ }^{1 / 2}$ ). Other values of the coefficient for different metals can also be found in Barsom and Rolfe (1999).

Depending on the crack shape, the value of $\Delta K$ is calculated using equation (4), (6), or (7), except that $\Delta \sigma$ is used rather than $\sigma$. It is important to note that the $\Delta \sigma$ value used for the calculation of $\Delta K$ is the applied maximum stress range resulting from the fluctuation of the load. Therefore, residual stresses are not included. When a flaw exists in the welds (either aswelded or post-weld heat treatment welds), then residual stresses should be superimposed on the applied stresses. 


\section{References}

AASHTO. 2002. Bridge welding code. AASHTO/AWS-D1.5M/D1.5:2002. Washington, DC: American Association of State Highway and Transportation Officials.

AASHTO. 2004. AASHTO LRFD bridge design specifications. Third Edition. Washington, DC: American Association of State Highway and Transportation Officials.

AISC. 1999. Load and resistance factor design specification for structural steel buildings. Third Edition. Chicago: American Institute of Steel Construction.

Albrecht, P., and C. Shabshab. 1994. Fatigue strength of weathered rolled beam made of A588 steel. Journal of Materials in Civil Engineering, ASCE 6 (3): 407-428.

Anderson, T.L. 1995. Fracture mechanics - Fundamentals and applications. Second Edition. Boca Raton, FL: CRC Press.

AWS. 2000. Structural welding code - steel. D1.1: 2000. Miami: American Welding Society.

Barsom, J.M., and S.T. Rolfe. 1999. Fracture and fatigue control in structures: Applications of fracture mechanics. Third Edition. West Conshohocken, PA: American Society for Testing and Materials.

BSI. 1999. Guide on methods for assessing the acceptability of flaws in metallic structures. BS: 7910 1999. London: British Standards Institute.

Burdekin, F.M. 2002. The fracture behaviour of welded tubular joint - An ESIS TC1-3 round robin on failure assessment methods, Part III-UK BS7910 methodology. Journal of Engineering Fracture Mechanics 69: 1119-1127.

Connor, R.J., E.J. Kaufmann, J .J in, and C.H. Davies. 2004. Forensic investigation of the SR422 over the Schuylkill River girder fracture. Proceedings of the Twenty First International Bridge Conference, Pittsburgh, PA.

Dexter, R.J . 2004. Fatigue and fracture. The structural engineering handbook. Second Edition. ed. E.M. Lui. Boca Raton, FL: CRC Press.

Dexter, R.J., and B.A. Kelly. 1997. Research on repair and improvement methods. International Conference on Performance of Dynamically Loaded Welded Structures, Proceedings of the IIW $50^{\text {th }}$ Annual Assembly Conference, San Francisco, California, July 13-19, 1997. p. 273-285. New York: Welding Research Council, Inc.

Dexter, R.J ., and J.W. Fisher. 1997. Fatigue and fracture. Chapter 8, Steel design handbook, LRFD method. New York: McGraw-Hill.

Dexter, R.J., W.J . Wright, and J.W. Fisher. 2004. Fatigue and fracture of steel girders. Journal of Bridge Engineering 9 (3): 278- 286. 
Dusel, J.P., J .P. Stoker, and R. Travis. 1984. Determination of fatigue characteristics of hot-dipped galvanized A307 and A449 anchor bars and A325 cap screws. California Department of Transportation.

ENR. 1970. State cites defective steel in Bryte Bend failure. Engineering News Record 185 (8): Aug. 20.

Fisher, J.W. 1984. Fatigue and fracture in steel bridges. NewYork: J ohn Wiley and Sons.

Frank, K.H. 1980. Fatigue strength of anchor bolts. Journal of the Structural Division, ASCE 106 (ST).

Frank, K.H., and J.W. Fisher. 1979. Fatigue strength of fillet welded cruciform joints. Journal of the Structural Division, ASCE 105 (ST9): 1727- 1740.

Ghosn, M., and F. Moses. 1998. Redundancy in highway bridge superstructures. National Cooperative Highway Research Program, Report 406. Washington, DC: National Academy Press.

Hartle, R.A., et al. 1991. Bridge inspector's training manual/9o. Revised 1995. Report FHWA-PD-91-015. Washington, DC: Federal Highway Administration.

Kaczinski, M.R., R.J . Dexter, and J.P. Van Dien. 1998. Fatigue-resistant design of cantilevered signal, sign, and light supports. National Cooperative Highway Research Program Report 412. Washington, DC: Transportation Research Board.

Kelly, B.A., and R.J . Dexter. 2003. Adequacy of weld repairs for ships. SSC-424. Washington, DC: Ship Structure Committee.

Kober, G.R., R.J. Dexter, E.J . Kaufmann, B.T. Yen, and J.W. Fisher. 1994. The effect of welding discontinuities on the variability of fatigue life. Fracture Mechanics. Twenty-Fifth Volume, ASTM STP 1220, ed. F. Erdogan and R.J . Hartranft. Philadelphia: American Society for Testing and Materials.

Kulak, G.L., J.W. Fisher, and J.H. Struick. 1987. Guide to design criteria for bolted and riveted joints. Second Edition. Englewood Cliffs, NJ : Prentice Hall.

Kuperus, A. 1973. The fatigue strength of tensile loaded non-tightened HSFG bolts. Report 6-73-3. Delft University of Technology.

Kuperus, A. 1974. The fatigue strength of tensile loaded tightened HSFG bolts. Report 674-4. Delft University of Technology.

Mahmoud, H.N., R.J . Connor, and J.W. Fisher. 2005. Finite element investigation of the fracture potential of highly constrained details in steel plate members. 20 (5): September.

Outt, J.M.M., J.W. Fisher, and B.T. Yen. 1984. Fatigue strength of weathered and deteriorated riveted members. Report DOT/OST/ P-34/85/016. Washington, DC: Department of Transportation, Federal Highway Administration. 
Paris, P., and F. Erdogan. 1963. A critical analysis of crack propagation laws. Trans. ASME, Ser. D., Journal of Basic Engineering 85 (4): 528-534-

Roberts, R., et al. 1986. Corrosion fatigue of bridge steels. Volumes 1-3. Reports FHWA/RD-86/ 165, 166, and 167. Washington, DC: Federal Highway Administration.

U.S. Army Corps of Engineers. 1994a. Design of hydraulic steel structures. Engineering Manual EM 1110-2-2105.

U.S. Army Corps of Engineers. 1994b. Design of lock gates and operating equipments. Engineering Manual EM 1110-2-2703.

U.S. Army Corps of Engineers. 1995. Planning and design of navigation dam. Engineering Manual EM 1110-2-2607.

U.S. Army Corps of Engineers. 2001. Inspection, evaluation, and repair of hydraulic steel structures. Engineering Manual EM 1110-2-6054.

Vehovar, L. 1998. Hydrogen-assisted stress-corrosion of prestressing wires in a motorway viaduct. Engineering Failure Analysis 5(1): 21- 27.

Wright, W.J., J.W. Fisher, and B. Sivakumar. 2001. Hoan Bridge failure investigation. Washington, D.C: Federal Highway Administration.

Youngberg, C.J ., R.J . Dexter, and P.M. Bergson. 2003. Fatigue evaluation of steel boxgirder pier caps: Bridge 69832. Report MN/RC 2004-xx. St. Paul: Minnesota Department of Transportation. 


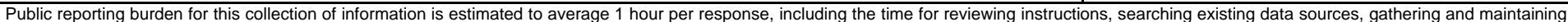

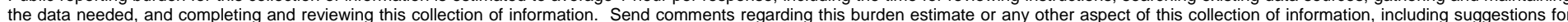

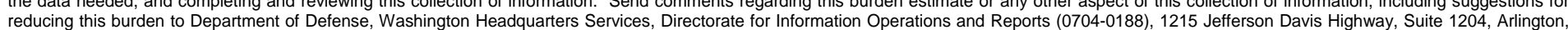

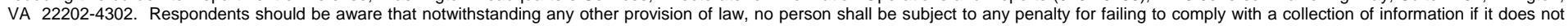
display a currently valid OMB control number. PLEASE DO NOT RETURN YOUR FORM TO THE ABOVE ADDRESS.

\begin{tabular}{l|l} 
1. REPORT DATE (DD-MM-YYYY) & 2. REPORT TYPE
\end{tabular}

November 2007

Final report

\section{TITLE AND SUBTITLE}

Fitness-for-Purpose Evaluation of Hydraulic Steel Structures

3. DATES COVERED (From - To)

5a. CONTRACT NUMBER

W912HZ-04-P-0235

5b. GRANT NUMBER

5c. PROGRAM ELEMENT NUMBER

\section{AUTHOR(S)}

Robert J. Dexter, Hussam N. Mahmoud, Joseph A. Padula, and Guillermo A. Riveros

\section{5d. PROJECT NUMBER}

5e. TASK NUMBER

5f. WORK UNIT NUMBER

9K76D4

8. PERFORMING ORGANIZATION REPORT NUMBER

ERDC TR-07-15

\section{PERFORMING ORGANIZATION NAME(S) AND ADDRESS(ES)}

U.S. Army Engineer Research and Development Center, Geotechnical and Structures Laboratory and Information Technology Laboratory, 3909 Halls Ferry Road,

Vicksburg, MS 39180-6199;

University of Minnesota, Department of Civil Engineering, 500 Pillsbury Drive S.E., Minneapolis, MN 55455-0116;

University of Illinois at Urbana-Champaign, The Multi-Axial Full-Scale Sub-Structured Testing and Simulation Facility, 2142 Newmark Civil Engineering Laboratory, MC-250, Urbana, IL 61822-2352

9. SPONSORING I MONITORING AGENCY NAME(S) AND ADDRESS(ES)

10. SPONSOR/MONITOR'S ACRONYM(S)

11. SPONSOR/MONITOR'S REPORT NUMBER(S)

\section{DISTRIBUTION I AVAILABILITY STATEMENT}

Approved for public release; distribution is unlimited.

\section{SUPPLEMENTARY NOTES}

\section{ABSTRACT}

Hydraulic structures such as locks, spillway gates, and maintenance closure structures may have fabrication defects and flaws that can be large enough to threaten the integrity of the structure. In addition, some defects that are not allowed based on stringent specifications are not at all harmful to the structure. "Fitness-for-purpose" evaluation is a method for determining a factor of safety against fracture and the risk of collapse in existing structures. This report discusses the different types of hydraulic steel structures, typical fatigue cracks that could exist in such structures, and details that could lead to brittle fracture. Using steps developed by the British Standards Institute, the report describes a fitness-for-purpose evaluation procedure for hydraulic control structures under Mode I loading, including how large a crack-like discontinuity would have to be before it could lead to fracture in a typical steel member.

\section{SUBJECT TERMS}

Fitness-of-purpose evaluation Hydraulic structures

\section{SECURITY CLASSIFICATION OF:}

\section{a. REPORT}

UNCLASSIFIED

b. ABSTRACT
UNCLASSIFIED

\section{Locks}

Maintenance closure structures Spillway gates

Spillway gates

c. THIS PAGE
UNCLASSIFIED

17. LIMITATION OF ABSTRACT

\section{NUMBER} OF PAGES 19a. NAME OF RESPONSIBLE PERSON

19b. TELEPHONE NUMBER (include area code) 